$$
\begin{gathered}
\text { Universidade de São Paulo } \\
\text { Instituto de Física }
\end{gathered}
$$

\title{
Medida da seção de choque de ionização da camada $K$ de Ta e Te por impacto de elétrons com energias do limiar até $100 \mathrm{keV}$
}

\author{
Osvaldo Camargo Botelho dos Santos \\ Orientador: Prof. Dr. Vito Roberto Vanin \\ Co-Orientador: Prof. Dr. José María Fernández-Varea
}

Dissertação apresentada ao Instituto de Física da Universidade de São Paulo para a obtenção do título de MESTRE EM CIÊNCIAS.

Comissão Examinadora:

Prof. Dr. Vito Roberto Vanin (IFUSP)

Prof. Dr. Odair Dias Gonçalves (UFRJ)

Prof. Dra. Carmen Cecilia Bueno (IPEN)

São Paulo

2016 
FICHA CATALOGRÁFICA

Preparada pelo Serviço de Biblioteca e Informação do Instituto de Física da Universidade de São Paulo

Santos, Osvaldo Camargo Botelho dos

Medida da seção de choque de ionização da camada $\mathrm{K}$ de Ta e Te por impacto de elétrons com energia do limiar até $100 \mathrm{KeV}$.

São Paulo, 2016.

Dissertação (Mestrado) - Universidade de São Paulo. Instituto de Física. Dept. Física Experimental.

Orientador: Prof. Dr. Vito Roberto Vanin

Área de Concentração: Física Atômica

Unitermos: 1.Física experimental; 2. Física atômica; 3. Raios X;

4. Eficiência de detectores de raios $X$.

USP/IF/SBI-036/2016 


$$
\begin{gathered}
\text { University of São Paulo } \\
\text { Institute of Physics }
\end{gathered}
$$

\title{
Measurements of cross sections for K-shell ionization of Ta and Te by electron impact from threshold to 100 keV
}

\section{Osvaldo Camargo Botelho dos Santos}

\author{
Advisor: Prof. Dr. Vito Roberto Vanin \\ Co-advisor: Prof. Dr. José María Fernández-Varea
}

Dissertation submitted to the Institute of Physics of the University of São Paulo for the Master of Science degree.

Examining Committee:

Prof. Dr. Vito Roberto Vanin (IFUSP)

Prof. Dr. Odair Dias Gonçalves (UFRJ)

Prof. Dra. Carmen Cecilia Bueno (IPEN) 

Dedico este trabalho à minha filha Beatriz que está vindo ao mundo. 


\section{Agradecimentos}

Meus sinceros agradecimentos:

Ao meu orientador Prof. Dr. Vito R. Vanin pela oportunidade de realizar este trabalho, pela paciência e por todo ensinamento com relação a tratamento de dados quanto de física.

Ao meu co-orientador Prof. Dr. José María Fernández-Varea, por me ensinar a fazer simulações, por ajudar com a parte teórica e por revisar meus trabalhos.

À Profa. Dra. Nora L. Maidana pelas discussões construtivas que contribuíram para minha formação e realização deste trabalho.

À Suelen Fernandes de Barros e Juan A. García-Alvarez pelas discussões e companheirismo que foram importantes para a conclusão deste trabalho.

Aos técnicos do Departamento de Física Experimental que são fundamentais para o funcionamento do laboratório, em partícular: Adriano J. Moraes, Eduardo Monteiro e Alexande Malafronte.

Aos técnicos do LAMFI pelos espectros de RBS e pela ajuda nas análises com os programas.

Ao Tiago Fiorini e Cleber Lima Rodrigues por me auxiliar com os softwares SIMNRA e MultiSIMNRA e por estarem sempre dispostos a solucionar minhas dúvidas.

Ao diretor do IFUSP Marcos Nogueira Martins.

À minha família, em especial aos meus avós Maria Geralda e Miguel Argemiro por sempre cuidarem de mim.

À minha mãe Maria Aparecida por todo apoio durante a graduação e, principalmente, nas greves.

Aos meus irmãos Vilson, Wericarmona e Gleika.

À minha esposa Kelly C. C. Pires pelo companheirismo e ajuda nas revisões dos meus trabalhos. 
Aos meus amigos do CRUSP: Matheus, Muriel, Jaqueline e Daniele pelos vários momentos alegres desfrutados juntos.

Pelo apoio financeiro, gostaria de agradecer:

Ao $\mathrm{CNPq}$ pelo suporte financeiro, fundamental para a realização deste trabalho.

Ao IFUSP pelo apoio financeiro para participação em eventos.

Osvaldo Camargo Botelho dos Santos Março, 2016 


\section{Resumo}

Neste trabalho são apresentadas medidas de seção de choque de ionização para a camada $\mathrm{K}$ do Te e Ta por impacto de elétrons, realizadas no acelerador Microtron do Instituto de Física da Universidade de São Paulo (IFUSP). Os alvos de Te e Ta foram produzidos por evaporação e por pulverização catódica (sputtering), respectivamente, sobre filmes de Carbono. Os raios-X emitidos nos ângulos de 35, 90 e 131 graus em relação a direção do feixe de elétrons incidente foram observados por detectores de HPGe, cuja eficiência foi determinada com fontes radiativas de ${ }^{133} \mathrm{Ba},{ }^{152} \mathrm{Eu} \mathrm{e}{ }^{241} \mathrm{Am}$. A energia do feixe cobriu o intervalo desde o limiar de ionização até $100 \mathrm{keV}$. Para determinar a densidade superficial de massa dos alvos foram feitas medidas de espalhamento Rutherford (Rutherford Backscattering Spectrometry) (RBS) no Laboratório de Análise de Materiais por Feixes Iônicos (LAMFI) do IFUSP, e os espectros adquiridos foram analisados utilizando os programas MultiSIMNRA e SIMNRA, que fornecem o perfil de profundidade da amostra. Os resultados obtidos para a seção de choque de ionização de ambos os elementos ( $\mathrm{Te}$ e $\mathrm{Ta}$ ) apresentam magnitude maior que os valores calculados com a teoria DWBA, onde o termo transversal da hamiltoniana de interação foi obtido utilizando a teoria de PWBA. O aumento observado é de aproximadamente $3 \%$ para o Te e $10 \%$ para o Ta, aumentando, portanto, com o número atômico do elemento.

Palavras chaves: Física experimental; Física atômica; Raios X; Eficiência de detectores de raios-X. 



\section{Abstract}

The K-shell ionization cross sections of Te and Ta by electron impact were measured using the Microtron accelerator of Institute of Physics of the University of Sao Paulo (IFUSP). Thin Te and Ta targets were obtained by evaporation and sputtering, respectively, on thin Carbon backings. The Xrays emitted at 35,90 and 131 degrees to the incident electron beam direction were detected by HPGe detectors, whose efficiencies were determined using ${ }^{133} \mathrm{Ba},{ }^{152} \mathrm{Eu}$ and ${ }^{241} \mathrm{Am}$ radioactive sources. The beam energy covered the interval from the ionization threshold up to $100 \mathrm{keV}$. The target surface mass densities were measured by Rutherford Backscattering Spectrometry (RBS) using the Tandem van de Graaff accelerator of the Laboratório de Análise de Materiais por Feixes Iônicos (LAMFI) at the IFUSP, and the spectra were analyzed using the Multi-SIMNRA code, which provides the sample depth profile. The resulting ionization cross section of both elements (Te and $\mathrm{Ta}$ ) are greater than expected from calculations based on the DWBA theory and determining the matrix elements of the transverse term in the PWBA approximation. The observed diferences are approximately $3 \%$ for Te and $10 \%$ for $\mathrm{Ta}$, therefore increasing with the atomic number of the element.

key words: Atomic physics; $\mathrm{X}$ ray; $\mathrm{X}$ rays detection efficiency. 



\section{ÍNDICE}

Agradecimentos

Resumo v v

Abstract vii

\begin{tabular}{lll}
\hline 1 & Introdução & 1
\end{tabular}

2 Ionização de camadas internas atômicas por impacto de elé-

trons 3

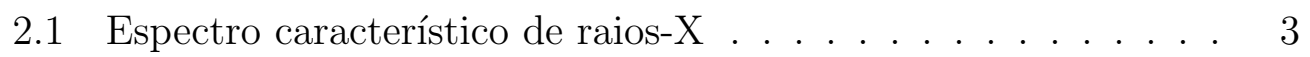

2.1 .1 Interação dos elétrons com os átomos . . . . . . . . . . 4

2.2 Aproximação de Born com ondas planas . . . . . . . . . . . . 6

2.3 Aproximação de Born com ondas distorcidas . . . . . . . . . . 9

2.4 Modelo corrigido para ondas planas . . . . . . . . . . . . . . . 10

3 Método experimental 13

3.1 Arranjo experimental . . . . . . . . . . . . . . . . . . . . . 13

3.1 .1 Acelerador Microtron . . . . . . . . . . . . . . . . . . 13

3.1 .2 Linha de $100 \mathrm{keV}$. . . . . . . . . . . . . . 16

3.1 .3 Alvos e fontes de calibração . . . . . . . . . . . . . 18

3.1 .4 Sistema de aquisição . . . . . . . . . . . . . . . . . . . 19

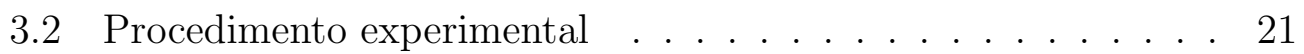

3.2.1 Densidade superficial de massa dos alvos . . . . . . . . 21

3.2 .2 Seção de choque pelo método absoluto . . . . . . . . 23 
3.2.3 Seção de choque pelo método relativo ao bremsstrahlung 24

4 Modelagem para ajuste dos parâmetros dos picos de raios-X

e $\gamma$ no espectro de energia 31

4.1 Detecção de fótons . . . . . . . . . . . . . . . . . . . 31

4.2 Ajuste dos parâmetros dos picos de raios- $\gamma$ das fontes radiativas 33

4.3 Ajuste dos parâmetros dos picos de raios-X . . . . . . . . . . . 34

4.4 Estudo da influência dos degraus nos parâmetros de ajuste . . 36

4.5 Método para obter a área dos picos de raios-X do Te para o detector $\gamma \ldots \ldots \ldots \ldots$. . . . . . . . . . . . 4 41

5 Calibração do sistema de medidas 43

5.1 Calibração de energia . . . . . . . . . . . . . . . . . . . 43

5.2 Calibração da largura dos picos . . . . . . . . . . . . . . . 44

5.3 Calibração de eficiência . . . . . . . . . . . . . . . . . . . 46

$5.3 .1 \quad$ Eficiência para o detector $5 \mathrm{cc}$. . . . . . . . . . . 47

$5.3 .2 \quad$ Eficiência para o detector $8 \mathrm{cc}$. . . . . . . . . . 50

5.3 .3 Eficiência para o detector de raios- $\gamma$. . . . . . . . . . . 52

\begin{tabular}{lll}
\hline 6 & Resultados & 55
\end{tabular}

\begin{tabular}{lll}
\hline 7 & Conclusão & 69
\end{tabular}

\begin{tabular}{|ll}
\hline A Estudo da eficiência de detectores de HPGe & 71
\end{tabular}

A.1 Contribuição Compton . . . . . . . . . . . . . . . . . 73

A.2 Função geometria para o espalhamento Compton simples . . . 76

A.3 Eficiência . . . . . . . . . . . . . . . . . . . . . . . . . . . . . . 78

\begin{tabular}{ll}
\hline B Função Geometria & 81
\end{tabular}

\begin{tabular}{lr}
\hline Bibliografia & 88
\end{tabular}

\begin{tabular}{lr}
\hline Lista de Figuras & 89
\end{tabular}

\begin{tabular}{ll}
\hline Lista de Tabelas & 93
\end{tabular} 


\section{Introdução}

Medidas de seção de choque de ionização por impacto de elétrons são importantes para a compreensão dos fenômenos da física atômica e molecular.

Medidas recentemente publicadas [1, 2, 3] indicam que os cálculos teóricos de seção de choque de ionização das camadas K e L estão subestimados. Desta forma, há a necessidade de aprimorar os modelos vigentes adotados atualmente para os cálculos de seção de choque de ionização. Outro ponto importante é que para alguns elementos não há medidas na literatura que avaliem os cálculos de seção de choque existentes [4].

O Instituto de Física da Universidade de São Paulo (IFUSP) possui um acelerador de elétrons do tipo race-track microtron, onde atualmente é possível a realização de experimentos utilizando feixe de elétrons com energia de até $1,9 \mathrm{MeV}$. A linha para realização de experimentos com feixe de energia até $5 \mathrm{MeV}$ deverá entrar em funcionamento em breve.

Neste trabalho foi realizado um estudo de seção de choque de ionização da camada $\mathrm{K}$ dos elementos Telúrio (Te) e Tântalo (Ta) por impacto de elétrons com energias próximas ao limiar de ionização até $100 \mathrm{keV}$. Essas medidas, além de serem inéditas, foram as primeiras realizadas utilizando o método absoluto no Microtron do IFUSP, ou seja, todas as variáveis relevantes necessárias para a obtenção da seção de choque foram medidas sendo possível obter uma incerteza entre 3-4\%. As medidas apresentadas nas Refs. [1, 2, 3] utilizaram o método relativo ao bremsstrahlung para a obtenção da seção de choque de ionização da camada K, onde as incertezas são da ordem de $11 \%$. 
A principal diferença entre os métodos, absoluto e relativo ao bremsstrahlung, está na maneira empregada para se obter a densidade superficial da amostra. No caso do método absoluto a densidade superficial da amostra foi determinada pela técnica de espalhamento Rutherford. No método relativo, foi feito uso da seção de choque de bremsstrahlung para obter a função que descreve o espectro de bremsstrahlung.

A estrutura desta dissertação segue a seguinte organização: no capítulo 2 será discutida a interação dos elétrons com a matéria e os modelos teóricos utilizados para se obter a seção de choque de ionização por impacto de elétrons. No capítulo 3 serão apresentados o acelerador Microton, os alvos, as fontes de calibração e o sistema de aquisição de dados. Além disso, o procedimento adotado para a obtenção da seção de choque experimental será mostrado. No capítulo 4 será discutida a metodologia empregada na determinação do número de fótons detectados nos espectros obtidos através das fontes radiativas e através das irradiações dos alvos com o feixe de elétrons. No capítulo 5 serão apresentadas as calibrações do sistema de medidas. Por fim, nos capítulos 6 e 7 serão apresentados os resultados e a conclusão deste trabalho.

Nos apêndices A e B um estudo sobre eficiência para detectores HPGe de raios- $\gamma$ será apresentado. No trabalho desenvolvido por Seltzer [5] considerase fótons incidindo no centro do detector. Nesse trabalho será considerado que os fótons atingem a superfície frontal do detector. Simulações mostraram que a contribuição Compton sofre bastante alteração, por esse motivo foi desenvolvido uma função geometria com objetivo de descrever o espalhamento Compton para determinar a eficiência do detector. 


\section{Ionização de camadas internas}

\section{atômicas por impacto de}

\section{elétrons}

Neste capítulo serão discutidos os processos envolvidos na produção dos raios$X$ e os modelos que descrevem a ionização por impacto de elétrons.

\subsection{Espectro característico de raios-X}

Quando um elétron incide em um alvo fino pode ocorrer a interação com algum elétron constituinte do alvo. Esse processo gera ionização, dando origem ao que é chamado de vacância atômica. Neste momento o átomo permanece em um estado excitado e os elétrons, de uma camada ou subcamada mais externa, migram para a vacância criada na camada ou subcamada mais interna. Essa migração pode ser descrita por dois tipos de transições:

- Transição Radiativa

Ocorre quando o elétron de uma camada mais externa migra para a vacância criada em uma camada mais interna. Como produto dessa transição, um fóton com energia igual à diferença de energia entre as 
camadas envolvidas é emitido.

- Transição Auger

A transição Auger ocorre quando um elétron de uma camada $n_{1}$ preenche a vacância de uma camada mais interna $n_{0}$ e como produto dessa transição um elétron de uma camada mais externa que $n_{0}$ é emitido.

\subsubsection{Interação dos elétrons com os átomos}

As medidas de seção de choque foram realizadas utilizando-se alvos finos. Dessa forma, nos cálculos de ionização por impacto de elétrons pode-se considerar que o elétron incidente (projétil) ioniza apenas uma vez o alvo.

Quando um elétron incidente interage com o alvo, um elétron atômico pode ser emitido, criando assim uma vacância. Antes da interação, o sistema é descrito por um átomo neutro e um elétron livre. Depois da interação o sistema será representado por dois elétrons livres e um átomo ionizado. A hamiltoniana do sistema pode ser descrita da seguinte forma:

$$
H=H_{\mathrm{p}}+H_{\mathrm{A}}+H_{\mathrm{int}},
$$

onde $H_{\mathrm{p}}$ é a hamiltoniana do projétil, $H_{\mathrm{A}}$ e $H_{\text {int }}$ são as hamiltonianas do alvo e de interação, respectivamente.

Nesse caso, $H_{\text {int }}$ é tratada como uma perturbação do sistema cuja hamiltoniana é:

$$
H_{0}=H_{\mathrm{p}}+H_{\mathrm{A}}
$$

Para descrever a hamiltoniana do átomo é necessário considerar a interação entre os elétrons do átomo e entre os elétrons e o núcleo. Por esse 
motivo, a hamiltoniana que descreve o átomo é dada por:

$$
H_{\mathrm{A}}=\sum_{i=1}^{Z}\left[\frac{-Z e^{2}}{4 \pi \epsilon_{0} r_{i}}+c \boldsymbol{\alpha}_{i} \cdot \mathbf{p}_{i}+\left(\boldsymbol{\beta}_{i}-1\right) m_{\mathrm{e}} c^{2}\right]+\sum_{i<j}^{Z} \frac{e^{2}}{4 \pi \epsilon_{0}\left|\mathbf{r}_{i}-\mathbf{r}_{j}\right|}
$$

A solução da equação (2.4) fornece a energia do átomo, $E_{\mathrm{A}}$ :

$$
H_{\mathrm{A}} \Psi=E_{\mathrm{A}} \Psi
$$

Devido à complexidade de $H_{\mathrm{A}}$, utilizam-se aproximações para resolver a equação (2.4). Desta forma supõem-se que os elétrons se movem de forma independente uns dos outros na presença de um potencial central comum [4] (apud [6]). Além disso, foi adotado o potencial auto-consistente DiracHartree-Fock-Slater (DHFS) para o átomo neutro. Desta forma, $H_{\mathrm{A}}$ pode ser escrita como:

$$
H_{\mathrm{A}} \approx \sum_{i=1}^{Z}\left[c \boldsymbol{\alpha}_{i} \cdot \mathbf{p}_{i}+\left(\boldsymbol{\beta}_{i}-1\right) m_{\mathrm{e}} c^{2}+V_{\mathrm{T}}\left(r_{i}\right)\right]
$$

Com essa aproximação, cada elétron do átomo obedece a relação de autovalor e auto-vetor dada pela seguinte equação:

$$
\left[c \boldsymbol{\alpha}_{i} \cdot \mathbf{p}_{i}+\left(\boldsymbol{\beta}_{i}-1\right) m_{\mathrm{e}} c^{2}+V_{\mathrm{T}}\left(r_{i}\right)\right] \psi_{i}=\epsilon_{i} \psi_{i}
$$

Segundo a Ref. [4] (apud [6, 7]), a função de onda para os estados ligados da equação de Dirac (2.6) adquire a seguinte forma:

$$
\psi_{n \kappa m}(\mathbf{r})=\frac{1}{r}\left(\begin{array}{c}
P_{n \kappa}(r) \Omega_{\kappa m}(\hat{r}) \\
\mathrm{i} Q_{n \kappa}(r) \Omega_{-\kappa m}(\hat{r})
\end{array}\right)
$$

onde $\kappa=(l-j)(2 j+1)$ sendo $l$ (momento angular orbital) e $j$ (momento angular total). Para garantir que o Princípio da Exclusão de Pauli seja satisfeito, a função de onda do átomo deve ser descrita através do Determinante 
de Slater:

$$
\Psi\left(\mathbf{r}_{1}, \mathbf{r}_{2}, \ldots, \mathbf{r}_{i}, \ldots, \mathbf{r}_{Z}\right)=\frac{1}{\sqrt{Z !}}\left|\begin{array}{ccc}
\psi_{1}\left(\mathbf{r}_{1}\right) & \ldots & \psi_{1}\left(\mathbf{r}_{Z}\right) \\
\vdots & \ddots & \vdots \\
\psi_{Z}\left(\mathbf{r}_{1}\right) & \ldots & \psi_{Z}\left(\mathbf{r}_{Z}\right)
\end{array}\right|
$$

onde $\psi_{i}$ são as funções de onda apresentadas na equação (2.7).

Tendo encontrada a função de onda que descreve o átomo, torna-se necessário determinar a função de onda que descreve o projétil. Essa função vai depender da escolha feita para $H_{\mathrm{p}}$.

Nas seções a seguir serão discutidos dois modelos utilizados para descrever a ionização por impacto de elétrons.

\subsection{Aproximação de Born com ondas planas}

Neste modelo, a hamiltoniana que descreve o projétil é dada pela equação de Dirac supondo um elétron com $V(r)=0$ :

$$
H_{\mathrm{p}}=c \boldsymbol{\alpha} \cdot \mathbf{p}+(\boldsymbol{\beta}-1) m_{\mathrm{e}} c^{2}
$$

A função de onda pode ser obtida da relação de auto-valor e auto-vetor da hamiltoniana descrita na equação (2.9) [4, 8]:

$$
H_{\mathrm{p}} \phi_{\mathbf{k} m_{s}}\left(\mathbf{r}_{\mathrm{p}}\right)=E_{\mathrm{P}} \phi_{\mathbf{k} m_{s}}\left(\mathbf{r}_{\mathrm{p}}\right)
$$

onde $\mathbf{k}$ é o vetor de onda e $m_{s}$ é o número quântico de spin. A solução da equação 2.10 são as ondas planas de Dirac, descrita por:

$$
\phi_{\mathbf{k} m_{s}}\left(\mathbf{r}_{\mathrm{p}}\right)=\frac{1}{(2 \pi)^{3 / 2}} \exp \left(\mathrm{ik} \cdot \mathbf{r}_{\mathrm{p}}\right) U_{m_{s}}
$$

onde $U_{m_{s}}$ é a função de onda de spin. 
A hamiltoniana de interação $H_{\text {int }}$ é dada pela interação do projétil com os elétrons do átomo e com o núcleo:

$$
H_{\mathrm{int}}=\frac{-Z e^{2}}{4 \pi \epsilon_{0}\left|\mathbf{r}_{\mathrm{p}}\right|}+\sum_{i=1}^{Z} H_{\mathrm{int}}^{\prime}\left(\mathbf{r}_{\mathrm{p}}-\mathbf{r}_{i}\right)
$$

onde $H_{\mathrm{int}}^{\prime}\left(\mathbf{r}_{\mathrm{p}}-\mathbf{r}_{i}\right)$ é a interação do projétil com o $i$-ésimo elétron atômico.

Fazendo uso da teoria de perturbação em primeira ordem é possível obter os elementos de matriz de transição com o operador $H_{\text {int }}$ e, consequentemente, descrever as funções de onda do projétil e do elétron atômico alvo antes e depois da ionização:

$$
\begin{aligned}
& \left|\phi_{\mathbf{k} m_{s}}\left(\mathbf{r}_{\mathrm{p}}\right) \psi_{\mathrm{a}}\left(\mathbf{r}_{i}\right)\right\rangle \\
& \left|\phi_{\mathbf{k}^{\prime} m_{s}^{\prime}}\left(\mathbf{r}_{\mathrm{p}}\right) \psi_{\mathrm{d}}\left(\mathbf{r}_{i}\right)\right\rangle
\end{aligned}
$$

onde $\phi_{\mathbf{k} m_{s}}\left(\mathbf{r}_{\mathrm{p}}\right)$ e $\psi_{\mathrm{a}}\left(\mathbf{r}_{i}\right)$ são as funções de onda para o projétil e o elétron do átomo envolvido na ionização (elétron "ativo"), respectivamente. O símbolos "a" e "d" representam antes e depois da ionização.

As funções de onda $\psi_{\mathrm{a}}\left(\mathbf{r}_{i}\right)$ e $\psi_{\mathrm{d}}\left(\mathbf{r}_{i}\right)$ são soluções da equação 2.6), porém $\psi_{\mathrm{a}}\left(\mathbf{r}_{i}\right)$ é obtida considerando estado ligado, ou seja, a energia $\epsilon_{i}$ da equação 2.6 é negativa. Por outro lado, a solução de $\psi_{\mathrm{d}}\left(\mathbf{r}_{i}\right)$ considera a energia $\epsilon_{i}$ positiva, pois deve-se supor que o $i$-ésimo elétron possui energia cinética maior do que a energia potencial de atração do núcleo, caracterizando assim um processo de ionização. Desta forma, os elementos da matriz de transição podem ser obtidos da seguinte forma [4, 8]:

$$
T=\left\langle\phi_{\mathbf{k}^{\prime} m_{s}^{\prime}}\left(\mathbf{r}_{\mathrm{p}}\right) \psi_{\mathrm{d}}\left(\mathbf{r}_{i}\right)\left|H_{\mathrm{int}}\right| \phi_{\mathbf{k} m_{s}}\left(\mathbf{r}_{\mathrm{p}}\right) \psi_{\mathrm{a}}\left(\mathbf{r}_{i}\right)\right\rangle
$$

O termo $H_{\text {int }}$ que fornece a interação elétrica entre o projétil e o núcleo não contribui no cálculo de perturbação, como descrito a seguir:

$$
\left\langle\phi_{\mathbf{k}^{\prime} m_{s}^{\prime}}\left(\mathbf{r}_{\mathrm{p}}\right)\left|\frac{-Z e^{2}}{4 \pi \epsilon_{0}\left|\mathbf{r}_{\mathrm{p}}\right|}\right| \phi_{\mathbf{k} m_{s}}\left(\mathbf{r}_{\mathrm{p}}\right)\right\rangle\left\langle\psi_{\mathrm{d}}\left(\mathbf{r}_{i}\right) \mid \psi_{\mathrm{a}}\left(\mathbf{r}_{i}\right)\right\rangle=0
$$


onde $\left\langle\psi_{\mathrm{d}}\left(\mathbf{r}_{i}\right) \mid \psi_{\mathrm{a}}\left(\mathbf{r}_{i}\right)\right\rangle=0$, pois são estados ortogonais. Dessa forma, os elementos da matriz de transição obtidos da equação (2.14 podem ser simplificados como segue:

$$
T=\left\langle\phi_{\mathbf{k}^{\prime} m_{s}^{\prime}}\left(\mathbf{r}_{\mathrm{p}}\right) \psi_{\mathrm{d}}\left(\mathbf{r}_{i}\right)\left|H_{\mathrm{int}}^{\prime}\right| \phi_{\mathbf{k} m_{s}}\left(\mathbf{r}_{\mathrm{p}}\right) \psi_{\mathrm{a}}\left(\mathbf{r}_{i}\right)\right\rangle
$$

De acordo com as regras de Slater-Condon, os elementos de matriz da equação (2.16) serão nulos caso os estados atômicos sejam diferentes em mais de um orbital, antes e depois da interação. Esse fato garante que somente um elétron participa da interação e os outros são mantidos "congelados".

De acordo com a Ref. [8], a seção de choque diferencial de ionização é obtida pela regra de ouro de Fermi, mostrada a seguir:

$$
\mathrm{d} \sigma^{\text {ion }}=\frac{(2 \pi)^{4}}{\hbar v}\left|T_{\mathrm{da}}\right|^{2} \delta\left(E-E^{\prime}-\epsilon_{\mathrm{d}}+\epsilon_{\mathrm{a}}\right) \mathrm{d}^{\prime} \mathrm{d}^{\mathrm{d}} \mathbf{k}_{\mathrm{d}}
$$

onde $E$ e $E^{\prime}$ são as energia do projétil antes e após a ionização, respectivamente. Assim, a energia transferida ao elétron no processo de ionização é dada por $\left(\epsilon_{\mathrm{d}}-\epsilon_{\mathrm{a}}\right)$. Por último, $\mathbf{k}^{\prime}$ e $\mathbf{k}_{\mathrm{d}}$ são os vetores de onda do projétil e do elétron emitido depois da interação, respectivamente.

A seção de choque de ionização duplamente diferencial na perda de energia do elétron incidente $W=E-E^{\prime}$ e na energia de retrocesso $Q=$ $\sqrt{(\hbar \mathbf{q} c)^{2}+m_{\mathrm{e}}^{2} c^{4}}-m_{\mathrm{e}} c^{2}$ pode ser obtida através da equação 2.17) Ref. 8], onde $\hbar \mathbf{q}=\mathbf{p}-\mathbf{p}^{\prime}$ é o momento transferido na ionização. Dessa forma:

$$
\frac{\mathrm{d}^{2} \sigma^{\text {ion }}}{\mathrm{d} W \mathrm{~d} Q}=\frac{(2 \pi)^{5}}{c^{2} \hbar^{4} v^{2}} \frac{E-W+m_{\mathrm{e}} c^{2}}{E+m_{\mathrm{e}} c^{2}}\left(Q+m_{\mathrm{e}} c^{2}\right) \varsigma_{\mathrm{da}}
$$

onde

$$
\varsigma_{\mathrm{da}}=k_{\mathrm{d}} \frac{\epsilon_{\mathrm{d}}+m_{\mathrm{e}} c^{2}}{c^{2} \hbar^{2}} \frac{1}{2\left(2 j_{\mathrm{a}}+1\right)} \sum_{m_{s \mathrm{a}}, m_{s}} \sum_{m_{s \mathrm{~d}}, m_{s}^{\prime}} \int \mathrm{d} \hat{\mathbf{k}}_{\mathrm{d}}\left|T_{d \mathrm{a}}\right|^{2}
$$

Note que $m_{\mathrm{s}}$ e $m_{\mathrm{s}}^{\prime}$ são os números quânticos associados ao spin do projétil antes e depois da interação, respectivamente. Os números quânticos $m_{s a} \mathrm{e}$ 
$m_{s \mathrm{~d}}$ são, respectivamente, os números quânticos associados ao sub-estado do elétron ligado (antes da interação) e o estado de spin do elétron (depois da interação), no qual ele não se encontra ligado. A seção de choque $\sigma^{\text {ion }}$ é, portanto, obtida integrando a equação (2.18) em $W$ e $Q$.

Para que a teoria de perturbação seja aplicável, $H_{\text {int }}^{\prime}$ deve ser pequena comparada à hamiltoniana do sistema estudado. No caso do formalismo PWBA, é necessário que a energia do projétil seja grande comparada ao limiar de ionização Ref.[9]. Outro fato não levado em consideração nos cálculos empregando a teoria PWBA é a indistinguibilidade entre os elétrons do alvo e do projétil.

\subsection{Aproximação de Born com ondas distor- cidas}

Quando a energia está próxima ao limiar de ionização torna-se necessário considerar um modelo de ondas distorcidas (DWBA), pois a distorção na função de onda do projétil, causada pelo átomo, não pode ser mais ignorada. Neste modelo subtrai-se um potencial da hamiltoniana de interação e acrescenta-se esse mesmo potencial na hamiltoniana do projétil. O potencial escolhido para esse propósito é o potencial que descreve o átomo neutro, reproduzindo assim, a interação do projétil com os elétrons do átomo neutro, não envolvidos na ionização [8]. Esse potencial será aqui representado por $V_{\mathrm{T}}\left(r_{\mathrm{p}}\right)$, onde $r_{\mathrm{p}}$ é a posição do projétil em relação ao sistema de coordenadas centrado no núcleo. Dessa forma, da equação 2.1 é possível escrever:

$$
H=\left(H_{\mathrm{p}}+V_{\mathrm{T}}\left(r_{\mathrm{p}}\right)\right)+H_{\mathrm{A}}+\left(H_{\mathrm{int}}-V_{\mathrm{T}}\left(r_{\mathrm{p}}\right)\right)
$$


onde as novas hamiltonianas de interação e do projétil são:

$$
\begin{gathered}
H_{\mathrm{int}}^{\prime \prime}=H_{\mathrm{int}}-V_{\mathrm{T}}\left(r_{\mathrm{p}}\right) \\
H_{\mathrm{p}}^{\prime}=H_{\mathrm{p}}+V_{\mathrm{T}}\left(r_{\mathrm{p}}\right)
\end{gathered}
$$

A função de onda que descreve a partícula incidente torna-se distorcida devido ao potencial $V_{\mathrm{T}}\left(r_{\mathrm{p}}\right)$ da equação 2.22 e deve obedecer a seguinte expressão:

$$
\left[c \boldsymbol{\alpha} \cdot \mathbf{p}+(\boldsymbol{\beta}-1) m_{\mathrm{e}} c^{2}+V_{\mathrm{T}}\left(r_{\mathrm{p}}\right)\right] \psi_{\mathbf{k} m_{s}}^{( \pm)}\left(\mathbf{r}_{\mathrm{p}}\right)=E_{\mathrm{P}} \psi_{\mathbf{k} m_{s}}^{( \pm)}\left(\mathbf{r}_{\mathrm{p}}\right)
$$

As funções de onda que descrevem os elétrons atômicos não mudam, pois a hamiltoniana do átomo não foi alterada. Para a obtenção da seção de choque de ionização por impacto de elétrons utilizando ondas distorcidas é semelhante com a forma que foi discutida para ondas planas. Porém, de acordo com Bote et al [8], o termo transversal de $H_{\text {int }}^{\prime}$ deve ser desprezado por ser pequeno, comparado ao termo longitudinal. Essa aproximação é feita devido à complexidade numérica dos cálculos quando se trabalha com ondas distorcidas e é aceitável para velocidades muito menores quando comparadas à velocidade da luz. Quando se trabalha com alvos de elementos pesados, esse termo não pode ser desprezado, visto que os elétrons mais fortemente ligados são relativísticos. Se o projétil possui velocidade relativística, esse termo também não pode ser ignorado.

\subsection{Modelo corrigido para ondas planas}

O modelo para seção de choque usado neste trabalho foi o chamado Corrected Plane Wave Born Approximation (CPWBA), que é uma mistura de 
ondas planas com ondas distorcidas [9]. Nesse modelo as seções de choque de ionização calculadas com ondas planas são corrigidas para o termo longitudinal com ondas distorcidas, conforme apresentado na equação (2.24).

$$
\sigma^{C P W B A}=\sigma^{(P W)}+\left(\sigma^{(D W, L)}-\sigma^{(P W, L)}\right)
$$

Acredita-se que, utilizando esse modelo, os cálculos forneçam resultados confiáveis para feixes com energias até dezesseis vezes o limiar de ionização. Para outros intervalos de energia torna-se necessário realizar cálculos considerando somente ondas distorcidas. 



\section{Método experimental}

Nesse capitulo será apresentado o acelerador de elétrons Microtron do IFUSP, usado neste trabalho. Este acelerador é capaz de fornecer feixes com energias que variam de $10 \mathrm{keV}$ a $5 \mathrm{MeV}$. Além disso, serão discutidos os procedimentos experimentais adotados na obtenção das seções de choque de ionização por impacto de elétrons.

\subsection{Arranjo experimental}

\subsubsection{Acelerador Microtron}

O canhão de elétrons do acelerador Microtron tem a capacidade de injetar feixes com energia de $10 \mathrm{keV}$ até $100 \mathrm{keV}$. Há três linhas de feixe, sendo que a primeira pode atingir $100 \mathrm{keV}$, a segunda $1,9 \mathrm{MeV}$ e a terceira $5 \mathrm{MeV}$, onde a energia pode ser mudada de forma contínua. Neste trabalho foi usada a linha de $100 \mathrm{keV}$. Para experimentos com energia até $100 \mathrm{keV}$, o feixe é simplesmente desviado por um dipolo magnético para a linha onde existe uma câmara de espalhamento específica para a realização de medidas até $100 \mathrm{keV}$. Caso se utilize feixes com energia até 1,9 MeV, torna-se necessário usar um sistema de cavidades ressonantes, que pode ser visualizado na figura 
a seguir:

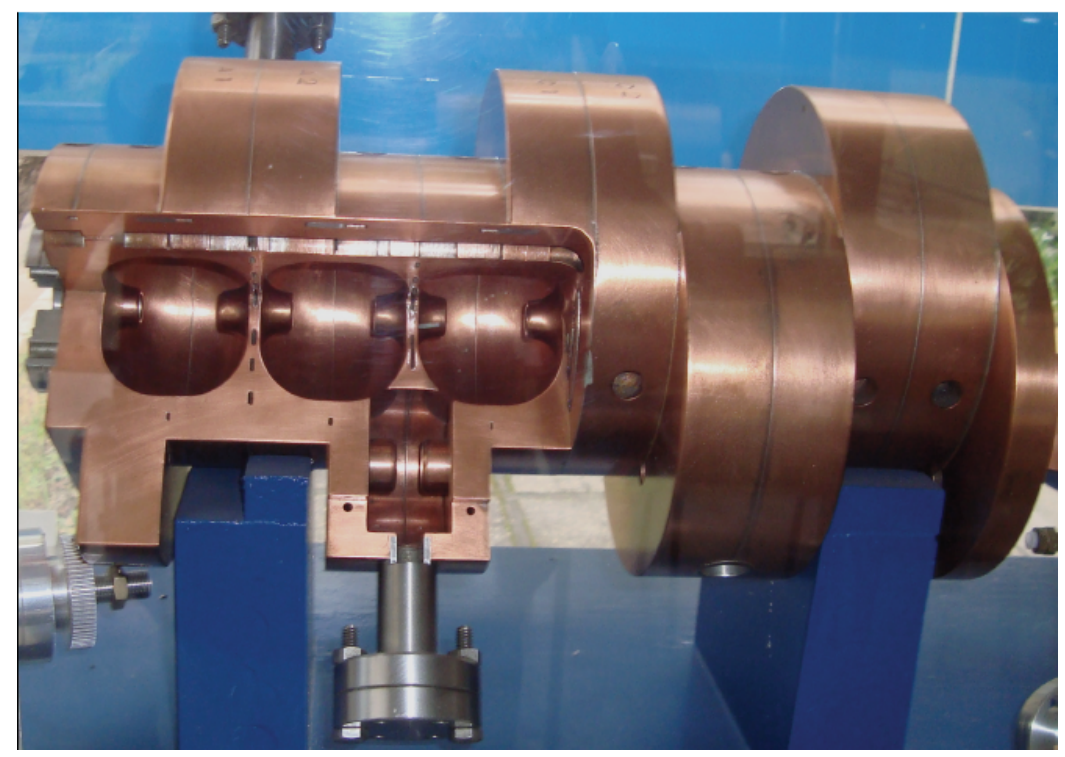

Figura 3.1: Sistema de cavidades ressonantes do acelerador Microtron do IFUSP.

Os elétrons ganham energia no percurso dentro das cavidades ressonantes (ver figura 3.1), o que provoca uma mudança na velocidade destes elétrons. Desta forma, torna-se necessário projetar essas cavidades com tamanhos diferentes para que os elétrons continuem em fase com as microondas. Depois de passar pelas cavidades, o feixe de elétrons é direcionado para a câmara de espalhamento específica para a realização de medidas até 1, $9 \mathrm{MeV}$.

Já em experimentos utilizando feixes com energia até $5 \mathrm{MeV}$, além da utilização do sistema de cavidades ressonantes, torna-se necessário desviar o feixe por um dipolo magnético para o sistema Racetrack Microtron, conforme mostra a figura 3.2 . 


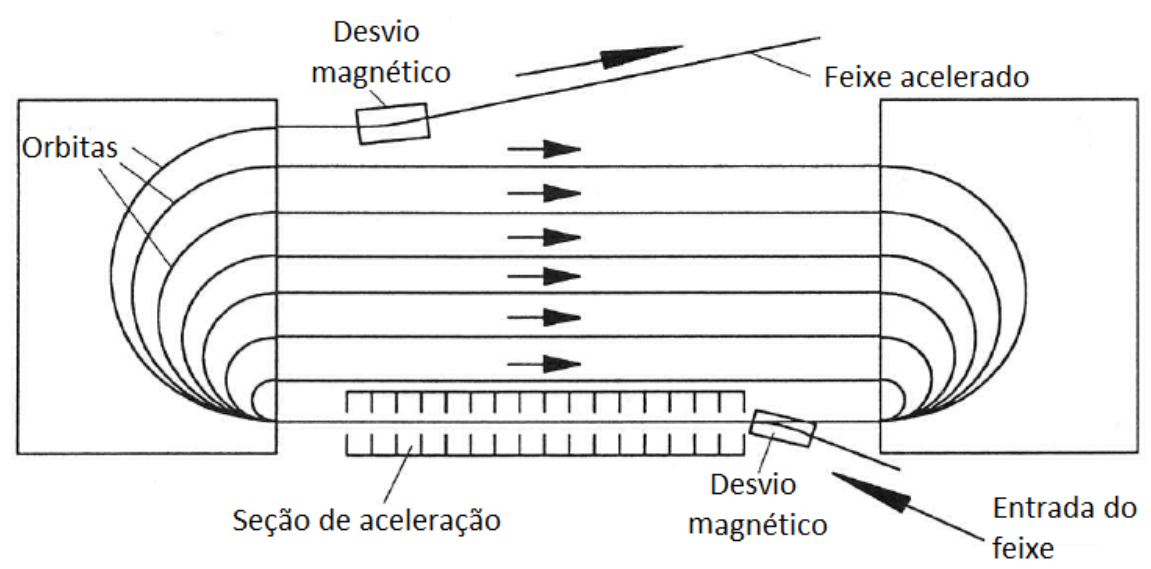

Figura 3.2: Sistema Racetrack Microtron utilizado para obter energias até $5 \mathrm{MeV}$.

Neste sistema, o feixe ganha energia quando passa na seção de aceleração (ver fig 3.2). Para aumentar a energia do feixe é necessário desviá-lo duas vezes por um sistema de eletroímãs para que ele volte novamente para a seção de aceleração. Quando se obtém a energia desejada, o feixe é desviado para a linha de $5 \mathrm{MeV}$, que atualmente se encontra em processo de montagem.

Para manter o feixe colimado utilizam-se solenóides na linha de $100 \mathrm{keV}$ e quadrupolos nas outras canalizações. A figura 3.3 apresenta uma visão geral do acelerador Microtron [10]. 


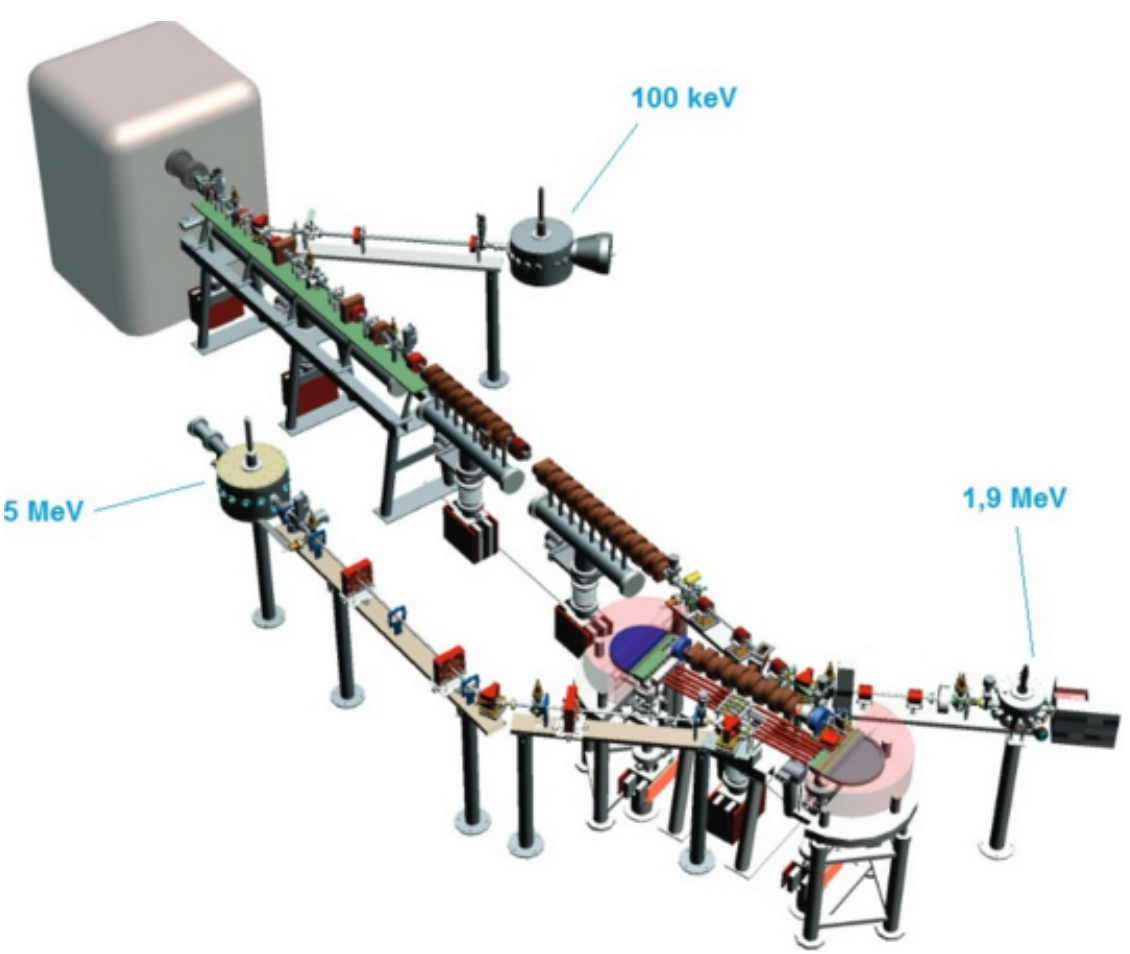

Figura 3.3: Esquema do acelerador Microtron do IFUSP[10].

\subsubsection{Linha de $100 \mathrm{keV}$}

Ao sair do canhão de elétrons o feixe passa por dois solenóides que, conforme mencionado, são necessários para manter o feixe colimado. Depois, o feixe atravessa um dipolo seletor e é então desviado para a linha onde as medidas são realizadas com elétrons de energia 10-100 keV. Nessa linha, o feixe atravessa outros dois solenóides e, ao final, chega na câmara de espalhamento que possui diâmetro de $50 \mathrm{~cm}$ e janelas com $50 \mu \mathrm{m}$ de Al. A figura 3.4 apresenta uma imagem da linha de $100 \mathrm{keV}$. 


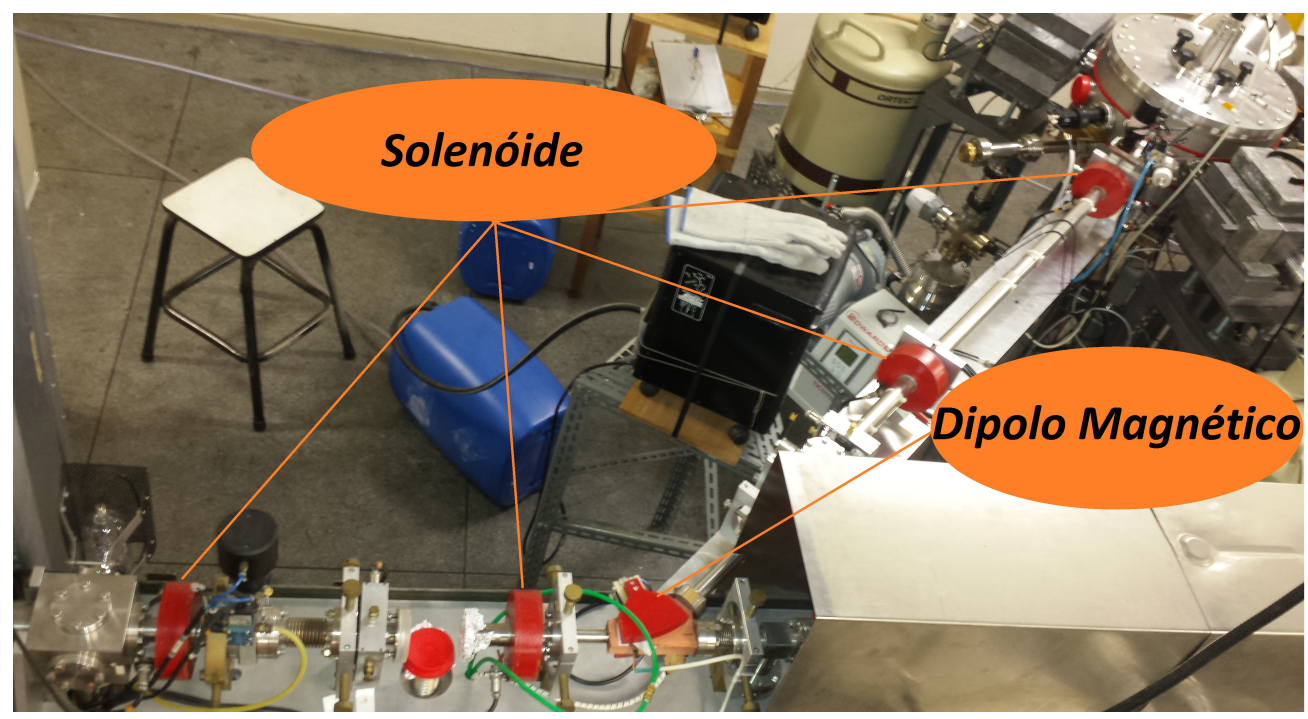

Figura 3.4: Linha de $100 \mathrm{keV}$ do acelerador Microtron do IFUSP.

O alvo é posicionado no centro da câmara de espalhamento e ao lado de fora são posicionados os detectores utilizados na aquisição dos dados.

A câmara de espalhamento tem paredes laterais de aço, tampas de Alumínio e copo de Faraday de Carbono. O copo de Faraday é de carbono para diminuir a influência do bremsstrahlung.

Como a energia do feixe de elétrons é baixa nessa linha alguns elétrons, ao interagir com o alvo, podem ser espalhados por ângulos suficientemente grandes para que não sejam coletados no copo de Faraday. Sabe-se que para determinar a seção de choque de ionização da camada K experimentalmente é necessário normalizar o número de fótons detectados pelo número de elétrons que incide no alvo. Por esse motivo, foi necessário a utilização de um sistema integrador de carga que também conta os elétrons espalhados que não atingem o copo de Faraday. 


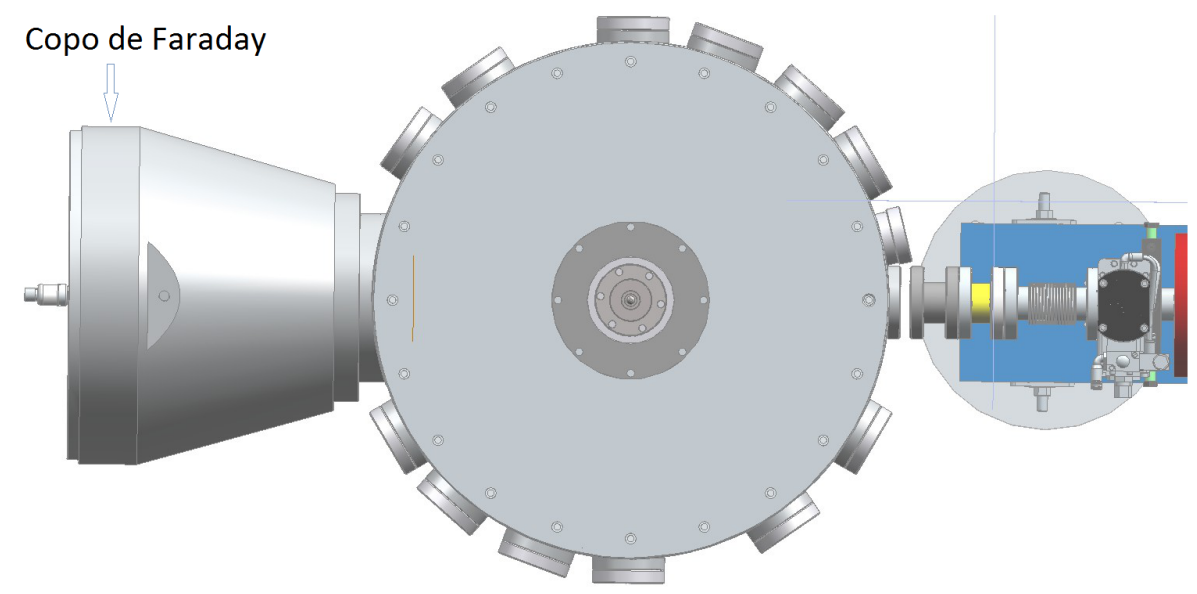

Figura 3.5: Esquema da câmara de $100 \mathrm{keV}$ do acelerador Microtron do IFUSP.

\subsubsection{Alvos e fontes de calibração}

Os alvos de Telúrio (Te) foram produzidos por evaporação no Laboratório de Alvos Nucleares do Departamento de Física Nuclear do IFUSP enquanto que os alvos de Tântalo (Ta) foram produzidos por sputtering no Laboratório de Materiais Magnéticos do IFUSP. Os alvos foram montados em molduras confeccionadas em fibra de Carbono contendo orifício de $10 \mathrm{~mm}$ de diâmetro, onde o material de estudo foi depositado nos $8 \mathrm{~mm}$ centrais com objetivo de diminuir a foto-ionização provocada por espalhamento na moldura,ver figura 3.6. Os elementos de estudo ( $\mathrm{Te}$ ou $\mathrm{Ta}$ ) foram depositados sobre filmes de Carbono.

Para calibrar o sistema de aquisição foram utilizadas fontes radiativas de ${ }^{133} \mathrm{Ba},{ }^{152} \mathrm{Eu}$ e ${ }^{241} \mathrm{Am}$ produzidas e calibradas no Laboratório de Metrologia Nuclear (LMN) do Instituto de Pesquisas Energéticas e Nucleares (IPEN).

Para manter as mesmas condições do experimento nas calibrações de 
eficiência, as molduras dos alvos e das fontes de calibração são idênticas. Na figura 3.6 é apresentado, como exemplo, a fonte de ${ }^{133} \mathrm{Ba}$ e o alvo de Ta utilizados neste trabalho.

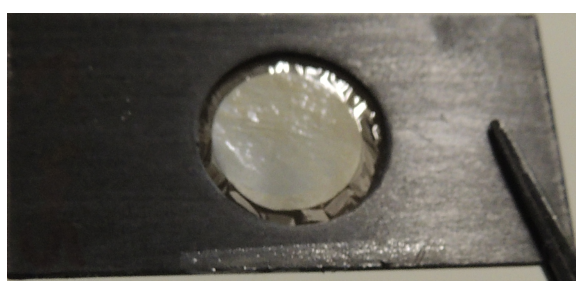

(a)

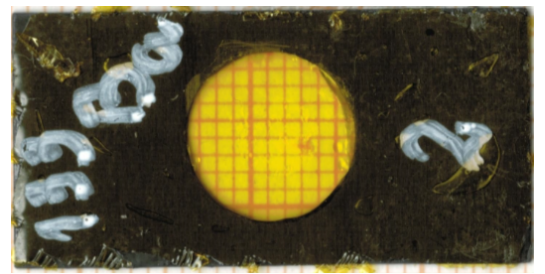

(b)

Figura 3.6: (a) Alvo de Ta e (b) fonte radioativa de ${ }^{133} \mathrm{Ba}$ com molduras idênticas.

As fontes radiativas foram seladas por finas camadas de Kapton de $7.5 \mu \mathrm{m}$ de espessura.

\subsubsection{Sistema de aquisição}

No experimento realizado neste trabalho foram usados três detectores de Germânio hiperpuro (HPGe): dois planares e específicos para detecção de raios-X, denominados pelos seus volumes que são: 5 cc (cinco centímetros cúbicos) e 8cc (oito centímetros cúbicos) e um detector coaxial, específico para detecção de raios- $\gamma$. O detector de raios- $\gamma$ possui uma janela de fibra de Carbono que possibilita o estudo de fótons de raios-X K $\alpha$. Porém, devido a sua geometria coaxial, a resolução é pior do que a dos detectores de raios-X.

Além dos detectores de HPGe, que precisam estar em contato térmico com nitrogênio líquido para diminuir a corrente de fuga gerada termicamente e que compromete a resolução em energia, também foram utilizados um computador e equipamento eletrônico conforme a figura 3.7 . 


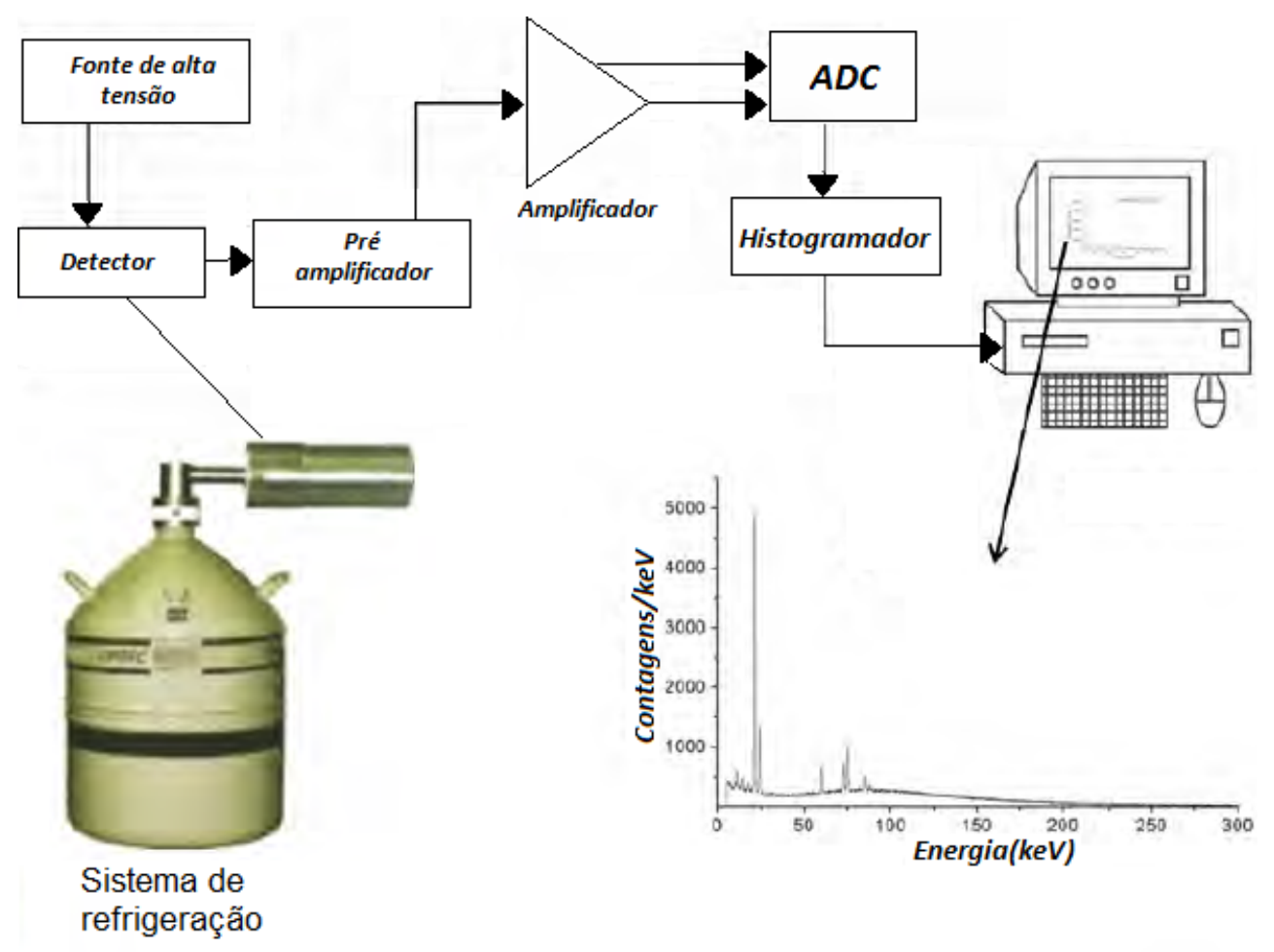

Figura 3.7: Esquema da eletrônica utilizada.

No esquema apresentado na figura 3.7 pode-se observar uma fonte de alta tensão, necessária para alimentar o detector. O detector envia o sinal recebido durante o experimento para um pré-amplificador, que por sua vez manda para o amplificador. O sinal amplificado é convertido de analógico para digital por meio de um ADC (Analog to Digital Converter) e então é enviado para um histogramador, chegando finalmente ao computador. Usamos também equipamentos digitais - DSPEC - que digitaliza e processa os dados diretamente do pré-amplificador. Foi utilizado o sistema descrito na figura 3.7 para o detector 5cc e dois DSPEC para os demais detectores.

Para diminuir a detecção da radiação externa no sistema, os detectores foram cobertos por uma blindagem de Cobre e, mais externamente, por paredes de Chumbo. Na frente dos detectores foi posicionado um colimador de Cobre com o objetivo de focalizar o alvo e diminuir a detecção do fundo produzido pelos elétrons na câmara. Esta estratégia também serve para garantir 
que os fótons incidentes atinjam uma região próxima ao centro do cristal (detector), no caso do detector $\gamma$. No caso do detector 5cc, esse colimador também serve para evitar as camadas mortas laterais, conforme discutido na Ref. [11. Foram realizadas medidas de fundo durante um extenso período de tempo, aproximadamente 12 horas para cada fonte, para garantir estatística significativa. Essas medidas são necessárias para avaliar a influência do fundo nos espectros experimentais.

\subsection{Procedimento experimental}

Os detectores foram posicionados em três ângulos diferentes com relação à direção incidente do feixe de elétrons. O detector 8cc foi posicionado a $35^{\circ}$, o 5 cc a $90^{\circ}$ e o de raio- $\gamma$ a $131^{\circ}$, o que permitiu a obtenção de dados experimentais para os três simultaneamente. Devido o fato que a seção de choque de ionização da camada $K$ por impacto de elétrons não tem dependência angular, a escolha dos ângulos nesse experimento não tem relevância.

\subsubsection{Densidade superficial de massa dos al- VOS}

O método usado na determinação da densidade superficial dos alvos de Te e Ta foi o RBS. Nesse método o alvo é irradiado por um feixe de íons ${ }^{4} \mathrm{He}^{2+}$ com energia de 2,2 MeV, fornecido pelo acelerador Tandem van de Graaff do LAMFI e um detector de barreira de superfície é posicionado num ângulo $\theta=120^{\circ}$ em relação à direção do feixe incidente, como esquematizado na figura 3.8 .

Os íons ${ }^{4} \mathrm{He}^{2+}$ interagem com o campo Coulombiano dos átomos da amos- 


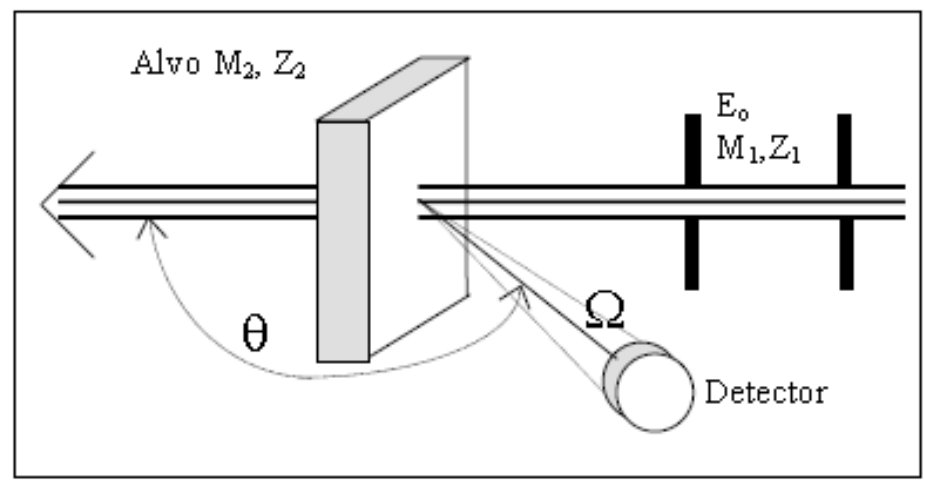

Figura 3.8: Esboço do experimento utilizado para determinação da espessura dos alvos pela técnica de RBS. A seta apontando para a esquerda representa o feixe. Figura retirada da Ref. [12].

tra sofrendo espalhamento elástico. As partículas espalhadas dentro do ângulo sólido $\Omega$, mostrado na figura 3.8 , chegam ao detector. A energia com que as partículas espalhadas chegam no detector dependerá do ângulo de espalhamento e também do quanto a partícula penetrou na amostra devido ao poder de freamento. Desta forma, quanto mais espesso o alvo mais larga será a distribuição de energia das partículas no espectro obtido. De forma simplificada podemos falar que para uma camada do alvo as partículas espalhadas seguem a seguinte expressão:

$$
n_{\mathrm{D}}=\sigma \Omega n_{\mathrm{I}} \lambda^{\prime}
$$

onde $n_{\mathrm{D}}$ é o número de partículas detectadas, $\sigma$ é a seção de choque diferencial de espalhamento Rutherford, $\Omega$ é o ângulo sólido, $n_{\mathrm{I}}$ é o número de partículas incidentes e $\lambda^{\prime}$ é a densidade superficial da amostra, quantidade que estamos interessados.

Os espectros obtidos foram ajustados utilizando os softwares de análise MultiSIMNRA e SIMNRA [13, 14], que simulam o espectro gerado na irradiação levando em consideração a rugosidade, o poder de freamento e o espalhamento Rutherford, fornecendo assim o perfil de profundidade do alvo estudado. 


\subsubsection{Seção de choque pelo método absoluto}

Para a determinação da seção de choque de ionização é necessário conhecer a seção de choque de produção de raios-X:

$$
\sigma_{\mathrm{K} \alpha_{2,1}}^{x}=\frac{n_{\mathrm{f}}}{n_{\mathrm{e}} \varepsilon \lambda}
$$

onde $n_{\mathrm{f}}$ é o número de fótons detectados de raios-X $\mathrm{K} \alpha_{2,1}$ dividido pelo tempo que o detector ficou ativo (tempo vivo), $\varepsilon$ é a eficiência de fotopico do detector na energia média do raios-X $\mathrm{K} \alpha_{2,1}, n_{\mathrm{e}}$ é o número de elétrons coletados normalizado pelo tempo real da medida e $\lambda=\lambda^{\prime} / \sin \left(30^{\circ}\right)$ é a densidade superficial de átomos nos alvos corrigida por $\sin \left(30^{\circ}\right)$, pois o alvo foi inclinado de $30^{\circ}$. A energia média pode ser obtida da seguinte forma:

$$
E_{\mathrm{K} \alpha_{2,1}}=\frac{\Gamma_{1} E_{\mathrm{K} \alpha_{1}}+\Gamma_{2} E_{\mathrm{K} \alpha_{2}}}{\Gamma_{1}+\Gamma_{2}}
$$

onde $\Gamma_{i}$ é a taxa de emissão do raio-X $\mathrm{K} \alpha_{i}$ obtida da Ref. [15] e $E_{\mathrm{K} \alpha_{i}}$ é a energia de transição obtida da Ref. [16].

Os valores obtidos para a seção de choque de produção de raios-X, $\sigma_{\mathrm{K} \alpha_{2,1}}^{\mathrm{x}}$, foram convertidos em seção de choque de ionização com a seguinte equação:

$$
\sigma_{\mathrm{K}}=\left(\omega_{\mathrm{K}} \frac{\Gamma_{\mathrm{K} \alpha_{2,1}}}{\Gamma_{\mathrm{K}, \text { total }}}\right)^{-1} \sigma_{\mathrm{K} \alpha_{2,1}}^{\mathrm{x}},
$$

onde $\omega_{\mathrm{K}}$ é o rendimento de fluorescência obtido da Ref. [17] e $\frac{\Gamma_{\mathrm{K} \alpha_{2,1}}}{\Gamma_{\mathrm{K}, \text { total }}}$ é a razão da soma das taxas de emissão de raios-X K $\alpha$ pela taxa de emissão total.

A incerteza relativa da seção de choque $\sigma_{\mathrm{K}}$ é obtida pela soma quadrática das incertezas relativas para cada parâmetro, já que são parâmetros independentes.

No capítulo 4 serão discutidos os métodos usados na obtenção das áreas dos picos de raios-X K $\alpha$ para os alvos de Te e Ta e no capítulo 5 a curva de 
Tabela 3.1: Valores de rendimento de fluorescência e razão das taxas de emissão de raios-X K $\alpha$ para os alvos de Te e Ta.

\begin{tabular}{llll}
\hline Alvo & $Z$ & $\omega_{\mathrm{K}}$ & $\Gamma_{\mathrm{K} \alpha_{2,1}} / \Gamma_{\mathrm{K}, \text { total }}$ \\
\hline $\mathrm{Te}$ & 52 & 0,877 & 0,824 \\
$\mathrm{Ta}$ & 73 & 0,957 & 0,797 \\
\hline
\end{tabular}

eficiência de fotopico será apresentada para os detectores.

\subsubsection{Seção de choque pelo método relativo ao bremsstrahlung}

A seção de choque de bremsstrahlung foi calculada para os elementos He, $\mathrm{O}, \mathrm{Al}, \mathrm{Ag}, \mathrm{Au}$ e U, Ref.[18] e para outros é obtida através de interpolação Ref. [19]; como consequência é confiável com um desvio padrão na faixa de 11\%. Os dados de seção de choque utilizados neste trabalho foram obtidas da base de dados do código PENELOPE [20]. Em alguns casos, quando não se conhece a densidade superficial do alvo, o uso da seção de choque de bremsstrahlung para se obter a seção de choque de ionização, método relativo, é bastante usado como mostram as Refs. [1, 2]. Neste trabalho o método relativo foi menos relevante, pois apresenta uma incerteza maior que a obtida pelo método absoluto. O método relativo teve o papel de verificar os resultados obtidos pelo método absoluto.

\section{Modelo para o espectro contínuo de fótons do brems- strahlung}

Quando um alvo é irradiado com feixe de elétrons de energia $E^{\prime}$, ao penetrar o alvo, esses elétrons são freados devido a perda de energia na 
interação com o campo Colombiano dos átomos. O número de fótons gerados, $\mathrm{d} N$, que atinge o detector com energia entre $E_{\mathrm{c}}$ e $E_{\mathrm{c}}+\mathrm{d} E_{\mathrm{c}}$ pode ser descrito por:

$$
\mathrm{d} N=n_{\mathrm{e}} \lambda \Omega \frac{\mathrm{d}^{2} \sigma_{\mathrm{b}}\left(E^{\prime}, E_{\mathrm{c}}, \theta\right)}{\mathrm{d} E_{\mathrm{c}} \mathrm{d} \Omega} \mathrm{d} E_{\mathrm{c}}
$$

onde $\lambda$ é a densidade superficial de átomos no alvo, $\Omega$ é o ângulo sólido do detector em relação ao alvo, $\mathrm{d}^{2} \sigma_{\mathrm{b}} / \mathrm{d} E_{\mathrm{c}} \mathrm{d} \Omega$ é a seção de choque duplamente diferencial de bremsstrahlung (SCDD) e $E_{\mathrm{c}}$ é a energia do fóton emitido no ângulo $\theta$.

Devido ao fato do canhão de elétrons possuir uma pequena instabilidade, não é uma boa aproximação considerar que a energia do feixe possui dispersão desprezível. Portanto, para levar em conta essa flutuação, a equação (3.5) foi convoluída com uma Gaussiana de energia média $E_{\mathrm{e}}$ e dispersão de energia $\sigma_{\mathrm{e}}$ :

$$
\mathrm{d} N\left(E_{\mathrm{e}}, \sigma_{\mathrm{e}}, \lambda, E_{\mathrm{c}}\right)=n_{\mathrm{e}} \lambda \Omega\left(\int_{0}^{\infty} \frac{\mathrm{d}^{2} \sigma_{\mathrm{b}}\left(E^{\prime}, E_{\mathrm{c}}, \theta\right)}{\mathrm{d} E_{\mathrm{c}} \mathrm{d} \Omega} G\left(E_{\mathrm{e}}, \sigma_{\mathrm{e}}, E^{\prime}\right) \mathrm{d} E^{\prime}\right) \mathrm{d} E_{\mathrm{c}}
$$

A função que descreve a forma do espectro de bremsstrahlung é definida a partir da relação $\mathrm{d} N / \mathrm{d} E_{\mathrm{c}}$, convoluída com a função resposta do detector conforme:

$$
f\left(E ; E_{\mathrm{e}}, \sigma_{\mathrm{e}}, \lambda\right)=\int_{0}^{\infty} \frac{\mathrm{d} N\left(E_{\mathrm{e}}, \sigma_{\mathrm{e}}, E_{\mathrm{c}}\right)}{\mathrm{d} E_{\mathrm{c}}} R\left(E ; E_{\mathrm{c}}\right) \mathrm{d} E_{\mathrm{c}}
$$

A equação (3.7) pode ser reescrita da seguinte forma:

$$
f\left(E ; E_{\mathrm{e}}, \sigma_{\mathrm{e}}, \lambda\right)=n_{\mathrm{e}} \lambda \Omega I\left(E ; E_{\mathrm{e}}, \sigma_{\mathrm{e}}\right)
$$

onde

$$
I\left(E ; E_{\mathrm{e}}, \sigma_{\mathrm{e}}\right)=\int_{0}^{\infty} R\left(E ; E_{\mathrm{c}}\right) \int_{0}^{\infty} \frac{\mathrm{d}^{2} \sigma_{\mathrm{b}}\left(E^{\prime}, E_{\mathrm{c}}, \theta\right)}{\mathrm{d} E_{\mathrm{c}} \mathrm{d} \Omega} G\left(E_{\mathrm{e}}, \sigma_{\mathrm{e}}, E^{\prime}\right) \mathrm{d} E^{\prime} \mathrm{d} E_{\mathrm{c}}
$$




\section{Ajuste da região do tip de bremsstrahlung}

Os dados da SCDD de bremsstrahlung foram obtidos com o código computacional PENELOPE [20]. Desta forma, a equação (3.7) foi ajustada na região do espectro de energia máxima dos fótons de bremsstrahlung que é igual a energia dos elétrons incidentes. A seção de choque para geração dos fótons com energia igual a dos elétrons exibe um degrau característico chamado tip de bremsstrahlung. A região do tip foi ajustada pelo Método dos Mínimos Quadrados (MMQ). Os fótons observados não são provenientes somente de bremsstrahlung do elemento estudado, torna-se necessário fazer correções no espectro para levar em consideração os efeitos secundários de detecção citados a seguir. Medidas de fundo foram realizadas e o espectro obtido foi normalizado pelo tempo vivo do experimento e subtraído do espectro de bremsstrahlung. Outros efeitos secundários de detecção, como espalhamento dos fótons na janela de espectroscopia e escape de elétrons no detector, são considerados na função resposta, porém vale ressaltar que o efeito no espectro é muito pequeno. Essas influências foram estudadas observando os degraus à esquerda dos picos das fontes radiativas. $\mathrm{O}$ espectro de bremsstrahlung produzido no carbono também foi subtraído.

Para ajustar a equação (3.7) foi necessário integrá-la na largura de um canal para posterior comparação com o espectro experimental:

$$
Y_{i}\left(E_{\mathrm{e}}, \sigma_{\mathrm{e}}, \lambda\right)=\int_{E_{i}-\frac{\Delta}{2}}^{E_{i}+\frac{\Delta}{2}} f\left(E ; E_{\mathrm{e}}, \sigma_{\mathrm{e}}, \lambda\right) \mathrm{d} E
$$

Depois, foi construída a função de mérito definida como:

$$
Q\left(E_{\mathrm{e}}, \sigma_{\mathrm{e}}, \lambda\right)=\sum_{i=1}^{N} \frac{\left[Y_{i, \exp }-Y_{i}\left(E_{\mathrm{e}}, \sigma_{\mathrm{e}}, \lambda\right)\right]^{2}}{\sigma_{i}{ }^{2}}
$$

Optou-se por fixar as variáveis de ajuste não lineares, $E_{\mathrm{e}}$ e $\sigma_{\mathrm{e}}$, e pelo MMQ ajusta-se $\lambda$. Depois, a função $Q$ é mapeada variando os valores de $E_{\mathrm{e}}$ 
e $\sigma_{\mathrm{e}}$ descrevendo curvas de nível. O menor valor de $Q$, representado por $\chi^{2}$, define o valor de $E_{\mathrm{e}}, \sigma_{\mathrm{e}}$ e $\lambda$ que melhor ajusta a função (3.8) no espectro de bremsstrahlung. As figuras 3.9 e 3.10 apresentam, respectivamente, as curvas de nível de $Q$ definidas por: $Q=\chi^{2}+n^{2}$ e a comparação entre o espectro experimental e o calculado para o alvo de Ta à $E_{\mathrm{e}} \approx 95 \mathrm{keV}$, com o detector $8 \mathrm{cc}$.

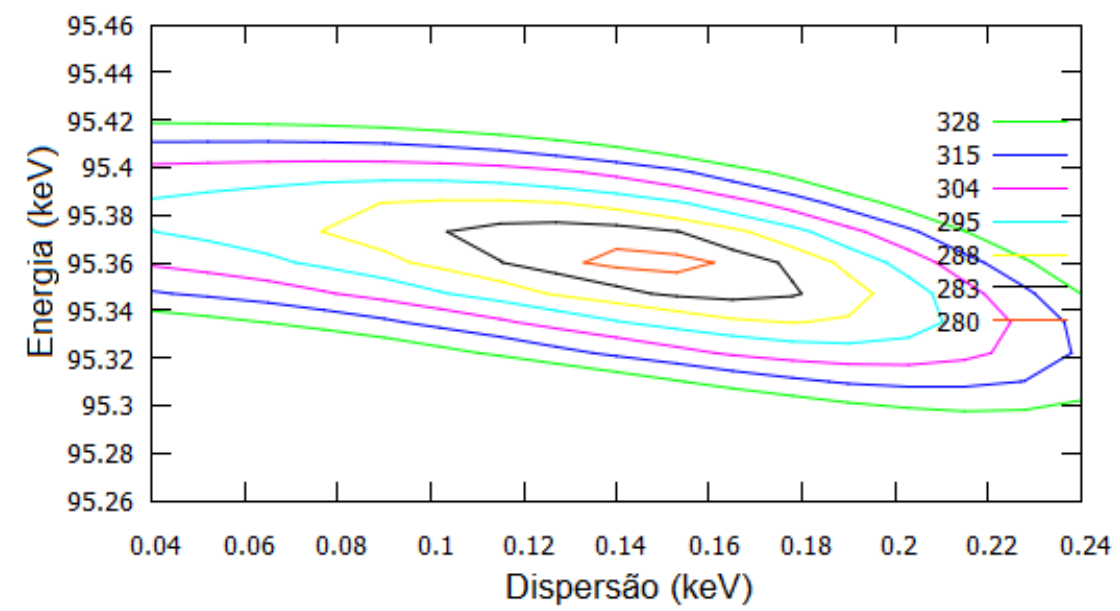

Figura 3.9: Curvas de nível $Q=\chi^{2}+n^{2}, \operatorname{com} n=1,2, \ldots, 7$ para o ajuste do tip de bremsstrahlung para o alvo de Ta, $E \approx 95 \mathrm{keV}$ e $\theta=35^{\circ}$. 


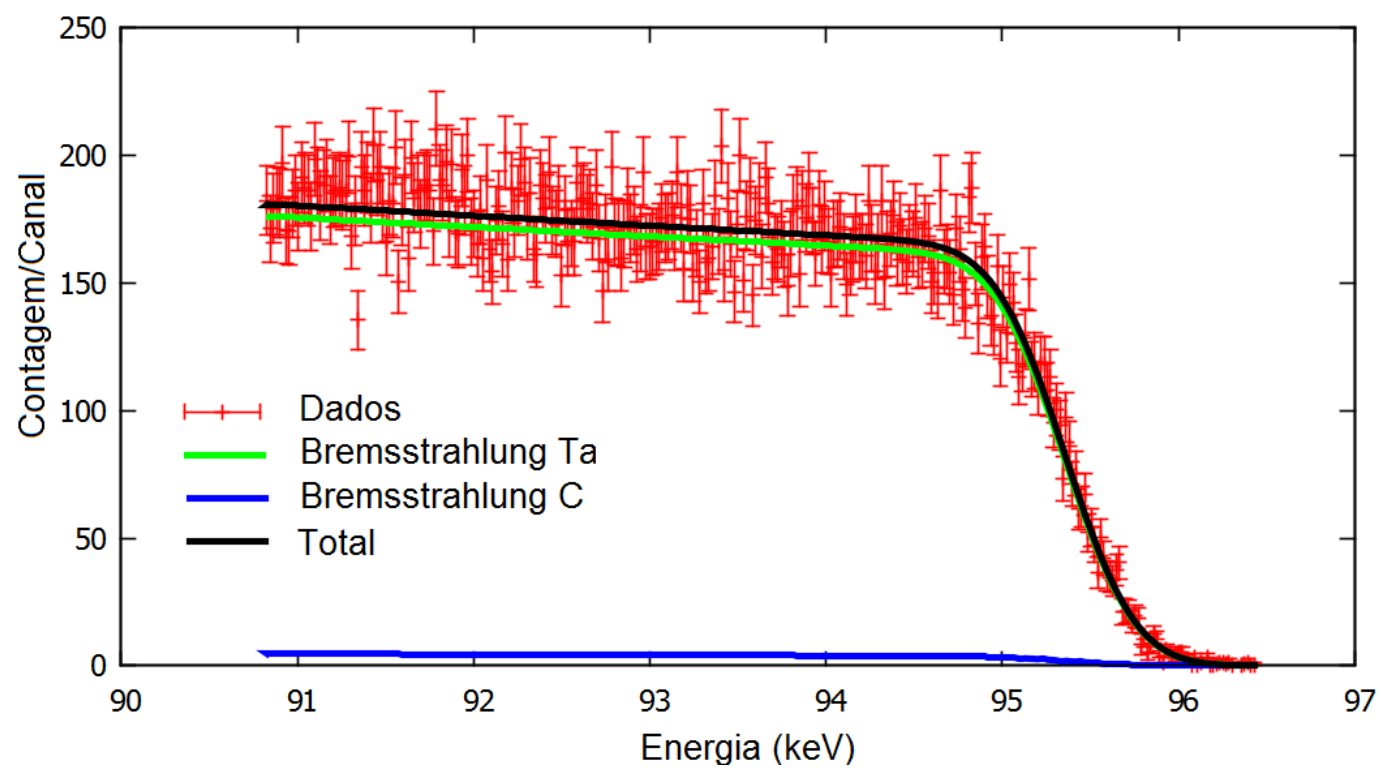

Figura 3.10: Ajuste do tip de bremsstrahlung para o alvo de Ta, com feixe de energia $E \approx 95 \mathrm{keV}$ e $\theta=35^{\circ}$. Os dados experimentais são apresentados pelos pontos com barras, o fundo pela curva azul, o espectro de bremsstrahlung (alvo) pela curva verde e a soma dos espectros pela curva preta.

Escrevendo a eficiência de fotopico em termos da eficiência intrínseca do detector, tem-se:

$$
\varepsilon=\frac{\Omega}{4 \pi} \varepsilon_{\mathrm{int}}
$$

Desta forma, é possível reescrever a seção de choque experimental, ver equação (3.4), da seguinte forma:

$$
\sigma_{\mathrm{K}}=\left(\omega_{\mathrm{K}} \frac{\Gamma_{\mathrm{K} \alpha_{2,1}}}{\Gamma_{\mathrm{K}, \text { total }}}\right)^{-1} \frac{4 \pi n_{\mathrm{f}}}{n_{\mathrm{e}} \varepsilon_{\mathrm{int}} \Omega \lambda}
$$

A função que descreve a forma do espectro de bremsstrahlung, equação (3.8), foi integrada no intervalo de energia [91 keV, $96 \mathrm{keV}]$ para obter o número de fótons de bremsstrahlung detectados na região do tip ver figura 3.10 .

$$
n_{\mathrm{b}}{ }^{\prime}=n_{\mathrm{e}} \lambda \Omega \int_{E_{\mathrm{a}}}^{E_{\mathrm{b}}} I\left(E ; E_{\mathrm{e}}, \sigma_{\mathrm{e}}\right) \mathrm{d} E
$$


onde o parâmetro $n_{\mathrm{b}}{ }^{\prime}$ deve ser normalizado pelo tempo vivo do detector $n_{\mathrm{b}}=n_{\mathrm{b}}{ }^{\prime} / t_{\text {vivo }}$.

Combinando as equações 3.13) e 3.14 é possível obter a seção de choque de ionização pelo método relativo ao bremsstrahlung:

$$
\sigma_{\mathrm{K}}=\left(\omega_{\mathrm{K}} \frac{\Gamma_{\mathrm{K} \alpha_{2,1}}}{\Gamma_{\mathrm{K}, \text { total }}}\right)^{-1} \frac{4 \pi n_{\mathrm{f}}}{n_{\mathrm{b}} \varepsilon_{\mathrm{int}}} \int_{E_{\mathrm{a}}}^{E_{\mathrm{b}}} I\left(E ; E_{\mathrm{e}}, \sigma_{\mathrm{e}}\right) \mathrm{d} E
$$

Para determinar o número de fótons de raio-X $\mathrm{K} \alpha_{2,1}$, foi utilizada uma função na forma de polinômio para separar os picos de raios-X do contínuo do espectro e, assim, obter o número de fótons que depois foi dividido pelo tempo vivo e representado por $n_{\mathrm{f}}$ na equação 3.15) utilizada para determinar a seção de choque de ionização. A figura 3.11 é um exemplo de ajuste feito para o alvo de Ta com o detector posicionado a $35^{\circ}$.

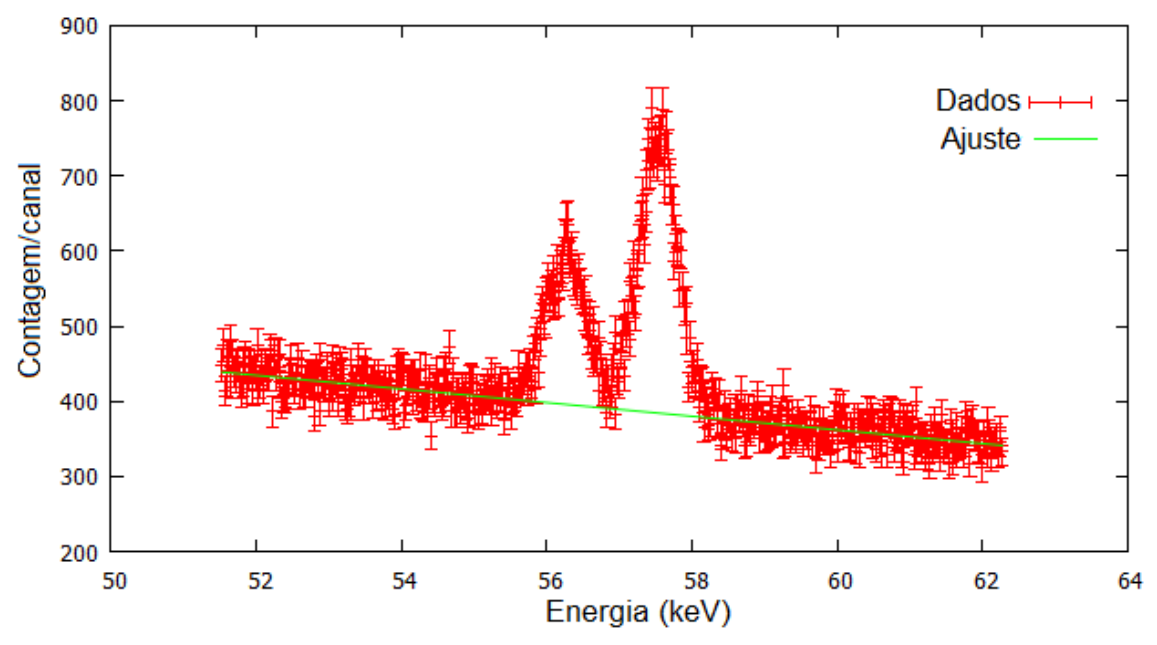

Figura 3.11: Ajuste do contínuo abaixo dos picos de raios-X $\mathrm{K} \alpha_{2,1}$ do Ta com feixe de $E \approx 95 \mathrm{keV}$, utilizado no método relativo ao bremsstrahlung. 



\section{Modelagem para ajuste dos}

\section{parâmetros dos picos de raios-X}

e $\gamma$ no espectro de energia

\subsection{Detecção de fótons}

Para detectar raios-X ou raios- $\gamma$ são utilizados detectores semicondutores devido à alta resolução, consequência da baixa energia necessária para produzir um par elétron-buraco $(\approx 3 \mathrm{eV})$. Esses detectores também são utilizados com baixa temperatura que evita corrente térmica e melhora a resolução em energia. Quando um fóton entra no volume ativo de um detector, ele pode depositar sua energia (toda ou parte) através de processos conhecidos como fotoelétrico, espalhamento Compton ou produção de pares [21]. A carga coletada é diretamente proporcional à energia depositada no detector e gera uma contagem em um canal do espectro multicanal, como descrito na seção 3.1.3. Porém, o processo de produção de pares eletrón-buraco é aleatório e deveria ser descrito pela Função de Probabilidade de Poisson (FPP), mas não é o que se observa experimentalmente [21].

Se o processo for descrito por uma FPP, a flutuação estatística no número de pares elétron-buraco seria dada por:

$$
\Delta N_{\mathrm{p}}=\sqrt{\bar{N}}
$$


4 Modelagem para ajuste dos parâmetros dos picos de raios-X e $\gamma$ no

espectro de energia

onde $N_{\mathrm{p}}$ é igual a energia do fóton dividido pela energia para produzir um par elétron buraco, $\Delta N_{\mathrm{p}}$ é o desvio padrão e $\bar{N}$ é o valor médio [22].

Existe uma grandeza que só depende do cristal do detector, que tem o nome de fator de Fano e é definida como a razão da variância observada e a prevista por um processo FPP:

$$
F=\left(\frac{\Delta N}{\Delta N_{\mathrm{p}}}\right)^{2}
$$

Cada cristal semicondutor possui um fator de Fano característico, que se encontra no intervalo $0<F<1$.

A função que descreve a forma do pico de raios-X ou raios- $\gamma$ é dada pela convolução da resposta esperada de um detector considerado ideal com a função Gaussiana equação (4.3), que leva em consideração a flutuação estatística [23, 24]:

$$
G\left(E ; E_{0}, \sigma\right)=\frac{1}{\sqrt{2 \pi} \sigma} \exp \left[-\frac{\left(E-E_{0}\right)^{2}}{2 \sigma^{2}}\right]
$$

onde $E$ é a energia, $E_{0}$ é a posição do pico da Gaussiana e $\sigma$ é o desvio padrão, que se relaciona com a largura à meia altura (FWHM), $\gamma_{\mathrm{G}}$, da Gaussiana através da equação:

$$
\gamma_{\mathrm{G}}=2 \sqrt{2 \ln 2} \sigma
$$

Além disso, sabe-se que $\gamma_{\mathrm{G}}$ também pode ser escrita como:

$$
\gamma_{\mathrm{G}}=\sqrt{\eta+\delta E}
$$

Na equação 4.5, a constante $\eta$ está relacionada com o ruído eletrônico e $\delta$ é igual o fator de Fano vezes a energia necessária para criar um par elétron buraco. Esta equação é muito importante para ajuste de vários picos simultaneamente, como será discutido nas seções 4.2 e 4.3 . 


\subsection{Ajuste dos parâmetros dos picos de raios- $\gamma$ das fontes radiativas}

A distribuição em energia de um raio- $\gamma$ pode ser representada aproximadamente por uma função-delta, pois a meia vida de um raio- $\gamma$ é da ordem de $10^{-12}$ s. Desta forma, a função que melhor representa um pico de raios- $\gamma$ é a própria função Gaussiana dada pela equação (4.3), pois a convolução de qualquer função com uma função-delta é a própria função.

Os picos de raios- $\gamma$ também possuem um degrau à esquerda, que pode ser representado pela função descrita na equação (4.12), além de um contínuo descrito utilizando polinômios de grau 1 ou 2, dado pela seguinte equação:

$$
P(E)=\sum_{i=1}^{n} a_{\mathrm{i}}\left(E-E_{\mathrm{c}}\right)^{i}
$$

onde $E_{\mathrm{c}}$ é a energia central da região de ajuste.

Somando as equações 4.3), 4.12 e 4.6 obtém-se a função para o ajuste de um pico de raios- $\gamma$. Para ajustar vários picos é necessário realizar essa soma para cada pico, de tal forma que se obtém:

$$
\sum_{i=1}^{n} A_{i}\left[G\left(E ; E_{i}, \sigma\left(E_{i}\right)\right)+D\left(E ; E_{i}, h_{i}, \sigma\left(E_{i}\right)\right)\right]+P(E)
$$

Quando não se tem estatística suficiente para a identificação do degrau, pode-se desprezá-lo na equação (4.7). 
4 Modelagem para ajuste dos parâmetros dos picos de raios-X e $\gamma$ no

\subsection{Ajuste dos parâmetros dos picos de raios- $\mathrm{X}$}

A distribuição em energia característica dos picos de raios-X possui a forma de uma função Lorentziana, onde a largura está relacionada com a meia-vida do nível excitado do átomo dada pela seguinte equação:

$$
L\left(E ; E_{0}, \Gamma\right)=\frac{1}{\pi} \frac{\frac{\Gamma}{2}}{\left(E-E_{0}\right)^{2}+\left(\frac{\Gamma}{2}\right)^{2}}
$$

onde $E$ é a energia, $E_{0}$ a energia da linha de raios-X e $\Gamma$ a largura natural da linha de raios-X.

A largura natural $\Gamma$ [15] de uma linha de raio-X é dada pela soma das larguras dos níveis de energia envolvidos na transição:

$$
\Gamma=\sum \Gamma_{i}
$$

Pode-se utilizar $\sigma\left(E^{\prime}\right) \approx \sigma\left(E_{0}\right)$ devido a pequena dependência de $\sigma$ com a energia na região do pico. Desta forma, a função que melhor descreve a resposta esperada do detector para os raios-X será obtida pela convolução da equação (4.8) com (4.3), dando origem a função Voigt, $V$ [24]:

$$
V\left(E ; E_{0}, \Gamma, \sigma\left(E_{0}\right)\right)=\int_{-\infty}^{+\infty} L\left(E^{\prime} ; E_{0}, \Gamma\right) G\left(E ; E^{\prime}, \sigma\left(E_{0}\right)\right) \mathrm{d} E^{\prime}
$$

A função Voigt foi utilizada para obtenção das áreas dos picos de raios$\mathrm{X}$ dos espectros deste trabalho, através do software Mathematica 10.3. A integral da equação 4.10 pode ser escrita da seguinte maneira:

$$
V(x ; \delta, \sigma)=\frac{\exp \left(\frac{\delta-i x}{2 \sigma^{2}}\right) \operatorname{erfc}\left(\frac{\delta-i x}{\sqrt{2} \sigma}\right)+\exp \left(\frac{\delta+i x}{2 \sigma^{2}}\right) \operatorname{erfc}\left(\frac{\delta+i x}{\sqrt{2} \sigma}\right)}{2 \sigma \sqrt{2 \pi}}
$$

onde $\delta=\frac{\Gamma}{2}, x=E-E_{0}, \sigma=\sigma\left(E_{0}\right)$ e erfc é a função erro complementar. 
O fato de $\gamma_{\mathrm{G}}$ estar relacionada com $\sigma$ facilita o ajuste de múltiplos picos, pois ao ajustar a função dada pela equação 4.5 utilizando picos de raios- $\gamma$ é possível vincular as larguras dos picos. Para ajustar vários picos simultaneamente, caso muito comum em ajustes de picos de raio-X, foi utilizada a equação 4.5 para vincular a largura à meia altura com a energia de transição.

Uma análise cuidadosa mostrou que quando a razão $\frac{\Gamma}{\gamma_{\mathrm{G}}} \geq 0,1$, o uso da função Voigt é necessário. Porém, quando a razão $\frac{\Gamma}{\gamma_{\mathrm{G}}} \leq 0,01$, a diferença entre a função Voigt e a Gaussiana é muito pequena, de tal forma que é possível utilizar a função Gaussiana para ajustar os picos. Fora dos intervalos mencionados é necessário fazer uma verificação [24].

O escape de fotoelétrons e de elétrons do volume ativo do detector pode gerar um degrau à esquerda dos picos de raios-X ou $\gamma$ dependendo da estatística adotada. Esse degrau pode ser representado por uma função Theta de Heaviside convoluída com a Gaussiana:

$$
D\left(E ; E_{0}, h, \sigma\left(E_{0}\right)\right)=\frac{h}{2} \operatorname{erfc}\left(\frac{E-E_{0}}{\sqrt{2} \sigma\left(E_{0}\right)}\right)
$$

O contínuo abaixo dos picos de raios-X majoritariamente possui origem no bremsstrahlung gerado quando os elétrons do feixe atingem o alvo. O espectro de bremsstrahlung [25, 26] somado à constante $c$, inserida devido aos efeitos secundários de detecção, pode ser aproximado, para pequenas regiões, pela seguinte equação:

$$
B(E ; a, b)=a^{\prime}+c+\frac{b}{E}=a+\frac{b}{E}
$$

Somando a equação 4.3 ou 4.11 com as equações 4.12 e 4.13 obtém-se a função de ajuste para um único pico de raio-X. Para ajustar vários picos é necessário fazer essa soma para cada pico obtendo a equação (4.14) 
4 Modelagem para ajuste dos parâmetros dos picos de raios-X e $\gamma$ no

para Voigt ou a equação 4.15 para Gaussiana.

$$
\begin{gathered}
\sum_{i=1}^{n} A_{i}\left[V\left(E ; E_{i}, \Gamma_{i}, \sigma\left(E_{i}\right)\right)+D\left(E ; E_{i}, h_{i}, \sigma\left(E_{i}\right)\right)\right]+B(E ; a, b) \\
\sum_{i=1}^{n} A_{i}\left[G\left(E ; E_{i}, \sigma\left(E_{i}\right)\right)+D\left(E ; E_{i}, h_{i}, \sigma\left(E_{i}\right)\right)\right]+B(E ; a, b)
\end{gathered}
$$

onde $A_{\mathrm{i}}$ é a área do $i$-ésimo pico e $n$ é o número de picos ajustados.

Dependendo da estatística e da energia do pico ajustado torna-se difícil separar o contínuo e o degrau descrito pela equação (4.12). Desta forma, o degrau é ignorado nos casos onde sua identificação não é imediata, o que ocorre quando a estatística é baixa. Este procedimento não interfere no ajuste de forma quantitativa.

\subsection{Estudo da influência dos degraus nos pa- râmetros de ajuste}

Para determinar $n_{\mathrm{f}}$, equação 3.2 , os picos de raios-X $\mathrm{K} \alpha_{2,1}$ foram ajustados utilizando o método descrito na seção 4.3. Porém, existe uma correlação muito grande entre o degrau à esquerda do pico e a componente contínua do espectro. Esse fato dificulta o ajuste correto do degrau e, portanto, foi realizado um teste estatístico com a finalidade de estimar um valor realista para o degrau.

A função que descreve o degrau é dada pela equação 4.12, onde o termo $h$ é um parâmetro de forma que depende apenas do detector e da energia de transição. A amplitude do degrau é dada pelo produto entre a área e o parâmetro $h$, ou seja, quanto mais intenso o pico mais estatística terá o degrau e, consequentemente, mais fácil será a separação entre o degrau 
e o contínuo. Por esse motivo, os espectros para cada detector e alvo foram somados e a soma foi ajustada com objetivo de determinar o parâmetro $h$. A figura 4.1 apresenta um ajuste para o detector 8cc e alvo de Te, a e figura $4.1 \mathrm{~b}$ mostra em detalhe a região da base do pico.

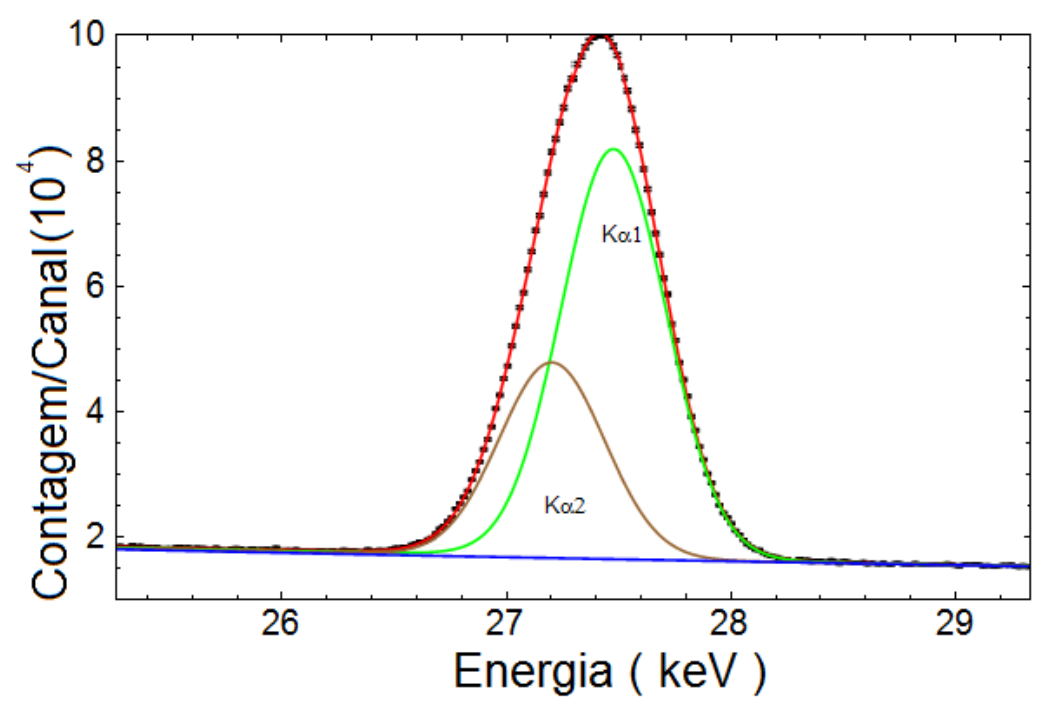

(a) Ajuste $\mathrm{Te} \mathrm{K}_{\alpha 2,1}$.

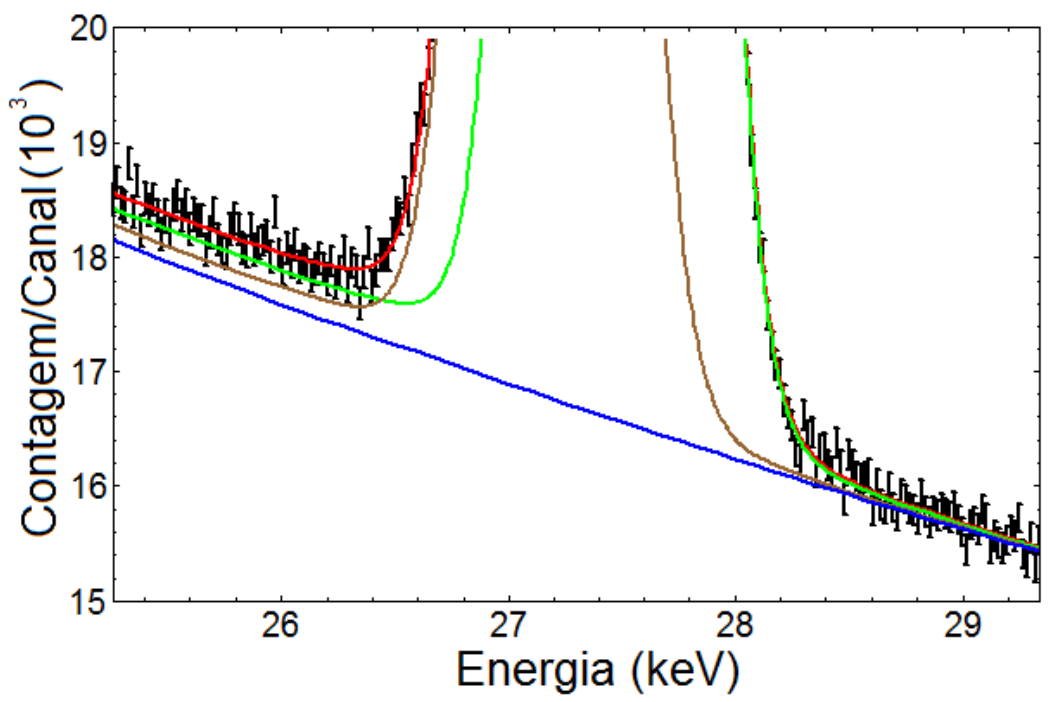

(b) Detalhe da base do pico.

Figura 4.1: Ajuste da soma dos espectros obtidos com alvo de Te e detector 8cc em todas as medições. Dispersão de energia de $\approx 18 \mathrm{eV}$ por canal. 
4 Modelagem para ajuste dos parâmetros dos picos de raios-X e $\gamma$ no

Com o resultado obtido através dos ajustes, foi feito um teste-z com nível de significância de $5 \%$ para analisar a compatibilidade do parâmetro $h$ com zero. Na tabela abaixo são apresentados os valores de $h$ obtidos para todos os detectores e alvos.

Tabela 4.1: Testes de compatibilidade dos valores de $h$ com zero. Note que $\mathrm{z}=$ $\frac{d-d_{\mathrm{c}}}{\sigma_{\mathrm{d}}}$, onde $d_{\mathrm{c}}=0$.

\begin{tabular}{llll}
\hline Detector & Alvo & $h$ & teste-z \\
\hline $8 \mathrm{cc}$ & $\mathrm{Te}$ & $0,00012(3)$ & 4,47 \\
$8 \mathrm{cc}$ & $\mathrm{Ta}$ & $0,0000(2)$ & 0,0 \\
$5 \mathrm{cc}$ & $\mathrm{Te}$ & $0,00014(2)$ & 8,61 \\
$5 \mathrm{cc}$ & $\mathrm{Ta}$ & $0,00004(9)$ & 0,44 \\
Detector- $\gamma$ & $\mathrm{Ta}$ & $0,00015(8)$ & 1,83 \\
Detector- $\gamma$ & $\mathrm{Te}$ & -- & -- \\
\hline
\end{tabular}

Observando a tabela 4.1 nota-se que os valores de $h$ ajustados para o alvo de Te com os detectores 8cc e 5cc não são compatíveis com zero e, portanto, foram usados para ajustar os espectros obtidos com alvo de Te e detector $8 c c$ e alvo de Te e detector 5cc. Para o ajuste dos outros espectros não foi incluída a função descrita pela equação 4.12.

As figuras a seguir são exemplos dos ajustes dos picos de raios-X $\mathrm{K}_{\alpha 2,1}$ para os detectores 5cc, 8cc e $\gamma$. 


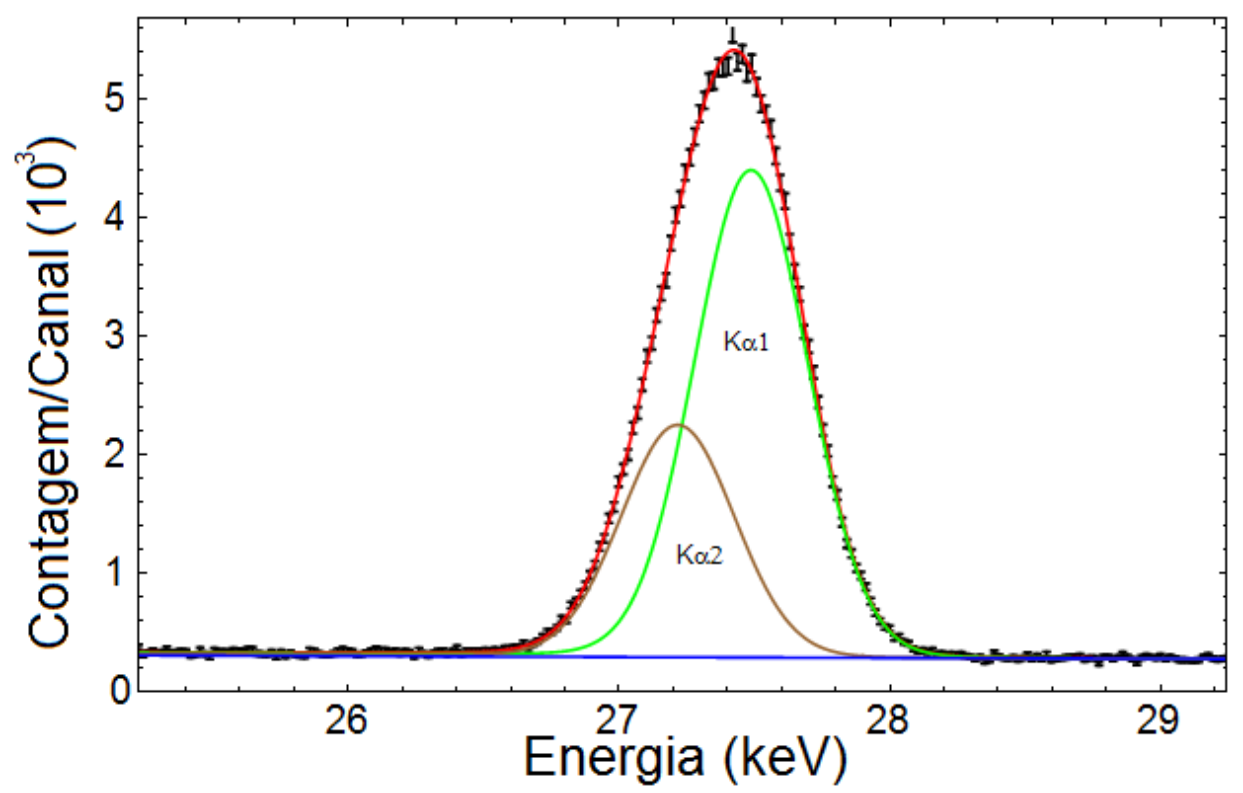

(a) Alvo de $\mathrm{Te} \mathrm{K}_{\alpha 2,1}$ a $E=85 \mathrm{keV}$.

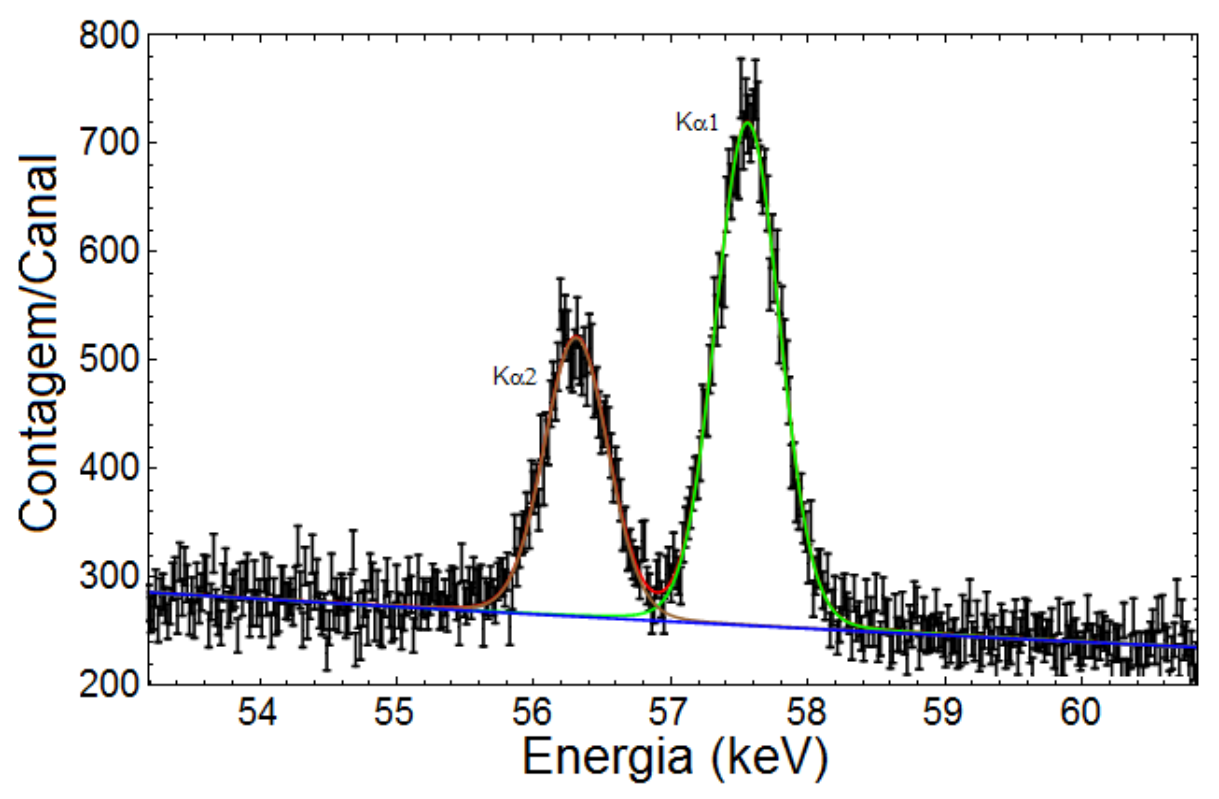

(b) Alvo de Ta $\mathrm{K} \alpha_{2,1}$ a $E=85 \mathrm{keV}$.

Figura 4.2: Exemplo de ajustes dos raios- $\mathrm{XK}_{\alpha}$ para o detector 5cc com feixe de energia $E=85 \mathrm{keV}$. Dispersão de energia de $\approx 18 \mathrm{eV}$ por canal. 
4 Modelagem para ajuste dos parâmetros dos picos de raios-X e $\gamma$ no

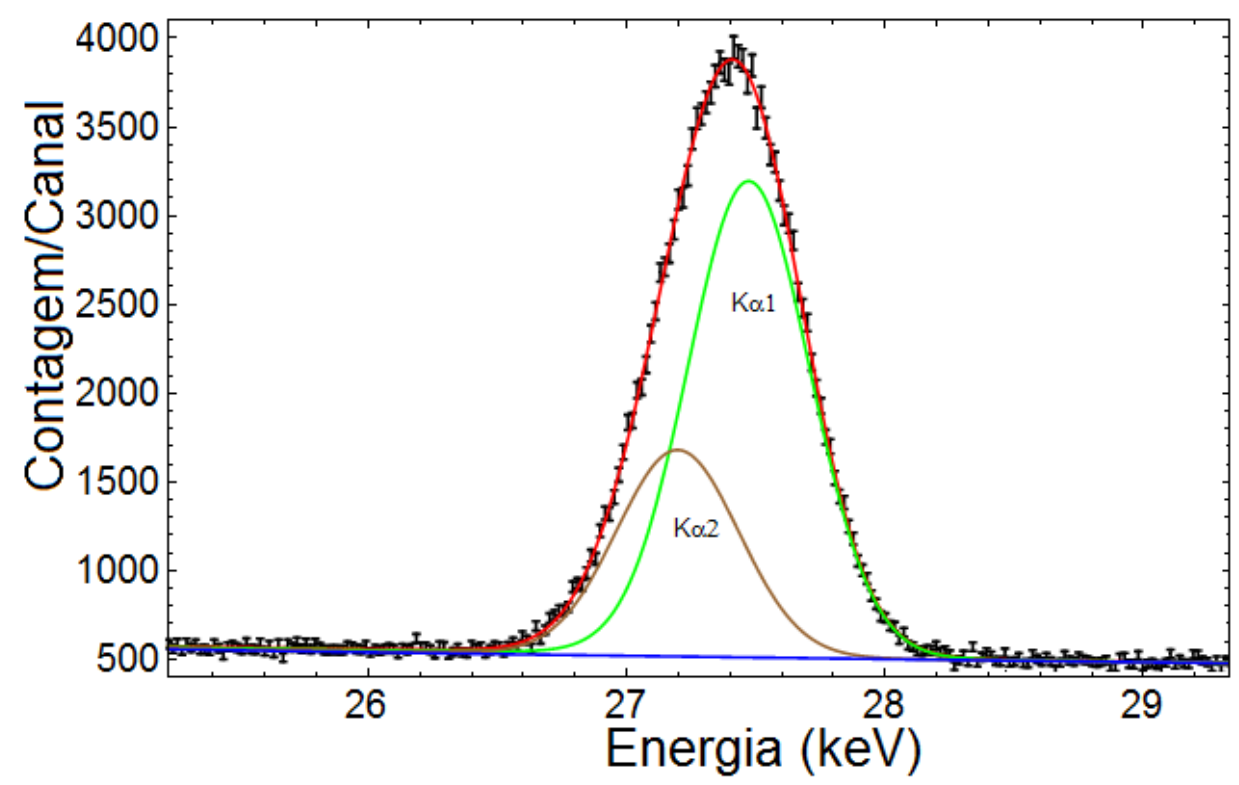

(a) Alvo de $\mathrm{Te} \mathrm{K}_{\alpha 2,1}$ a $E=95 \mathrm{keV}$.

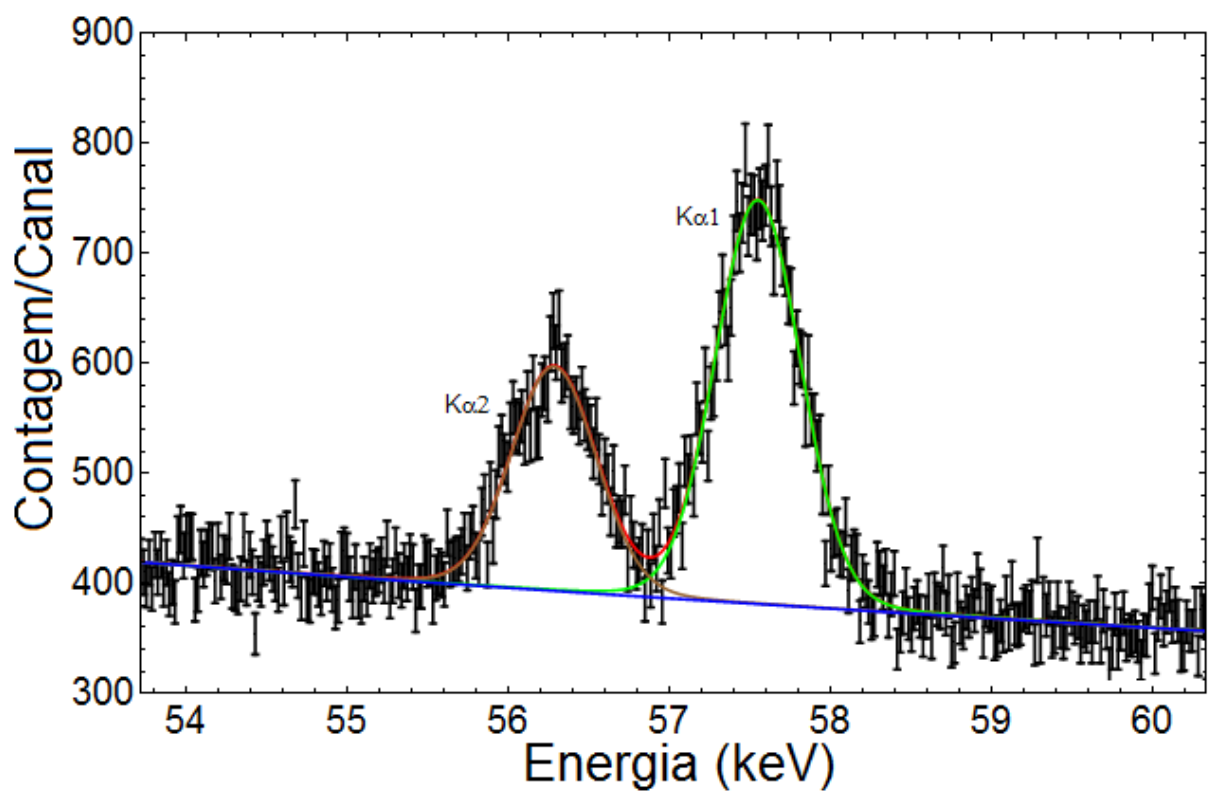

(b) Alvo de Ta $\mathrm{K} \alpha_{2,1}$ a $E=95 \mathrm{keV}$.

Figura 4.3: Exemplos de ajustes dos picos de raios-XK $\mathrm{XK}_{\alpha}$ para o detector $8 \mathrm{cc}$ com feixe de energia igual a $E=95 \mathrm{keV}$. Dispersão de energia de $\approx 18 \mathrm{eV}$ por canal. 


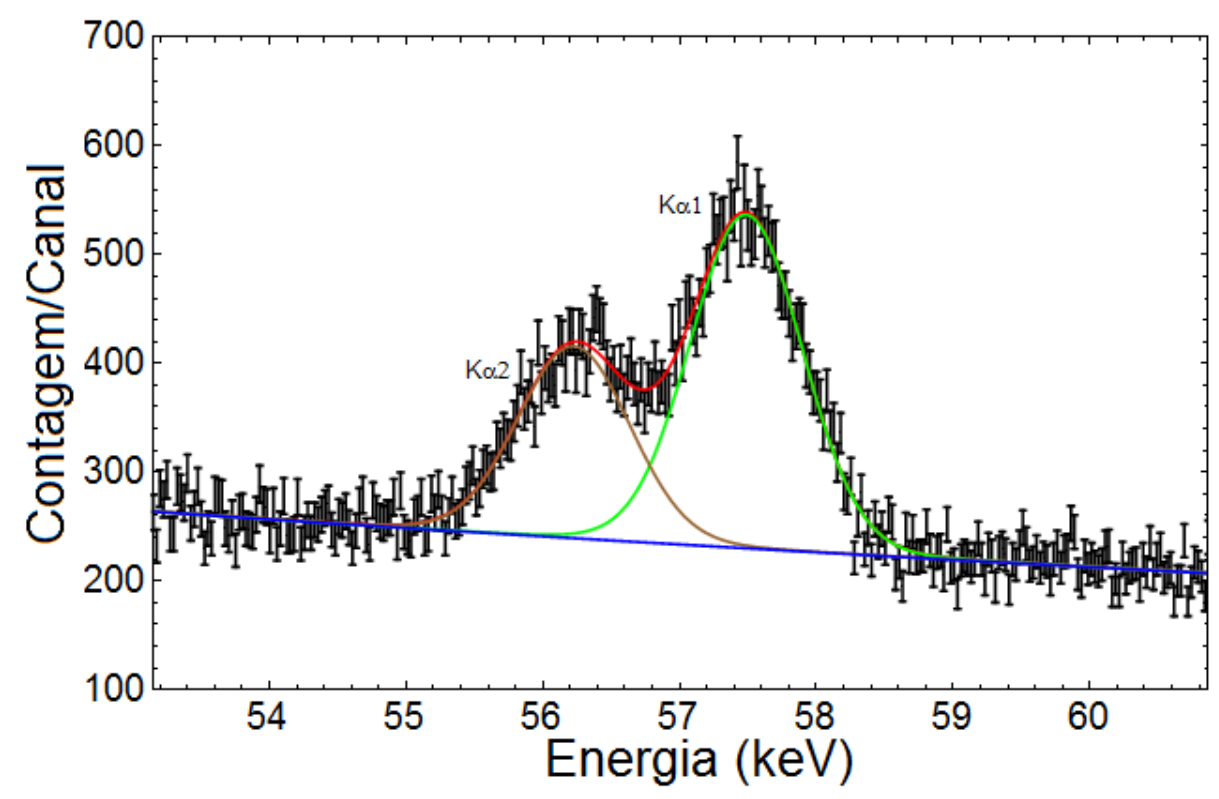

Figura 4.4: Exemplos de ajustes dos raios-XK $\mathrm{XK}_{\alpha}$ para o detector $\gamma$. Espectro obtido com o alvo de Ta $\mathrm{K} \alpha_{2,1}$ e $E=75 \mathrm{keV}$. Dispersão de energia de $\approx 25 \mathrm{eV}$ por canal.

\subsection{Método para obter a área dos picos de raios-X do Te para o detector $\gamma$}

Os dados obtidos com o alvo de Te e detector $\gamma$ foram ajustados de forma diferente dos demais, pois os picos $\mathrm{K} \alpha$ estavam muito próximos aos picos $\mathrm{K} \beta$, dificultando o ajuste dos parâmetros. Para esses espectros foram selecionados pontos à esquerda dos picos $\mathrm{K} \alpha$ e à direita dos picos $\mathrm{K} \beta$ e o contínuo abaixo dos picos foi ajustado conforme a equação 4.13. Para a determinação da área foi empregada a seguinte equação:

$$
A=N-\int_{x_{1}-0,5}^{x_{2}+0,5} B(x) \mathrm{d} x
$$

onde $A$ é a área do pico (usada para obter $n_{f}=A / t_{\text {vivo }}$ ) definida na seção 3.2 .2 e $N$ é a soma das contagens no intervalo de canais dado por $\left[x_{1}, x_{2}\right]$. 
4 Modelagem para ajuste dos parâmetros dos picos de raios-X e $\gamma$ no 42

espectro de energia

A integral apresentada na equação 4.16 é a contribuição do contínuo para o espectro. Para a determinação da incerteza foi adotada a expressão a seguir:

$$
\sigma_{\mathrm{A}}^{2}=\sigma_{N}^{2}+\vec{q}^{\mathrm{T}} V \vec{q}
$$

onde $q_{\mathrm{i}}=\int_{x_{1}-0,5}^{x_{2}+0,5} B_{\mathrm{i}}(x) \mathrm{d} x, V$ é a matriz de variância obtida do ajuste do contínuo, e $\sigma_{N}=\sqrt{N}$ é a incerteza estatística adotada para $N$, pois se trata de uma distribuição de Poisson.

Como já discutido, para determinar o contínuo foram adotados pontos à esquerda dos picos K $\alpha$ e à direita dos picos K $\beta$. Depois, através da equação 4.16 foi possível obter a área do pico $\mathrm{K} \beta$. A figura 4.5 mostra um exemplo do ajuste, onde são apresentados os picos $\mathrm{K} \alpha$ e $\mathrm{K} \beta$.

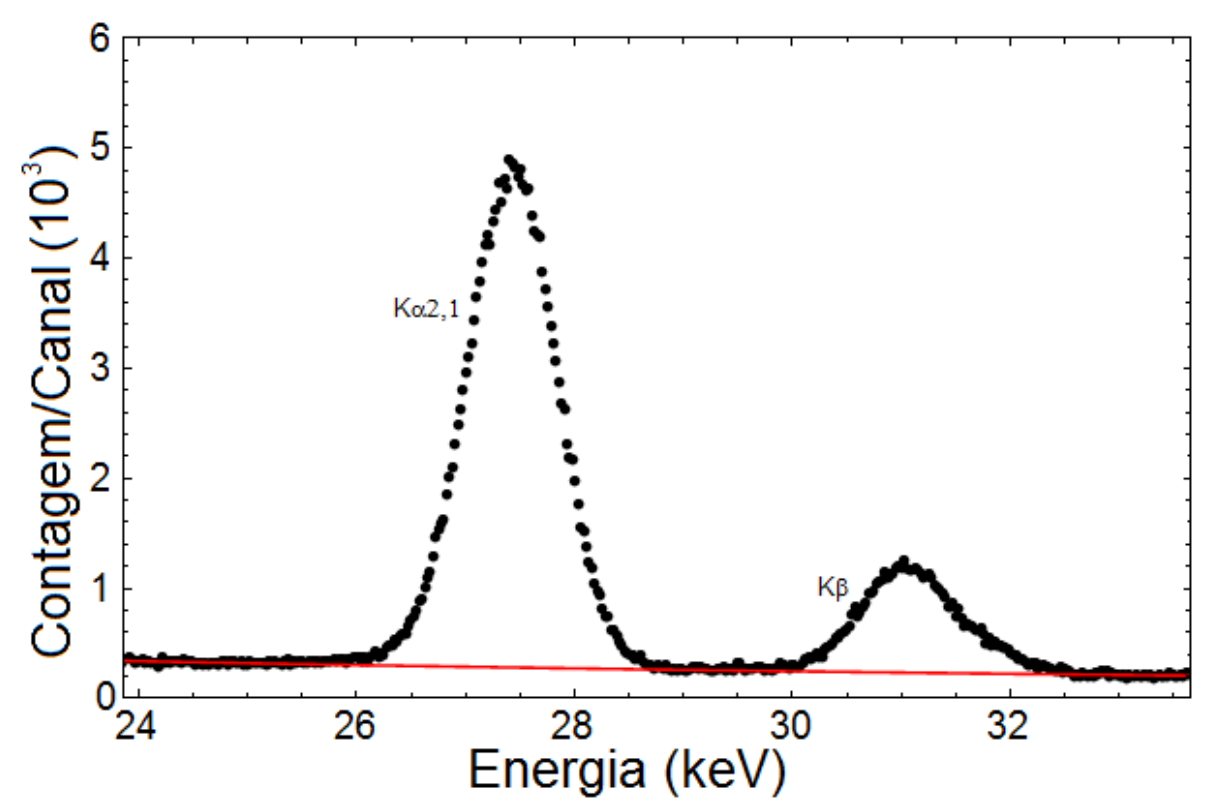

Figura 4.5: Exemplo de ajuste para o detector $\gamma$. Espectro obtido com alvo de Te e feixe com $E=75 \mathrm{keV}$. Dispersão de energia de $\approx 25 \mathrm{eV}$ por canal. 


\section{Calibração do sistema de medidas}

\subsection{Calibração de energia}

A calibração de energia foi feita com um polinômio de segundo grau:

$$
E=a_{0}+a_{1} C+a_{2} C^{2}
$$

onde o parâmetro $a_{0}$ está relacionado com a linha de base do amplificador, $a_{1}$ com o fator de amplificação e $a_{2}$ foi introduzido devido à não linearidade da eletrônica do sistema de aquisição.

O parâmetro $a_{1}$ da equação (5.1) é utilizado para converter a largura da função de Lorentz equação (4.8) dada em energia para canal. Essa largura é utilizada no ajuste dos picos de raios-X com a função descrita pela equação 4.14). Além disso, $a_{1}$ também foi usado para fixar a distância entre dois picos em canais, no caso de ajuste de multipletos. Como já mencionado na seção 3.1.3. para a calibração em energia utilizaram-se fontes radiativas de ${ }^{133} \mathrm{Ba},{ }^{152} \mathrm{Eu} \mathrm{e}{ }^{241} \mathrm{Am}$. Os canais que representam as posições dos picos foram obtidos através de ajustes nos picos utilizando a função apresentada na equação 4.7. As informações referentes às fontes radiativas foram obtidas da Ref. [27].

A incerteza obtida na calibração mostrou-se muito pequena (da ordem 
de dezenas de eV's), não sendo visível nos gráficos Energia versus Canal que, por esse motivo, foram omitidos deste trabalho. A tabela 5.1 apresenta os parâmetros ajustados. No caso do detector $\gamma$ o parâmetro parabólico foi compatível com zero, por esse motivo foi utilizado um ajuste linear.

Tabela 5.1: Parâmetros da calibração de energia ajustados.

\begin{tabular}{|llll|}
\hline Parâmetros & $5 \mathrm{cc}$ & $8 \mathrm{cc}$ & Detector $\gamma$ \\
\hline$a_{0}(\mathrm{keV})$ & $0.272(7)$ & $-0.024(9)$ & $0.15(2)$ \\
$a_{1}(\mathrm{keV} / \mathrm{Canal})$ & $0.0175613(3)$ & $0.017794(4)$ & $0.025142(2)$ \\
$a_{2}\left(\mathrm{keV} / \mathrm{Canal}^{2}\right)$ & $6 \times 10^{-10}(2)$ & $-0.15 \times 10^{-9}(4)$ & \\
\hline
\end{tabular}

\subsection{Calibração da largura dos picos}

A largura à meia altura (FWHM) possui a forma apresentada na equação $\gamma_{\mathrm{G}}=\sqrt{\eta+\delta E}$ (4.5). Devido ao fato dos picos de raios-X das fontes radiativas não serem representados por uma função Gaussiana é necessário utilizar os picos de raios- $\gamma$. Com os mesmos ajustes utilizados para a calibração em energia é possível obter a largura à meia altura dos picos e a partir desta informação, os parâmetros de forma $\eta$ e $\delta$ podem ser calibrados. Os gráficos das larguras à meia altura para os três detectores utilizados nesse trabalho podem ser vistos na figura 5.1 . 

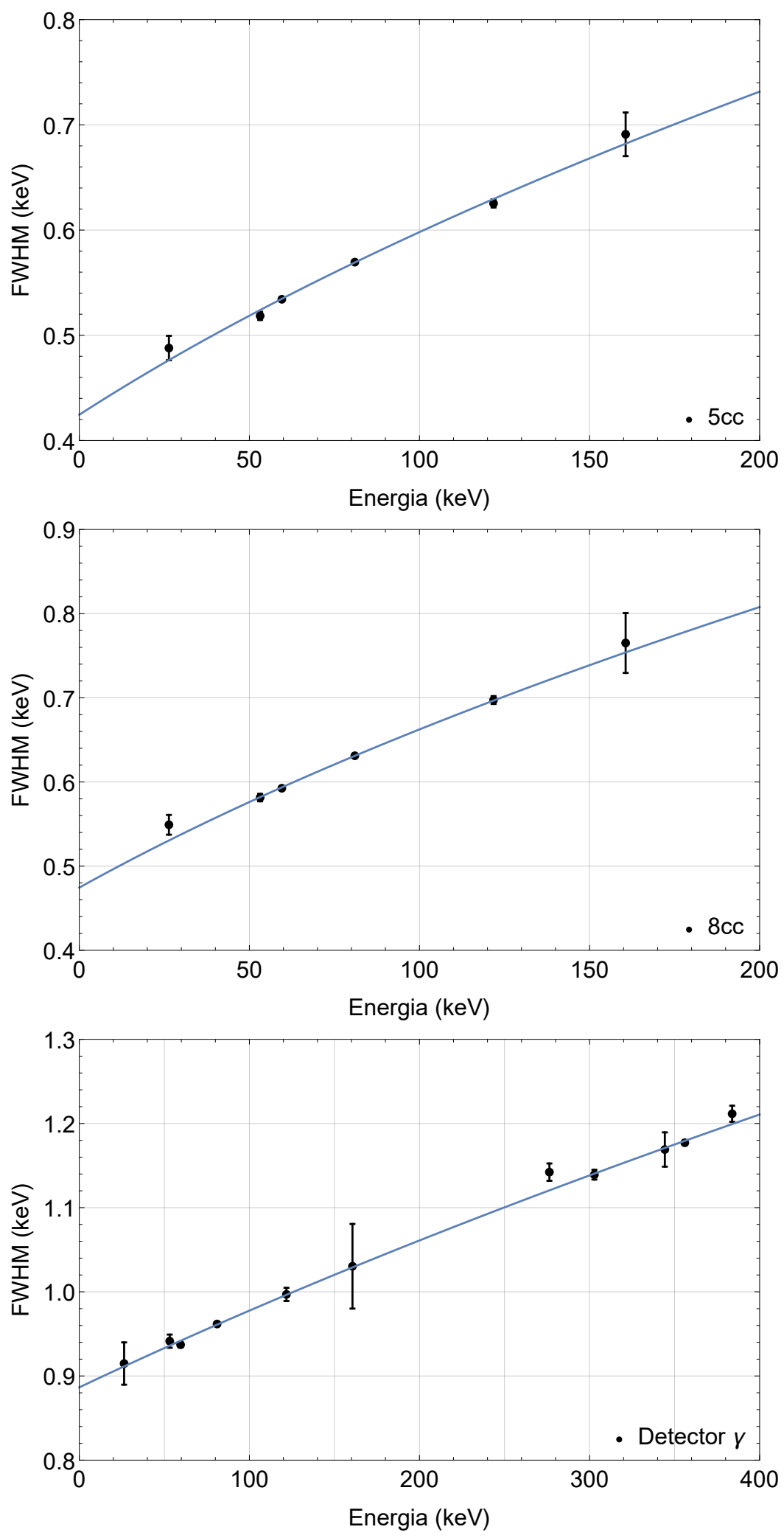

Figura 5.1: Ajuste da largura à meia altura. As barras de incerteza dos pontos experimentais correspondem a um desvio padrão. As linhas contínuas são dadas pela equação 4.5, com os parâmetros $\eta$ e $\delta$ ajustados. 


\subsection{Calibração de eficiência}

Neste trabalho a eficiência de absorção total de energia do fóton no detector será denominada somente de eficiência. A calibração baseia-se em um modelo de função resposta desenvolvido por Seltzer [5, 11], que supõe que os fótons incidam perpendicularmente ao centro da superfície frontal do detector. Essa aproximação é aceitável, visto que os fótons no arranjo experimental usado são colimados. No modelo de Seltzer a eficiência de detecção para um fóton de energia $E$ pode ser obtida isolando o termo $P_{\mathrm{f}}$ da equação 5.2 e o multiplicando pela função que descreve a atenuação nas janelas do detector equação (5.3):

$$
1-\mathrm{e}^{-\mu(E) l}=P_{\mathrm{f}}(E ; l, r)+P_{\mathrm{x} \alpha}(E ; l, r)+P_{\mathrm{x} \beta}(E ; l, r)+\int_{0}^{E} C(\epsilon, E ; l, r) \mathrm{d} \epsilon
$$

onde $\mu$ é o coeficiente de atenuação do Ge, $P_{\mathrm{f}}$ é a probabilidade de absorção total, $P_{\mathrm{x} \alpha}$ é a probabilidade de escape de um raio-X K $\alpha, P_{\mathrm{x} \beta}$ é a probabilidade de escape de um raio-X K $\beta$ e $C$ é o contínuo Compton.

$$
T(E ; \overrightarrow{d l})=\mathrm{e}^{-\vec{\mu}(E) \cdot \vec{d}}
$$

onde $\vec{\mu}=\left(\mu_{1}, \mu_{2},(\ldots), \mu_{\mathrm{i}},(\ldots)\right)$ e $\vec{d}=\left(d_{1}, d_{2},(\ldots), d_{\mathrm{i}},(\ldots)\right)$. A atenuação na camada morta do detector está sendo levada em consideração na equação 5.3. Portanto, para obter a eficiência é necessário levar em conta a fração de ângulo sólido subtendido pelo detector, como mostra a equação a seguir:

$$
\varepsilon(E ; l, r, \Omega, \vec{d})=\frac{\Omega}{4 \pi} T(E ; \vec{d}) P_{\mathrm{f}}(E ; l, r)
$$

O conhecimento de alguns parâmetros facilita o ajuste da eficiência. Para os detectores utilizados nesse trabalho, a eficiência é dada por $\varepsilon\left(E ; l, r, \Omega, d_{\mathrm{ar}}\right.$, $\left.d_{\mathrm{l}}, d_{\mathrm{Al}}, d_{\mathrm{j}}, d_{\mathrm{K}}\right)$, onde $d_{\mathrm{ar}}$ é a espessura da camada de ar, $d_{\mathrm{l}}$ é a espessura da 
camada morta do cristal, $d_{\mathrm{Al}}$ é a espessura da janela de Alumínio da câmara, $d_{\mathrm{j}}$ é a espessura da janela do detector, que pode ser de fibra de Carbono ou Berílio, e $d_{\mathrm{K}}$ é a espessura da película de Kapton que cobre a fonte radiativa.

A calibração de eficiência foi realizada utilizando fontes radiativas cobertas por Kapton e, por esse motivo, não foi feito vácuo na câmara de espalhamento, pois poderia danificar a fonte. Desta forma, a camada de ar (distância fonte-detector) durante a calibração de eficiência foi maior do que a camada de ar utilizada nas medidas experimentais (distância janela da câmara-detector), já que durante o experimento a câmara de espalhamento permaneceu em vácuo. Assim, depois de ajustar os parâmetros não conhecidos da eficiência foi necessário remover o atenuador $d_{\mathrm{k}}$, além de diminuir o valor de $d_{\mathrm{ar}}$, para obter a eficiência correta dos detectores quando utilizados no experimento.

O ajuste vermelho se refere a eficiência com a fonte radiativa e o verde tracejado que se refere a eficiência utilizada no experimento, onde a câmara se encontra em vácuo e o atenuador de Kapton não existe. Nas subseções a seguir serão discutidos os procedimentos adotados para a obtenção das eficiências dos três detectores.

\subsubsection{Eficiência para o detector 5cc}

Para ajustar a função que descreve a eficiência do detector (5cc), os parâmetros $l, r, d_{\mathrm{ar}}, d_{\mathrm{Al}}, d_{\mathrm{j}}$ e $d_{\mathrm{K}}$ foram mantidos fixos nos valores fornecidos pelo fabricante ou medidos no arranjo experimental. Desta forma, os parâmetros de ajuste, pelo MMQ, são: a camada morta do Ge, $d_{1}$, e a fração de ângulo sólido, $\Omega / 4 \pi$. Como a camada morta é um parâmetro não linear, optamos por ajustar $\Omega / 4 \pi$, fixando um valor de $d_{1}$ e, em seguida, variou-se $d_{1}$ até encontrar um mínimo global que representasse o valor verdadeiro de $d_{l}$.

A figura 5.2 mostra a curva de qui-quadrado $\left(\chi^{2}\right)$ em função de $d_{1}$ obtida 
para o ajuste do detector 5cc. O mínimo da curva fornece o valor de $d_{1}$ que melhor representa os dados experimentais e consequentemente $\Omega$. Para determinar a incerteza de $d_{1}$ foi variado o valor de $\chi^{2}$ em uma unidade. Esse procedimento fornece dois pontos na curva (ver figura 5.2) e a diferença entre esses pontos dividido por duas unidades fornece a incerteza procurada.

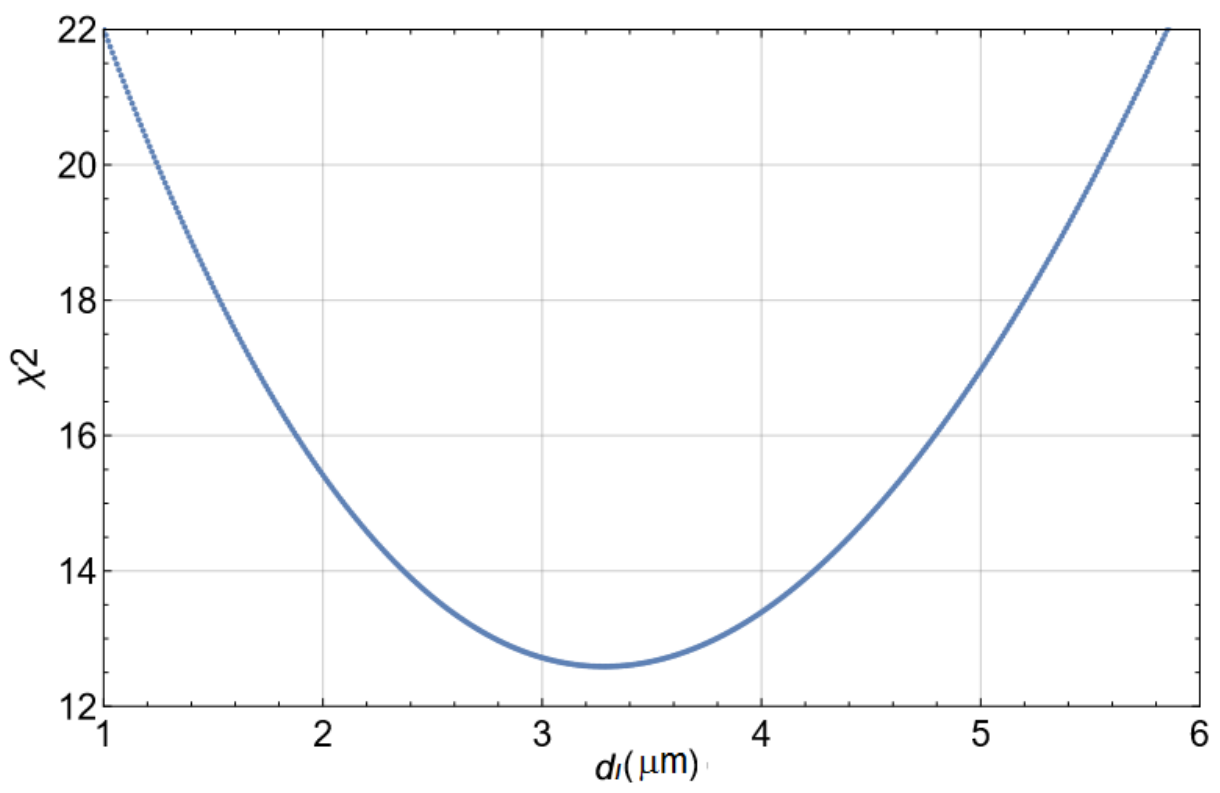

Figura 5.2: Curva de $\chi^{2}$ para determinação da camada morta do detector 5cc.

A tabela 5.2 e a figura 5.3 apresentam, respectivamente, os parâmetros adotados na obtenção da eficiência do detector 5cc e os gráficos de eficiência em função da energia do fóton. 
Tabela 5.2: Parâmetros necessários na obtenção da eficiência do detector 5cc.

\begin{tabular}{ll}
\hline Parâmetros & Valores \\
\hline$l(\mathrm{~mm})$ & 10 \\
$r(\mathrm{~mm})$ & 8 \\
$\Omega(\mathrm{sr})$ & $3,91(4) \times 10^{-5}$ \\
$d_{\mathrm{ar}}(\mathrm{mm})$ & $407,5(12)$ \\
$d_{\mathrm{l}}(\mu \mathrm{m})$ & $3,3(8)$ \\
$d_{\mathrm{Al}}(\mathrm{mm})$ & 0,05 \\
$d_{\mathrm{j}}(\mathrm{mm})$ & 0,25 \\
$d_{\mathrm{K}}(\mathrm{mm})$ & 0,025 \\
\hline
\end{tabular}

${ }^{a}$ A camada de ar no experimento foi de 157,2(12) $\mathrm{mm}$.

${ }^{b} \mathrm{O}$ atenuador Kapton não existe no experimento.

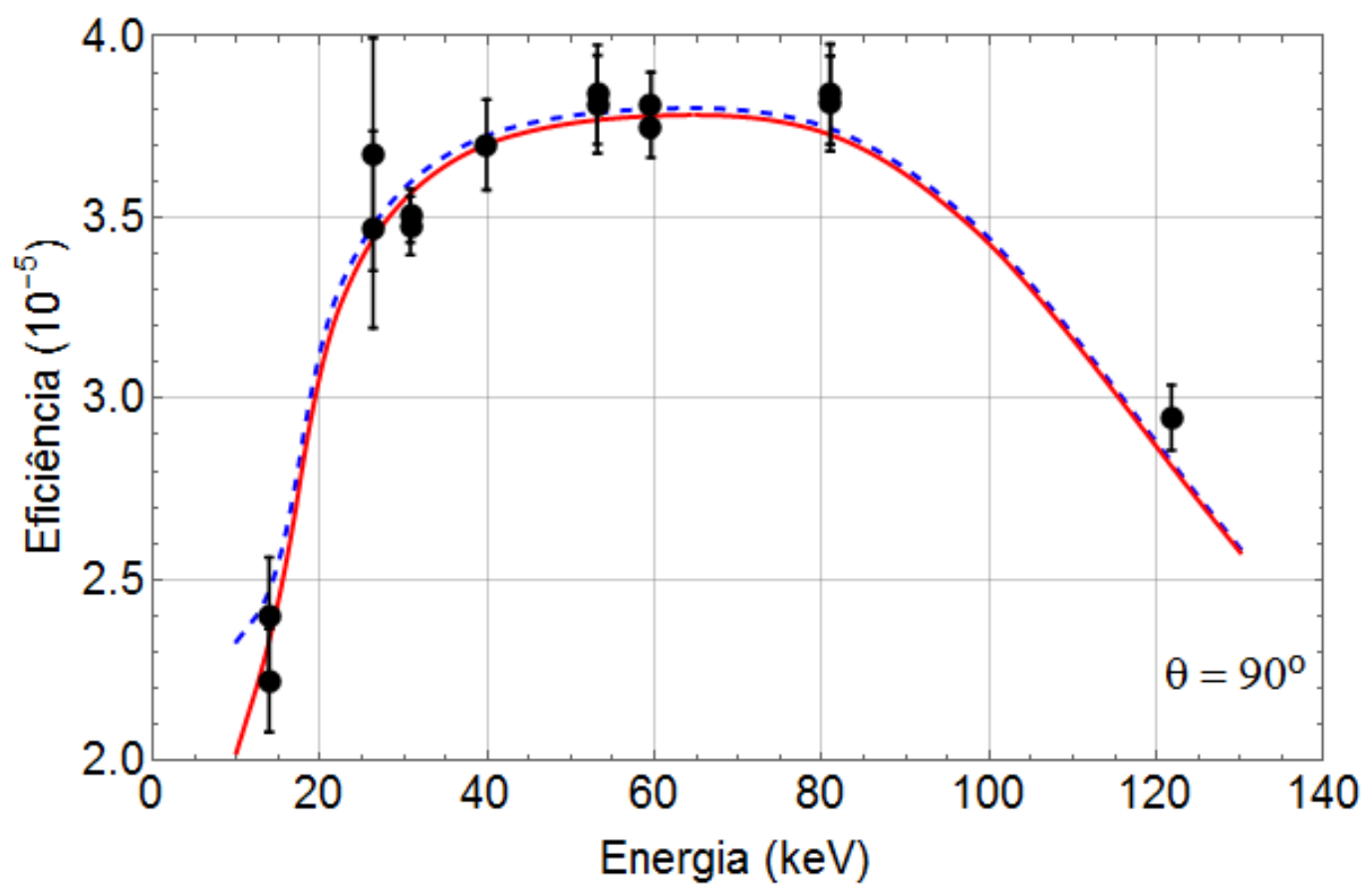

Figura 5.3: Eficiência do detector 5cc. A curva azul tracejada representa a eficiência utilizada na medição dos alvos durante a irradiação e a vermelha, a eficiência obtida com as fontes de calibração. Os pontos com barras de incerteza representam os dados experimentais. 


\subsubsection{Eficiência para o detector $8 \mathrm{cc}$}

Para o detector (8cc) foi realizado um ajuste da camada morta $d_{1}$, da espessura $l$ e do ângulo sólido $\Omega$. Como existem dois parâmetros não lineares $l$ e $d_{1}$, foi realizado o mesmo procedimento adotado no detector $5 \mathrm{cc}$, ou seja, fixou-se estes parâmetros e ajustou-se a fração de ângulo sólido $\Omega$ utilizando o MMQ.

Foi realizado um estudo variando o valor de $l$ e $d_{\mathrm{l}}$ com a finalidade de encontrar curvas de nível de $\chi^{2}$, determinando assim o valor mais provável de $l, d_{1}$, e, consequentemente de $\Omega$. A tabela 5.3 e as figuras 5.4 e 5.5 apresentam, respectivamente, os parâmetros adotados para obter a eficiência, as curvas de nível e de eficiência para o detector 8cc.

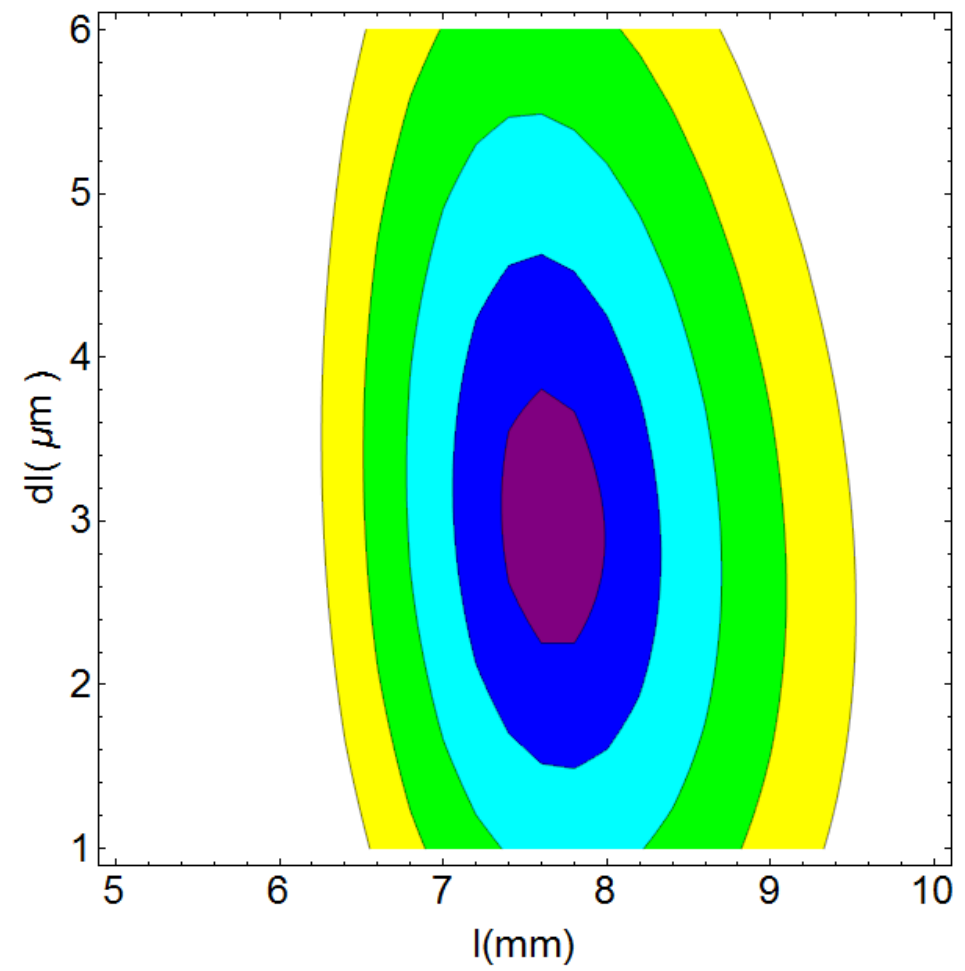

Figura 5.4: Curvas de nível para o detector 8cc definidas com $\chi^{2}+i^{2}$ onde $i=$ $1,2, \ldots, n$. 
Tabela 5.3: Parâmetros para obter a eficiência do detector 8cc.

\begin{tabular}{ll}
\hline Parâmetros & Valores \\
\hline$l(\mathrm{~mm})$ & $7,6(1)$ \\
$r(\mathrm{~mm})$ & 16 \\
$\Omega(\mathrm{sr})$ & $3,76(4) \times 10^{-5}$ \\
$\left.d_{\mathrm{ar}}(\mathrm{mm})\right)^{a}$ & $409,1(7)$ \\
$d_{\mathrm{l}}(\mu \mathrm{m})$ & $3,0(8)$ \\
$d_{\mathrm{Al}}(\mathrm{mm})$ & 0,05 \\
$d_{\mathrm{j}}(\mathrm{mm})$ & 0,25 \\
$\left.d_{\mathrm{K}}(\mathrm{mm})\right)^{b}$ & 0,025 \\
\hline
\end{tabular}

${ }^{a} \mathrm{~A}$ camada de ar no experimento foi de 159,1(7) $\mathrm{mm}$.

${ }^{b} \mathrm{O}$ atenuador Kapton não existe no experimento.

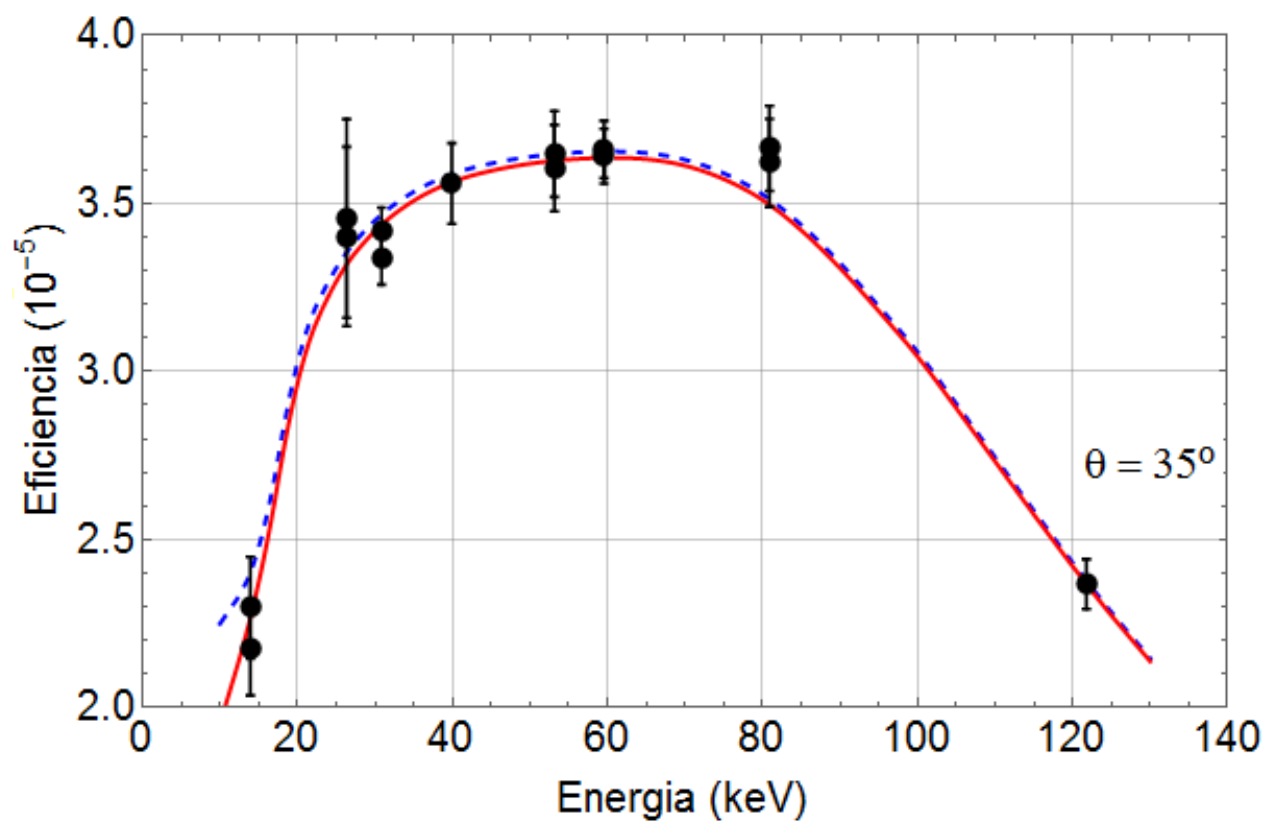

Figura 5.5: Mesmo que na figura 5.3, porém para o detector 8cc. 


\subsubsection{Eficiência para o detector de raios- $\gamma$}

Para o detector de raios $\gamma$, os parâmetros utilizados para o ajuste são: a camada morta $d_{1}$, a espessura $l$ e o ângulo sólido $\Omega$. O método usado neste ajuste foi o mesmo usado no detector 8cc, pois foi necessário determinar uma espessura efetiva devido ao buraco no centro do cristal do detector $\gamma$, que era um detector coaxial. A seguir são apresentados o gráfico das curvas de nível (ver figura 5.6), os parâmetros utilizados para obter a curva de eficiência (ver tabela 5.4 e a curva de eficiência (ver figura 5.7).

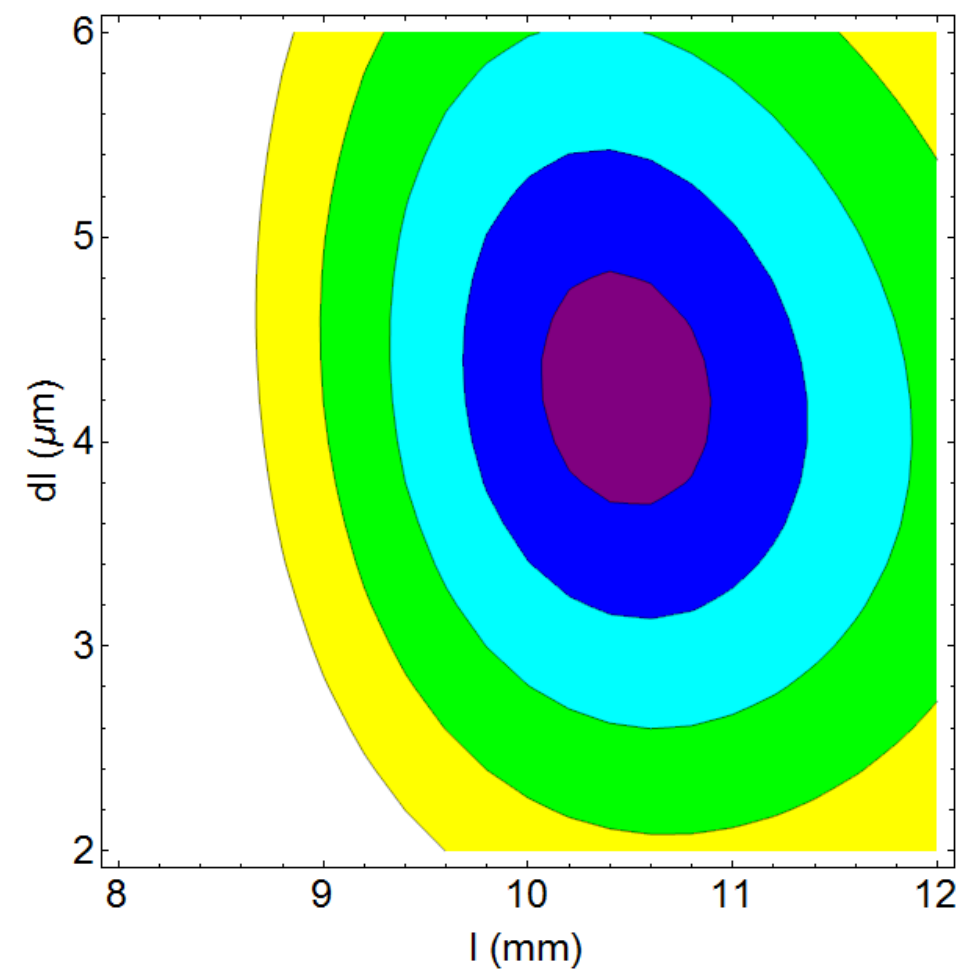

Figura 5.6: Curvas de nível para o detector de raios- $\gamma$ definidas com $\chi^{2}+i^{2}$ onde $i=1,2, \ldots, n$. 
Tabela 5.4: Parâmetros necessários na obtenção da eficiência do detector de raios- $\gamma$.

\begin{tabular}{ll}
\hline Parâmetros & Valores \\
\hline$l(\mathrm{~mm})$ & $10,48(17)$ \\
$r(\mathrm{~mm})$ & 29 \\
$\Omega(\mathrm{sr})$ & $3,91(3) \times 10^{-5}$ \\
$d_{\mathrm{ar}}(\mathrm{mm})$ & $410,5(7)$ \\
$d_{\mathrm{l}}(\mu \mathrm{m})$ & $4,25(3)$ \\
$d_{\mathrm{Al}}(\mathrm{mm})$ & 0,9 \\
$d_{\mathrm{j}}(\mathrm{mm})$ & 0,25 \\
$d_{\mathrm{K}}(\mathrm{mm})$ & 0,025 \\
\hline
\end{tabular}

${ }^{a}$ A camada de ar no experimento foi de 160,5(7) mm.

${ }^{b} \mathrm{O}$ atenuador Kapton não existe no experimento.

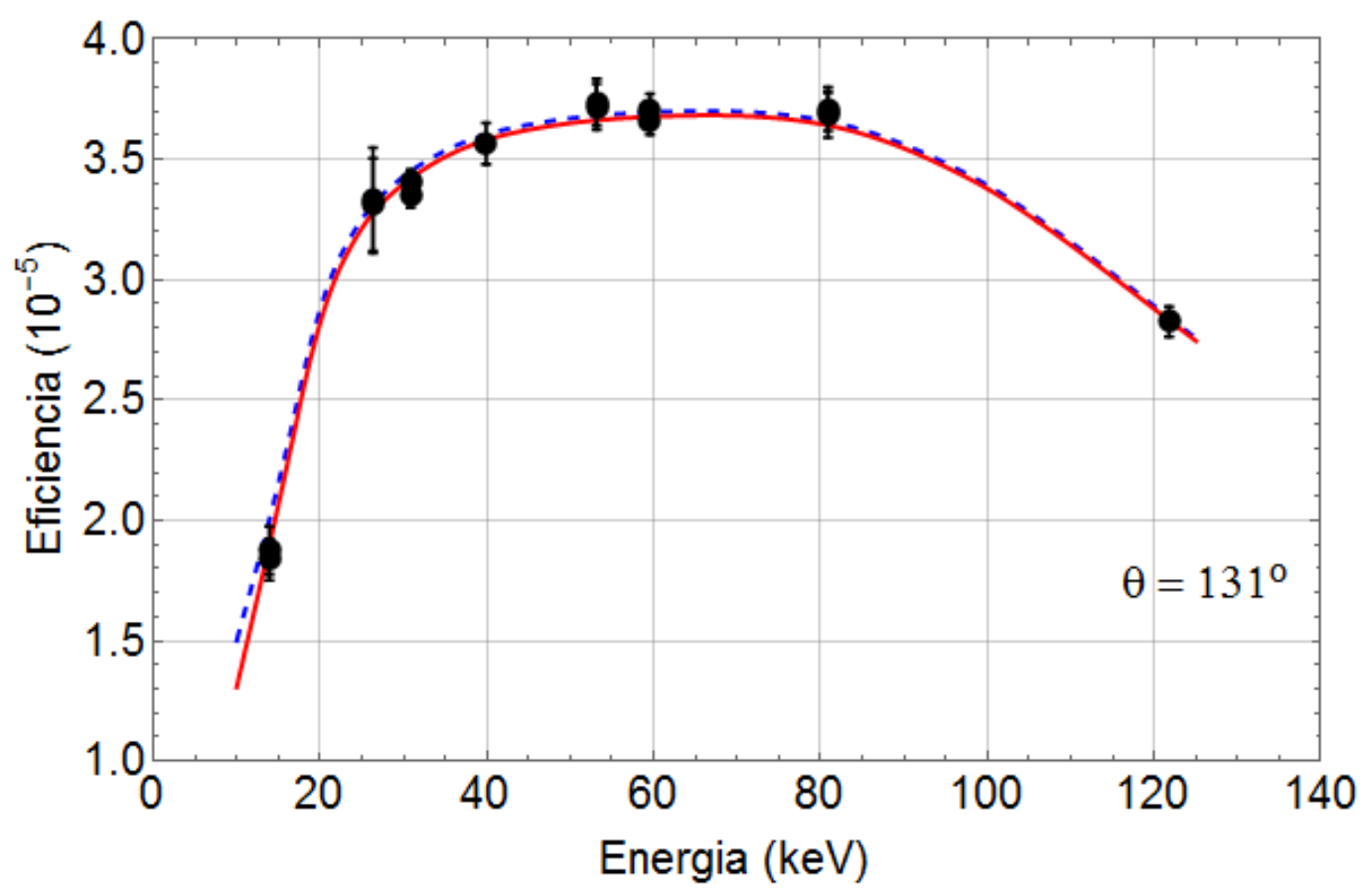

Figura 5.7: Mesmo que na figura 5.3 porém para o detector de raios- $\gamma$. 



\section{Resultados}

Neste capítulo serão apresentados os valores obtidos para os parâmetros utilizados na determinação da seção de choque de ionização por impacto de elétrons. Por último serão apresentadas as seções de choque experimentais.

\section{Densidade atômica superficial dos alvos}

Os ajustes de espectros RBS realizados para determinar as densidades superficiais dos alvos de Te e Ta são apresentados nas figuras 6.1 e 6.2. Além dos picos de Te e Ta, existem outros picos com origem no backing de Carbono e no contaminante Oxigênio.

Os valores obtidos para a densidade superficial dos alvos (espessuras) estão apresentados na tabela 6.1 .

Tabela 6.1: Valores de densidade superficial obtidos pelo método RBS.

\begin{tabular}{ll}
\hline Alvo & Espessura $\left(10^{15}\right.$ atomos $\left./ \mathrm{cm}^{2}\right)$ \\
\hline $\mathrm{Te}$ & $110(3)$ \\
$\mathrm{Ta}$ & $60.6(24)$ \\
\hline
\end{tabular}




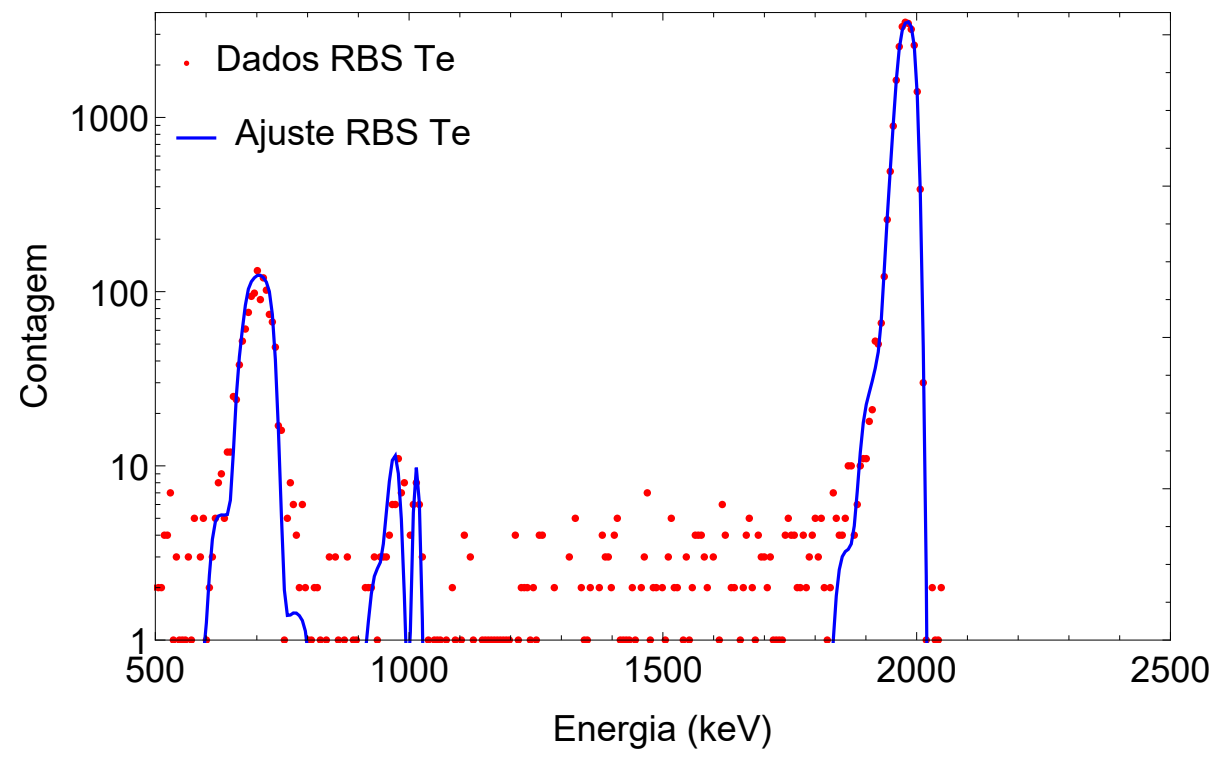

(a) Espectro de RBS para o alvo de Te. Pode-se observar da esquerda para direita os picos de $\mathrm{C}, \mathrm{O}$ e Te.

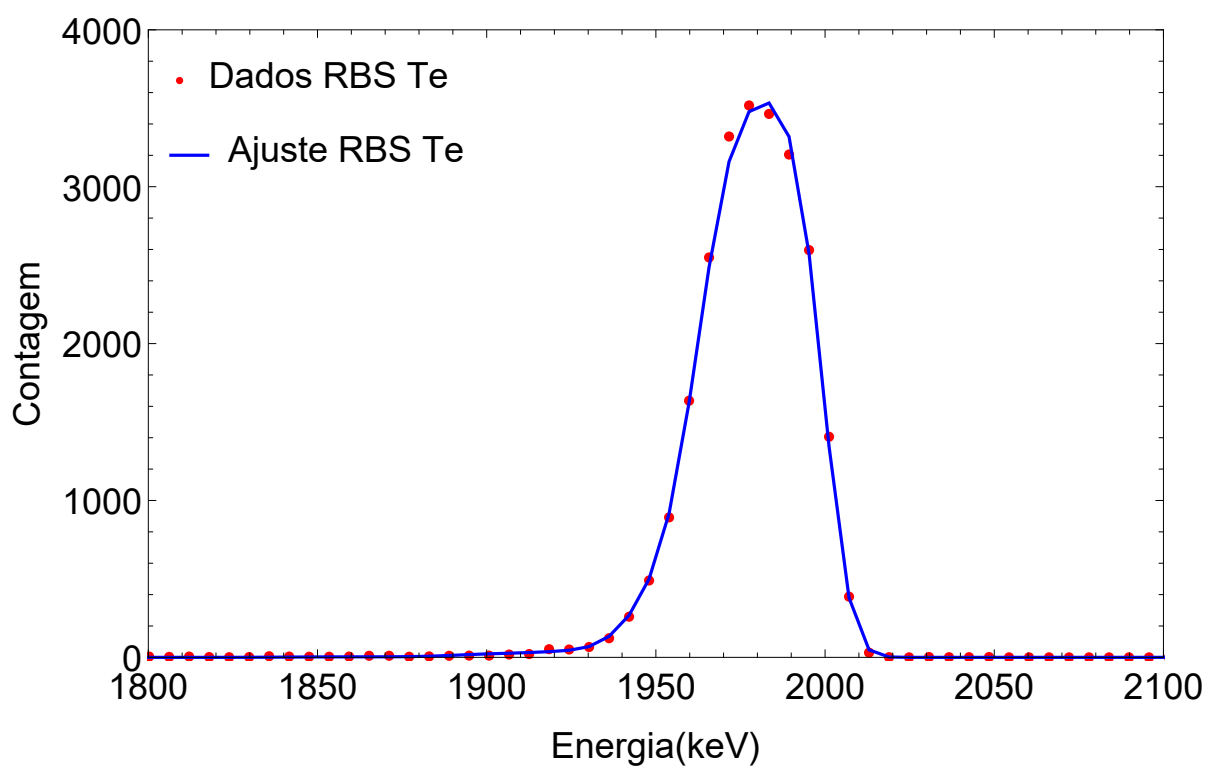

(b) Pico de Te.

Figura 6.1: Espectros obtido com a técnica RBS para o alvo de Te. Os pontos são os dados experimentais e a função obtida por simulação pelo programa SIMNRA e Mult-SIMNRA com os parâmetros ajustados. 


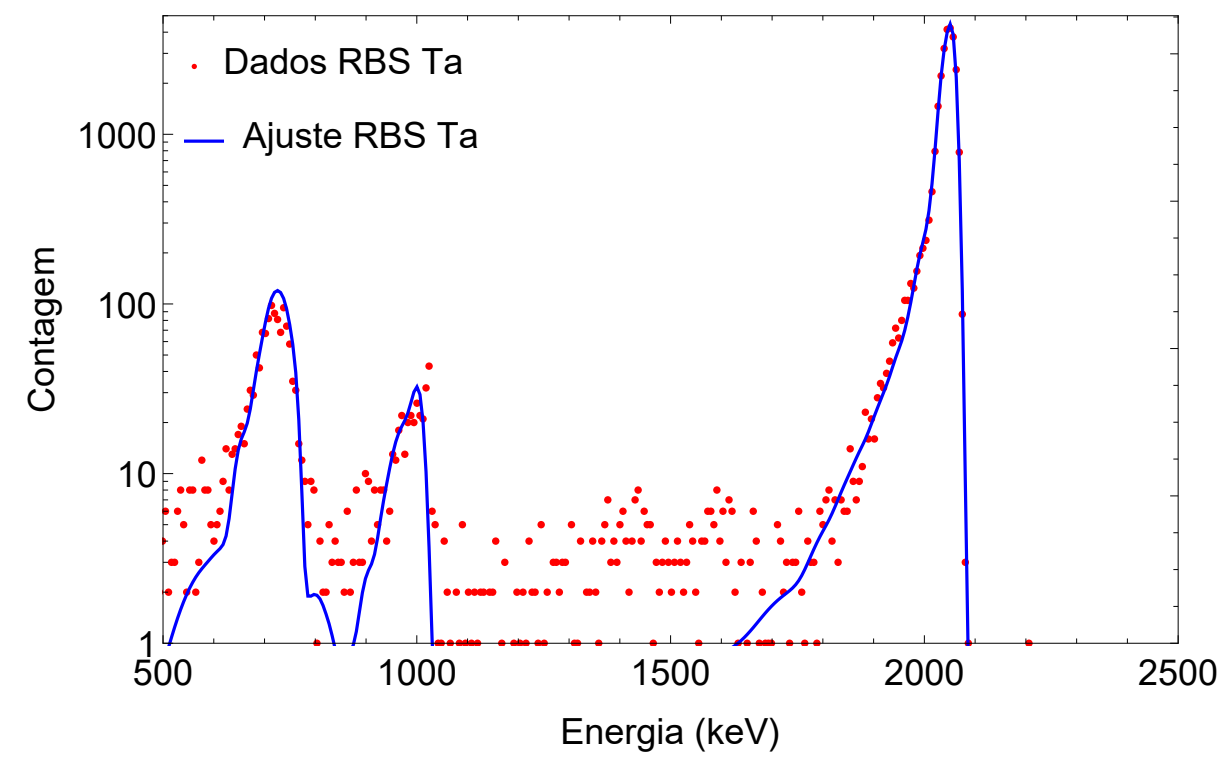

(a) Espectro de RBS para o alvo de Ta. Pode-se observar da esquerda para direita os picos de $\mathrm{C}, \mathrm{O}$ e Ta

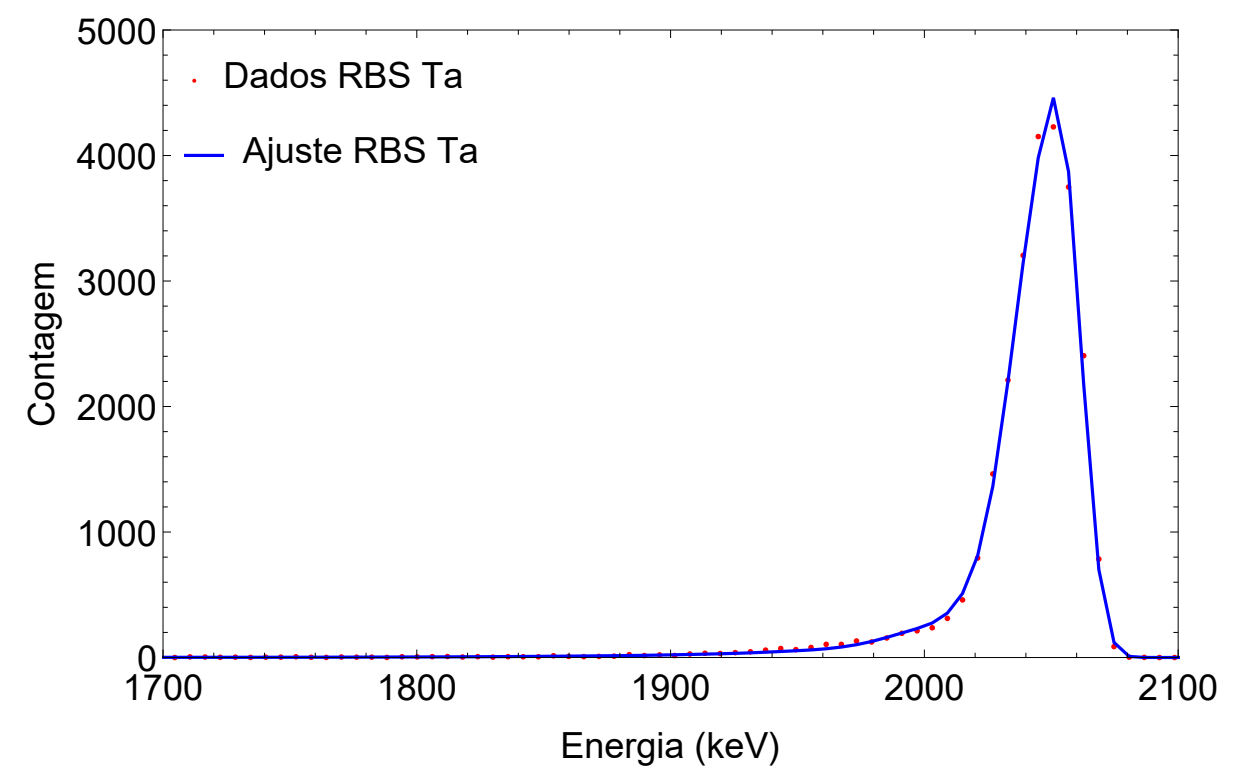

(b) Pico de Ta.

Figura 6.2: Mesmo que na figura 6.1. mas para o Ta. 


\section{Eficiência}

Na seção 5.3 foi discutido o método utilizado para determinar a curva de eficiência dos detectores $5 \mathrm{cc}, 8 \mathrm{cc}$ e $\gamma$. A partir da curva ajustada foi possível obter a eficiência na energia média dos picos de raios-X $\mathrm{K} \alpha_{2,1}$. A incerteza da eficiência foi obtida por propagação das incertezas dos parâmetros na curva ajustada. Os valores obtidos para a eficiência, utilizando a energia obtida da equação (3.3), são apresentados na tabela abaixo para cada detector e alvo.

Tabela 6.2: Valores de eficiência obtidos para os alvos de Te e Ta nos detectores $5 \mathrm{cc}, 8 \mathrm{cc}$ e $\gamma$ e energia média dos fótons $E_{K \alpha_{2,1}}$.

\begin{tabular}{llll}
\hline Alvo & Detector & $\varepsilon / \times 10^{-5}$ & $E_{\mathrm{K}_{2,1}}$ \\
\hline \multirow{3}{*}{$\mathrm{Te}$} & $5 \mathrm{cc}$ & $3,50(4)$ & \\
& $8 \mathrm{cc}$ & $3,38(4)$ & 27,3772 \\
& $\gamma$ & $3,33(2)$ & \\
\hline \multirow{3}{*}{$\mathrm{Ta}$} & $5 \mathrm{cc}$ & $3,79(4)$ & \\
& $8 \mathrm{cc}$ & $3,64(3)$ & 57,0564 \\
& $\gamma$ & $3,68(2)$ & \\
\hline
\end{tabular}




\section{Seção de choque}

Os valores das seções de choque de ionização da camada $\mathrm{K}$ de Te e Ta por impacto de elétrons obtidos com o método absoluto, para energias desde o limiar de ionização até $100 \mathrm{keV}$ são apresentadas nas tabelas 6.3 e 6.4 .

Tabela 6.3: Valores das seções de choque de ionização da camada K do Te por impacto de elétrons obtidas pelo método absoluto usando os detectores $5 \mathrm{cc}, 8 \mathrm{cc}$ e $\gamma$, com o respectivo valor médio.

\begin{tabular}{lllll}
\hline \multicolumn{5}{c}{$\sigma_{\mathrm{K}}(\mathrm{b})$} \\
\hline$E(\mathrm{keV})$ & $5 \mathrm{cc}$ & $8 \mathrm{cc}$ & $\gamma$ & Média \\
\hline $35,93(3)$ & $9,8(3)$ & $9,9(3)$ & $9,6(3)$ & $9,7(3)$ \\
$38,83(3)$ & $14,6(5)$ & $14,8(5)$ & $14,7(5)$ & $14,7(4)$ \\
$41,53(3)$ & $18,1(6)$ & $18,3(6)$ & $18,6(6)$ & $18,4(6)$ \\
$46,47(3)$ & $23,5(7)$ & $23,9(8)$ & $24,0(7)$ & $23,8(7)$ \\
$51,17(3)$ & $27,6(9)$ & $27,8(9)$ & $27,7(8)$ & $27,7(8)$ \\
$56,14(3)$ & $30,5(10)$ & $30,9(10)$ & $30,8(10)$ & $30,7(9)$ \\
$61,07(3)$ & $32,5(10)$ & $32,7(11)$ & $32,6(10)$ & $32,6(10)$ \\
$65,96(3)$ & $34,4(11)$ & $34,56(11)$ & $34,3(11)$ & $34,4(10)$ \\
$70,71(3)$ & $35,4(11)$ & $35,72(11)$ & $35,4(11)$ & $35,5(11)$ \\
$75,68(3)$ & $36,5(12)$ & $37,06(12)$ & $36,6(11)$ & $36,7(11)$ \\
$80,60(3)$ & $37,3(13)$ & $37,53(12)$ & $37,7(11)$ & $37,4(11)$ \\
$85,55(3)$ & $38,0(12)$ & $38,22(13)$ & $38,0(12)$ & $38,1(11)$ \\
$90,71(3)$ & $39,0(13)$ & $39,23(13)$ & $38,9(12)$ & $39,0(12)$ \\
$95,36(3)$ & $39,1(13)$ & $39,32(13)$ & $39,2(12)$ & $39,2(12)$ \\
$100,74(3)$ & $39,1(12)$ & $39,4(13)$ & $39,3(12)$ & $39,3(12)$ \\
\hline
\end{tabular}


Tabela 6.4: Mesmo que na tabela 6.3, mas para o Ta.

\begin{tabular}{lllll}
\hline \multicolumn{5}{l}{$\sigma_{\mathrm{K}}(\mathrm{b})$} \\
\hline$E(\mathrm{keV})$ & $5 \mathrm{cc}$ & $8 \mathrm{cc}$ & $\gamma$ & Média \\
\hline $70,63(3)$ & $1,06(5)$ & $1,01(6)$ & $1,03(5)$ & $1,04(5)$ \\
$72,58(3)$ & $1,58(7)$ & $1,54(8)$ & $1,59(7)$ & $1,58(7)$ \\
$75,66(3)$ & $2,36(11)$ & $2,35(12)$ & $2,37(10)$ & $2,36(10)$ \\
$80,61(3)$ & $3,38(15)$ & $3,34(16)$ & $3,37(15)$ & $3,37(14)$ \\
$85,51(3)$ & $4,14(18)$ & $4,15(19)$ & $4,21(18)$ & $4,18(18)$ \\
$90,73(3)$ & $5,09(23)$ & $5,09(23)$ & $5,11(22)$ & $5,10(22)$ \\
$95,41(3)$ & $5,7(3)$ & $5,8(3)$ & $5,78(25)$ & $5,77(24)$ \\
$100,76(3)$ & $6,2(3)$ & $6,2(3)$ & $6,2(3)$ & $6,2(3)$ \\
\hline
\end{tabular}

As figuras a seguir apresentam os gráficos correspondentes às seções de choque das tabelas 6.3 e 6.4. É importante mencionar que as barras de incertezas apresentadas representam apenas os valores médios e os pontos experimentais dos três detectores estão sem barra de incerteza. Não apresentar as barras de incertezas foi uma opção para deixar a leitura dos gráficos mais agradável. 


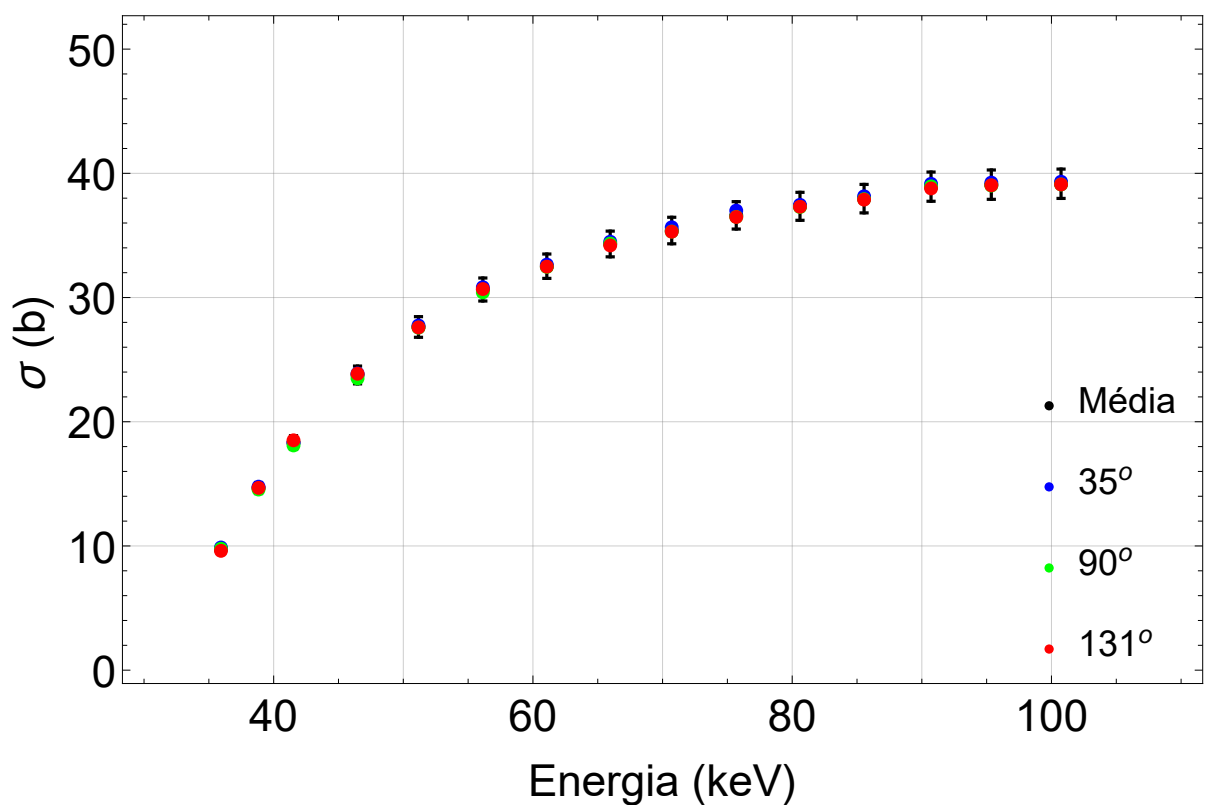

Figura 6.3: Seção de choque de ionização por impacto de elétrons obtida pelo método absoluto para o alvo de Te.

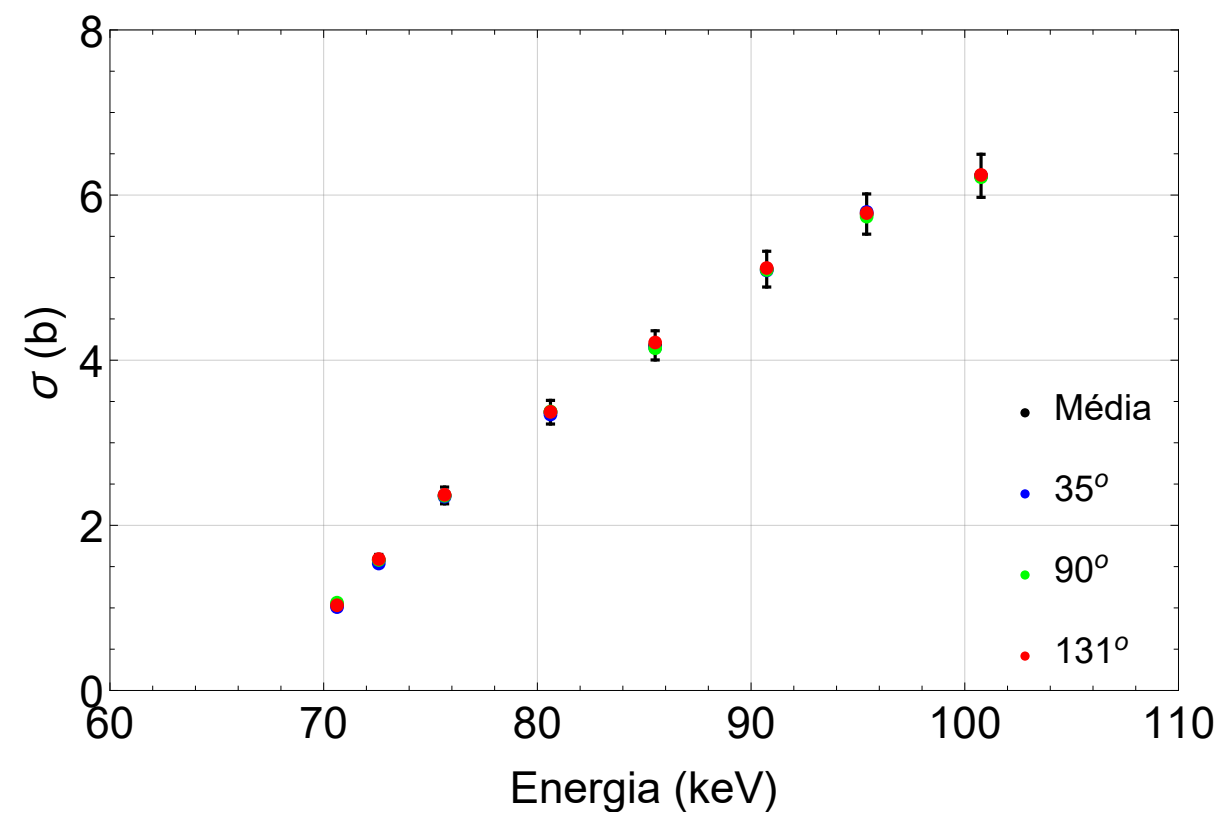

Figura 6.4: Mesmo que na figura 6.3 mas para o Ta. 
Das figuras 6.3 e 6.4 é possível observar que a análise feita nos três detectores fornece dados que são compatíveis dentro dos $3 \%$ e $4 \%$ de incerteza obtido para os valores médios.

As tabelas 6.5 e 6.6 apresentam as seções de choque obtidas pelo método relativo ao Bremsstrahlung.

Tabela 6.5: Valores das seções de choque de ionização da camada K do Te por impacto de elétrons obtidos pelo método relativo utilizando os detectores $5 \mathrm{cc}, 8 \mathrm{cc}$ e $\gamma$, com o respectivo valor médio.

\begin{tabular}{lllll}
\hline \multicolumn{5}{l}{$\sigma_{\mathrm{K}}(\mathrm{b})$} \\
\hline$E(\mathrm{keV})$ & $5 \mathrm{cc}$ & $8 \mathrm{cc}$ & $\gamma$ & Média \\
\hline $35,93(3)$ & $9,6(11)$ & $10,1(11)$ & $9,0(10)$ & $9,5(11)$ \\
$38,83(3)$ & $14,7(16)$ & $15,6(17)$ & $14,0(15)$ & $14,6(17)$ \\
$41,53(3)$ & $18(2)$ & $19(2)$ & $18,0(19)$ & $18(2)$ \\
$46,47(3)$ & $24(3)$ & $24(3)$ & $23(2)$ & $24(3)$ \\
$51,17(3)$ & $28(3)$ & $29(3)$ & $26(3)$ & $28(3)$ \\
$56,14(3)$ & $31(3)$ & $32(3)$ & $30(3)$ & $31(3)$ \\
$61,07(3)$ & $33(4)$ & $33(4)$ & $33(4)$ & $33(4)$ \\
$65,96(3)$ & $35(4)$ & $36(4)$ & $35(4)$ & $35(4)$ \\
$70,71(3)$ & $36(4)$ & $37(4)$ & $37(4)$ & $36(4)$ \\
$75,68(3)$ & $38(4)$ & $38(4)$ & $37(4)$ & $38(4)$ \\
$80,60(3)$ & $38(4)$ & $38(4)$ & $39(4)$ & $38(4)$ \\
$85,55(3)$ & $40(4)$ & $39(4)$ & $41(5)$ & $40(4)$ \\
$90,71(3)$ & $40(4)$ & $40(4)$ & $40(4)$ & $40(4)$ \\
$95,36(3)$ & $43(5)$ & $40(4)$ & $40(4)$ & $41(5)$ \\
$100,74(3)$ & $41(5)$ & $40(4)$ & $44(5)$ & $42(5)$ \\
\hline
\end{tabular}


Tabela 6.6: Mesmo que na tabela 6.5. mas para o Ta.

\begin{tabular}{lllll}
\hline \multicolumn{5}{c}{$\sigma_{\mathrm{K}}(\mathrm{b})$} \\
\hline$E(\mathrm{keV})$ & $5 \mathrm{cc}$ & $8 \mathrm{cc}$ & $\gamma$ & Média \\
\hline $70,63(3)$ & $1,10(13)$ & $1,02(12)$ & $1,03(12)$ & $1,05(12)$ \\
$72,58(3)$ & $1,69(19)$ & $1,61(19)$ & $1,62(18)$ & $1,64(18)$ \\
$75,66(3)$ & $2,6(3)$ & $2,4(3)$ & $2,5(3)$ & $2,5(3)$ \\
$80,61(3)$ & $3,8(4)$ & $3,6(4)$ & $3,7(4)$ & $3,7(4)$ \\
$85,51(3)$ & $4,7(5)$ & $4,5(5)$ & $4,7(5)$ & $4,6(5)$ \\
$90,73(3)$ & $5,9(7)$ & $5,4(6)$ & $5,5(6)$ & $5,7(6)$ \\
$95,41(3)$ & $6,3(7)$ & $5,9(7)$ & $6,3(7)$ & $6,2(7)$ \\
$100,76(3)$ & $6,9(8)$ & $6,5(7)$ & $7,1(8)$ & $6,8(8)$ \\
\hline
\end{tabular}

As figuras 6.5 e 6.6 apresentam as seções de choque do Te e Ta, respectivamente, obtidas pelo método relativo ao bremsstrahlung. É importante mencionar que as barras de incerteza referem-se ao valor médio. 


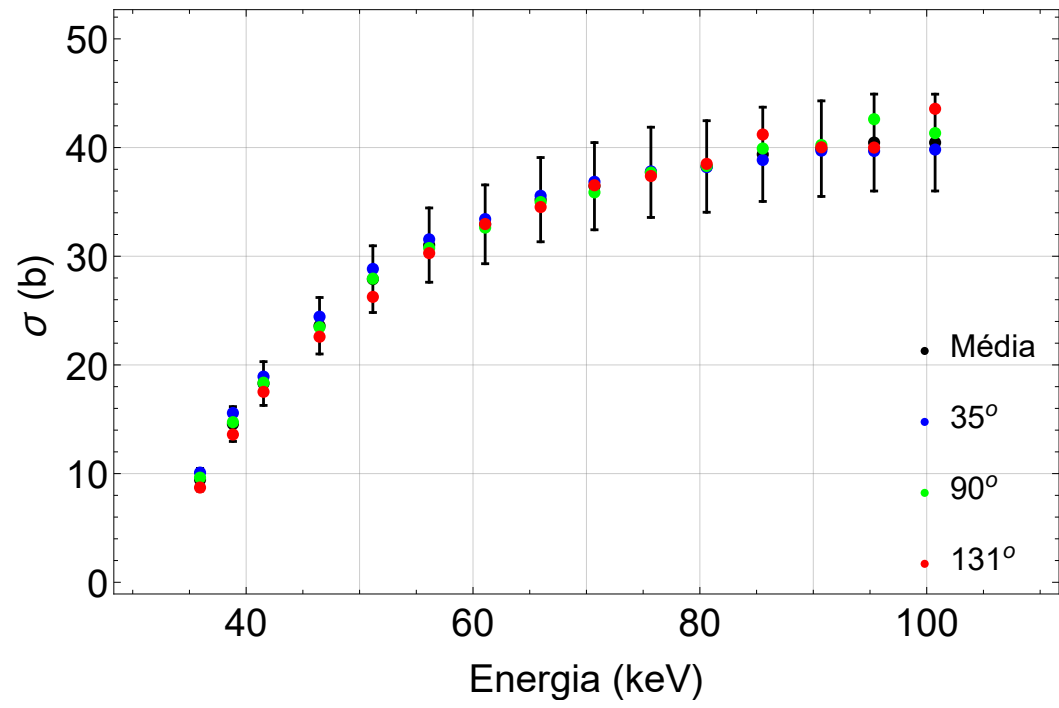

Figura 6.5: Seção de choque de ionização da camada $\mathrm{K}$ do Te por impacto de elétrons relativo ao bremsstrahlung para o alvo de Te.

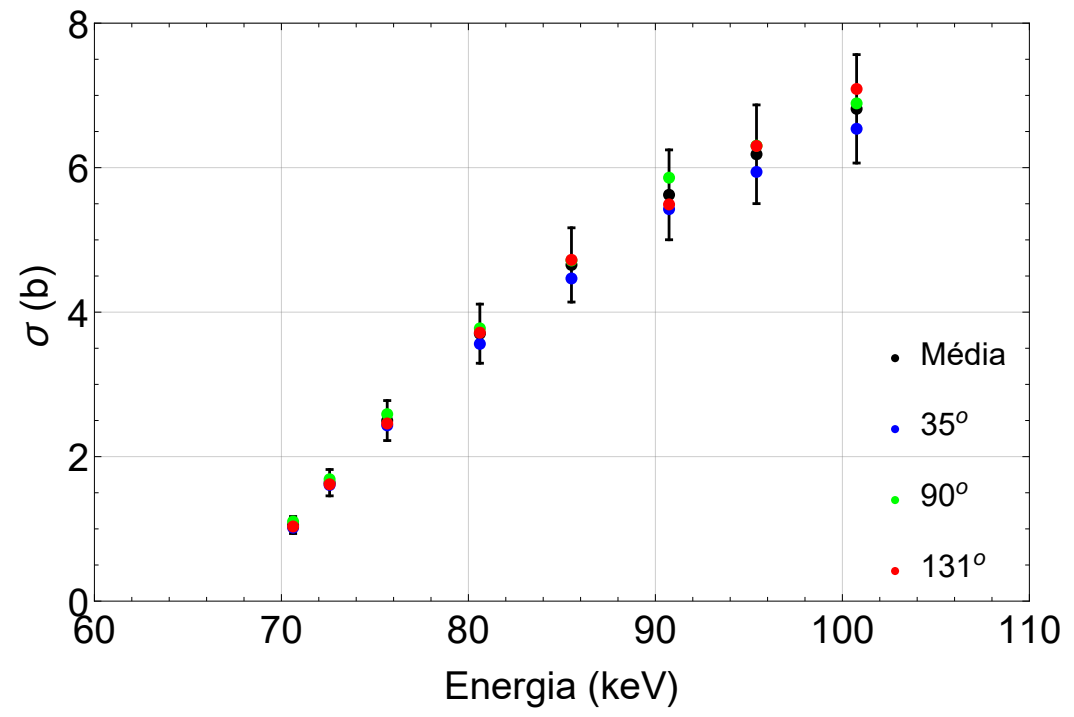

Figura 6.6: Mesmo que na figura 6.5. mas para o Ta.

As figuras 6.7 e 6.8 apresentam a comparação do valor médio obtido com os métodos absoluto e relativo, para os três detectores. 


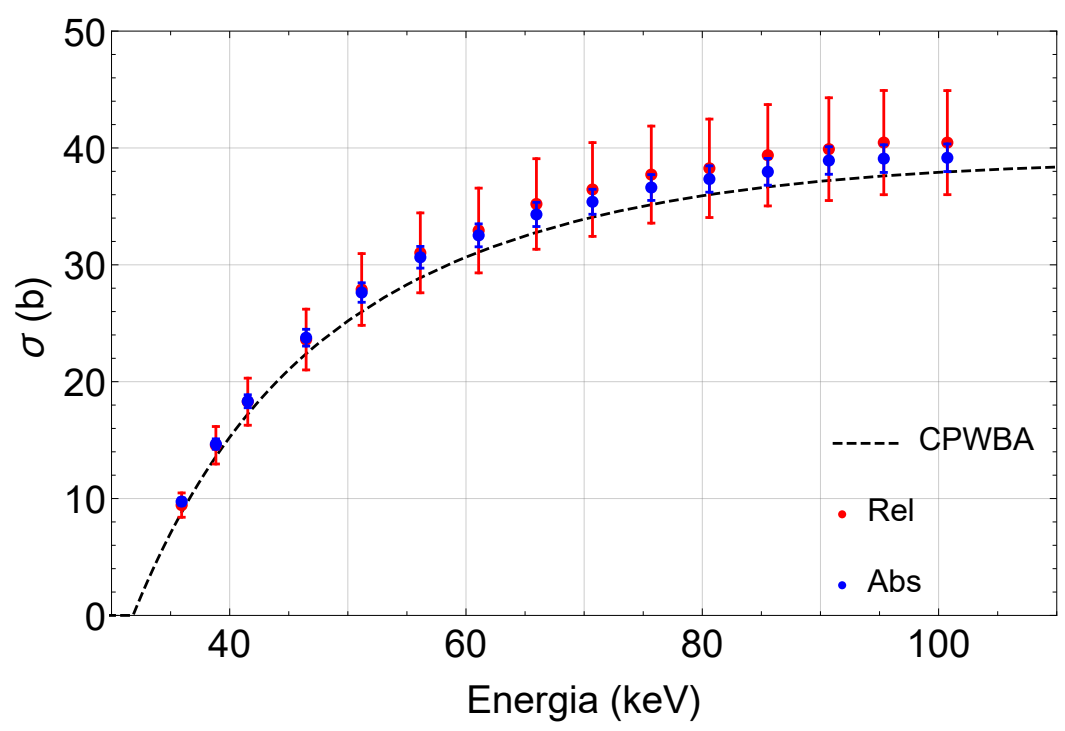

Figura 6.7: Comparação entre os valores médios da seção de choque obtidos com alvo de Te através dos métodos absoluto e relativo.

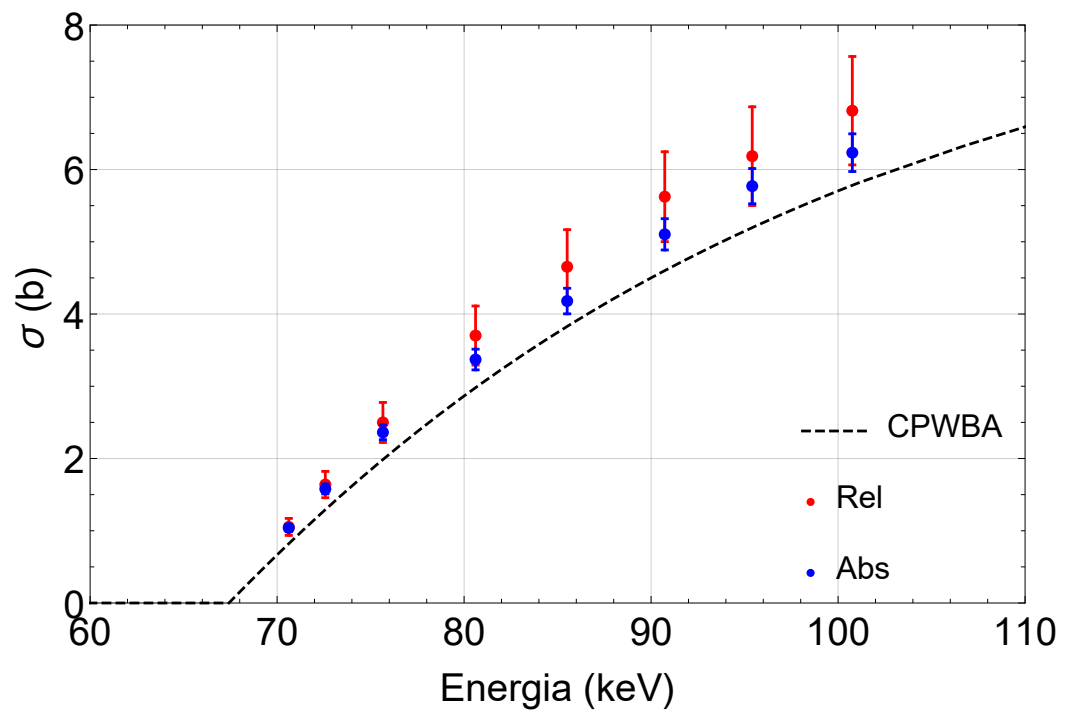

Figura 6.8: Mesmo que na figura 6.7, mas para o Ta. 
Nos resultados apresentados nas figuras 6.7 e 6.8, para o Te e Ta, é possível observar que o Te apresenta melhor compatibilidade que o Ta quando comparado com o modelo CPWBA, o que indica melhor acordo para elementos com baixo número atômico. O modelo denominado Subconfiguration-Average Distorted-Wave (SCADW) considera ondas distorcidas para o projétil proporcionando excelentes resultados quando comparado com dados obtidos no Microtron do IFUSP [28]. M. S. Pinzdola realizou cálculos para o Te e Ta na faixa de energia medida neste trabalho e os resultados são apresentados nas figuras 6.9 e 6.10. Esse trabalho será apresentado na EXRS Ref. [29] 


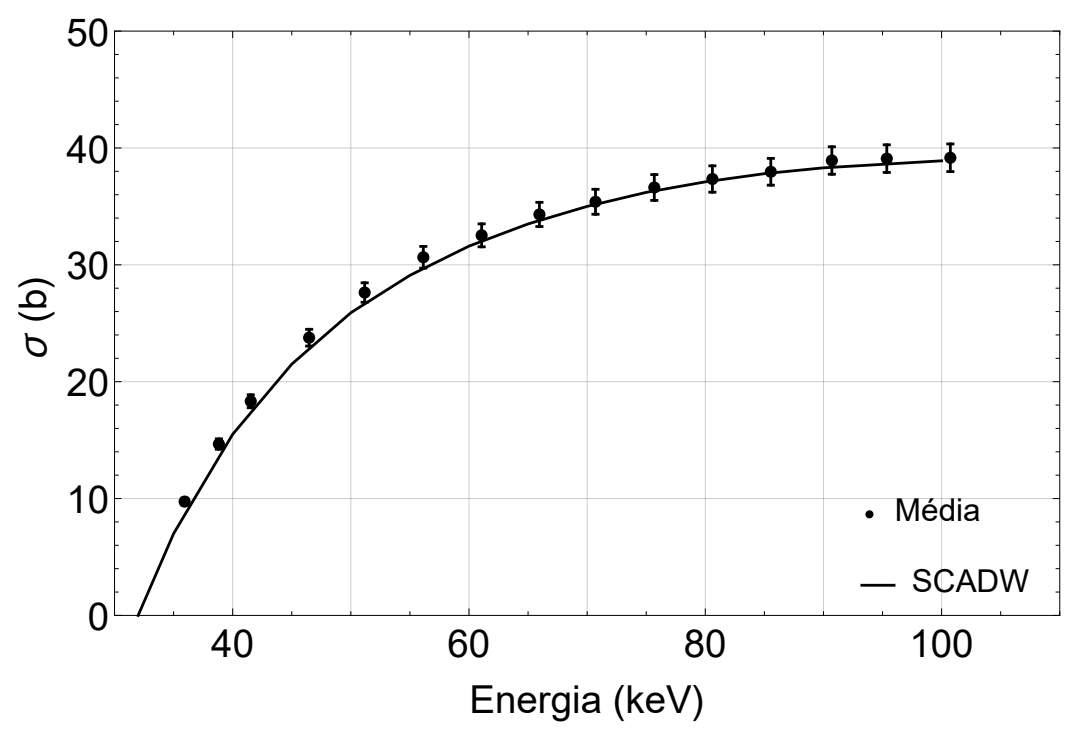

Figura 6.9: Comparação da seção de choque de ionização da camada K do Te com o modelo SCADW. Os dados experimentais são representados pelos pontos com barras de incerteza (um desvio padrão) e a curva teórica em linha contínua.

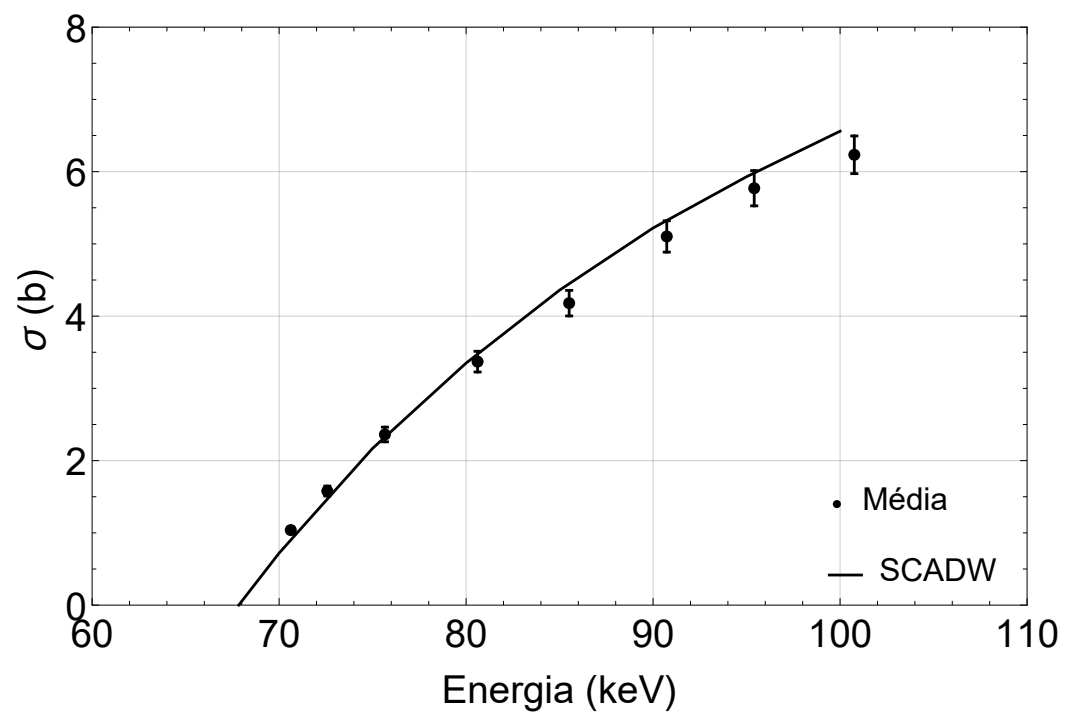

Figura 6.10: Mesmo que na figura 6.9, mas para o Ta. 



\section{Capítulo 7 \\ Conclusão}

Foram realizadas medidas de seção de choque de ionização da camada K com feixe de elétrons e alvos finos de Telúrio (Te) e Tântalo (Ta). O intervalo de energia medido cobriu desde o limiar de ionização dos elementos até $100 \mathrm{keV}$. Os valores absolutos das seções de choque foram obtidos por três detectores e são consistentes dentro da barra de incerteza. Isto reduz a possibilidade de erros oriundos do ajuste da eficiência, dos métodos de obtenção do número de fótons detectados ou do controle de tempo vivo do sistema de aquisição.

A comparação entre os resultados obtidos pelo método absoluto e o método relativo ao bremsstrahlung mostram-se compatíveis, dentro das incertezas.

Nos resultados obtidos para as seções de choque de ionização por impacto de elétrons pode-se observar um aumento da diferença entre a seção de choque experimental e a calculada em função do número atômico do elemento estudado. Essa mesma conclusão pode ser observada quando comparamos as Refs. [1] e [2]. Uma possível explicação pode estar na utilização de cálculos baseados na teoria de PWBA para o termo transversal da hamiltoniana de interação. Os resultados indicam que essa aproximação não é totalmente correta para elementos com número atômico elevado, pois os elétrons atômicos da camada K são relativísticos e os cálculos de PWBA para o termo transversal da hamiltoniana de interação não são totalmente eficazes nestes casos. Na Ref. [28], Pindzola usou os dados da Ref. [2] para verificar os cálculos realizados com DWBA também para o termo transversal da hamiltoniana 
para o $\mathrm{Au}(Z=79)$. Os resultados obtidos estão em acordo com os dados experimentais, indicando que o termo transversal não deve ser calculado com PWBA para elementos pesados. Essa mesma conclusão pode ser utilizada para explicar os resultados que foram obtidos para o Ta. 


\section{Estudo da eficiência de detectores de HPGe}

Foi proposto um modelo para a eficiência de detectores HPGe, válido no intervalo de 50-2000 keV. A resposta intrínseca dos detectores de Ge foi obtida no intervalo de baixas energias com o modelo de Seltzer [5], que assume que o feixe de fótons, colimados por um Pin-Hole, incidem perpendicularmente no centro da superfície frontal do cilindro de Ge. O espalhamento incoerente foi descrito pela seção de choque de Klein-Nishina [30]. A partir da resposta intrínseca é possível obter a eficiência intrínseca do detector e, adicionando os termos devido a atenuação das janelas do detector, camada morta e fração de ângulo sólido, é possível descrever a eficiência. No modelo aqui proposto, a condição de incidência central foi retirada, o que é mais realista. Desta forma, é possível descrever a incidência dos fótons para qualquer distância $r$ do centro do cilindro e, integrando sobre $r$, é possível obter o efeito médio provocado por fótons que iluminam o cristal.

Para energias mais altas $(\approx 200 \mathrm{keV})$ a eficiência foi ajustada com um modelo de potência de logaritmos [31, acrescentando termos devido à atenuação na camada morta do cristal de Ge e nas janelas.

No modelo de Seltzer, o espectro de deposição de energia de um fóton com energia $E$ em um detector de comprimento $L$ e raio $R$, sem o material 
de suporte, pode ser descrito pela seguinte equação:

$$
\begin{aligned}
D_{0}(\epsilon, E ; L, R)= & P_{\mathrm{f}}(E ; L, R) \delta(\epsilon-E) \\
& +P_{\mathrm{x} \alpha}(E ; L, R) \delta\left(\epsilon-E-E_{\alpha}\right) \\
& +P_{\mathrm{x} \beta}(E ; L, R) \delta\left(\epsilon-E-E_{\beta}\right)+C(\epsilon, E ; L, R)(\mathrm{A} .1)
\end{aligned}
$$

onde $P_{\mathrm{f}}$ é a probabilidade do fóton incidente ser completamente absorvido, $P_{\mathrm{x} \alpha}$ e $P_{\mathrm{x} \beta}$ são as probabilidades de escape dos raios-X $\mathrm{K} \alpha$ e raios-X $\mathrm{K} \beta$ do Ge, respectivamente, e $C$ é o contínuo Compton. O espectro de deposição de energia foi normalizado para um fóton incidente. Integrando a equação (A.1) é obtida a resposta do detector dada por:

$$
\begin{aligned}
\eta_{0}(E ; L, R)= & \int_{0}^{E} D_{0}(\epsilon, E ; L, R) \mathrm{d} \epsilon \\
= & P_{\mathrm{f}}(E ; L, R) \\
& +P_{\mathrm{x} \alpha}(E ; L, R)+P_{\mathrm{x} \beta}(E ; L, R) \\
& +\int_{0}^{E} C(\epsilon, E ; L, R) \mathrm{d} \epsilon .
\end{aligned}
$$

Para um feixe incidindo perpendicularmente à superfície frontal do detector, pode-se afirmar que:

$$
\eta_{0}(E ; L, R)=1-\exp [-\mu(E) L]
$$

onde $\mu$ é o coeficiente de atenuação total do Ge.

Para determinar a função $P_{\mathrm{f}}$, também conhecida como eficiência intrínseca do detector, combinam-se as equações A.2 e A.3 e isola-se a função de interesse.

$$
\begin{aligned}
P_{\mathrm{f}}(E ; L, R)= & 1-\exp [-\mu(E) L]-P_{\mathrm{x} \alpha}(E ; L, R) \\
& -P_{\mathrm{x} \beta}(E ; L, R)-P_{\mathrm{inc}}(E ; L, R)
\end{aligned}
$$


onde

$$
P_{\text {inc }}(E ; L, R)=\int_{0}^{E} C(\epsilon, E ; L, R) \mathrm{d} \epsilon
$$

é a contribuição Compton para o espectro. O livre caminho médio característico dos raios-X da camada $\mathrm{K}$ do Ge é da ordem de $0,05 \mathrm{~mm}$, ou seja, o escape de raios-X é mais provável na superfície do cristal, não dependendo da geometria do detector. Por esse motivo, a função relacionada ao escape de raios-X foi mantida idêntica à proposta por Seltzer [5]

$$
P_{\mathrm{x} \alpha, \beta}(E)=\frac{1}{2} \omega_{\mathrm{K}} \frac{\Gamma_{K \alpha, \beta}}{\Gamma_{K \text { Total }}} q_{\mathrm{K}}(E) \frac{\mu_{\mathrm{pe}}(E)}{\mu(E)}\left[1-\frac{\mu\left(E_{\alpha, \beta}\right)}{\mu(E)} \ln \left(1+\frac{\mu(E)}{\mu\left(E_{\alpha, \beta}\right)}\right)\right]
$$

Para determinar o contínuo Compton, foi necessário descrever o caminho percorrido pelos fótons incidentes e espalhados. Na Ref. [5] considera-se que os fótons incidem no centro da superfície frontal do detector, e portanto a simetria cilíndrica é utilizada para descrever o espalhamento Compton. No modelo aqui proposto a simetria cilíndrica não existe e, portanto, foi proposta uma modificação na função que descreve o contínuo Compton para, dessa forma, determinar a contribuição Compton para fótons que não incidem necessariamente no centro do cilindro de Ge.

\section{A.1 Contribuição Compton}

No esquema apresentado na figura A.1 um fóton, cujo trajeto está representado pela seta, incide normalmente à superfície frontal, distando $r$ da origem e depois é espalhado por um ângulo polar $\theta$ na direção do ângulo azimutal $\phi$. 


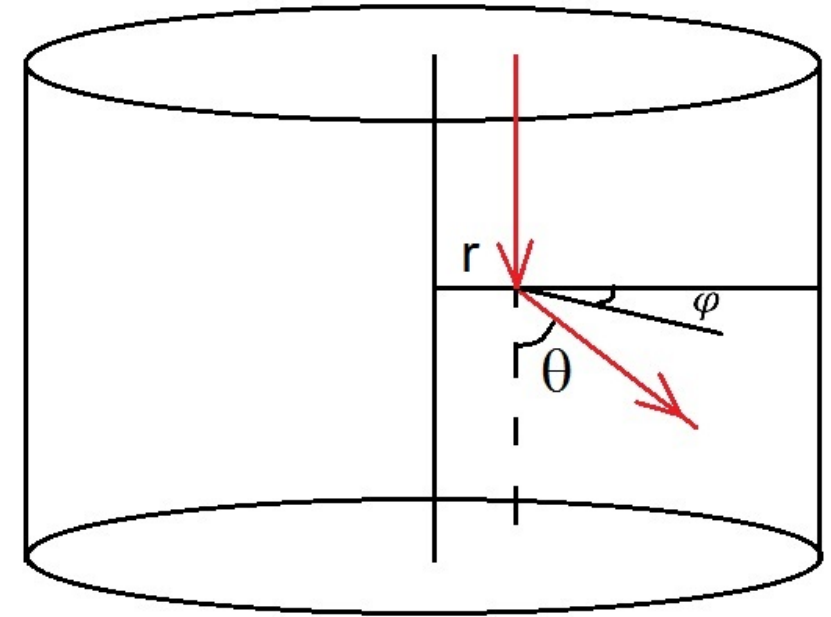

Figura A.1: Esboço de um cilindro de Ge com o fóton incidente percorrendo a trajetória representada pela seta distante $r$ do eixo do cilindro e desviando em um ângulo polar $\theta$ na direção do ângulo azimutal $\phi$.

Considerando eventos de espalhamento único pode-se demonstrar que a energia transferida do fóton, espalhando por um ângulo polar $\theta$, para um elétron livre e em repouso é dada por:

$$
\epsilon=\frac{E^{2}(1-\cos \theta)}{m_{\mathrm{e}} c^{2}+E(1-\cos \theta)}
$$

onde $E$ é a energia do fóton incidente, $m_{\mathrm{e}}$ é a massa do elétron e $c$ é a velocidade da luz. Por outro lado, a partir da equação A.7) é fácil demonstrar que o ângulo de espalhamento em função da energia depositada pode ser escrito como:

$$
\theta=\arccos \left(1-\frac{m_{\mathrm{e}} c^{2} \epsilon}{E(E-\epsilon)}\right)
$$

A maior transferência de energia ocorre quando o fóton espalha em um ângulo de $180^{\circ}$ e, por esse motivo, a região de espalhamento simples fica limitada no intervalo de energia dado por $0 \leq \epsilon \leq \epsilon_{\mathrm{C}}=2 E^{2} /\left(m_{\mathrm{e}} c^{2}+2 E\right)$. Quando a energia depositada é maior que $\epsilon>2 E^{2} /\left(m_{\mathrm{e}} c^{2}+2 E\right)$, tem-se a região de múltiplo espalhamento. Na Ref. [5] verificou-se que a região de múltiplo espalhamento é bem representada por uma distribuição triangular no intervalo de energia $\epsilon_{\mathrm{C}} \leq \epsilon \leq \epsilon_{\mathrm{C} 2}=4 E^{2} /\left(m_{\mathrm{e}} c^{2}+4 E\right)$, sendo $\epsilon_{\mathrm{C} 2}$ a 
energia depositada por dois espalhamentos sucessivos a $180^{\circ}$. A função que representa o espalhamento Compton é dada por:

$$
C(\epsilon, E ; L, R)= \begin{cases}C_{1}(\epsilon, E ; L, Z), & \text { para } 0 \leq \epsilon \leq \epsilon_{\mathrm{C}} \\ C_{2}(\epsilon, E ; L, R) & \text { para } \epsilon_{\mathrm{C}} \leq \epsilon \leq \epsilon_{\mathrm{C} 2}\end{cases}
$$

onde

$$
\begin{aligned}
C_{1}(\epsilon, E ; L, R)= & N_{\mathrm{A}}(Z / A) \frac{\mathrm{d} \sigma_{\mathrm{KN}}}{\mathrm{d} \epsilon} \\
& \times\left(\sigma_{\mathrm{inc}}(E) / \sigma_{\mathrm{KN}}(E)\right)\left(\mu(E) E^{2} / \rho_{\mathrm{Ge}}\right)^{-1} \\
& \times G(\epsilon, E ; L, R)
\end{aligned}
$$

e

$$
\frac{\mathrm{d} \sigma_{\mathrm{KN}}}{\mathrm{d} \epsilon}=\frac{m_{\mathrm{e}} c^{2} \pi r_{\mathrm{e}}^{2}}{E^{2}}\left[2+\frac{m_{\mathrm{e}} c^{2} \epsilon}{E(E-\epsilon)}\left(\frac{m_{\mathrm{e}} c^{2} \epsilon}{E(E-\epsilon)}+\frac{\epsilon}{m_{\mathrm{e}} c^{2}}-2\right)\right]
$$

onde $\sigma_{\mathrm{KN}}$ é a seção de choque de Klein-Nishina, $\sigma_{\text {inc }}$ é a seção de choque de espalhamento incoerente, $r_{\mathrm{e}}$ é o raio clássico do elétron, $N_{\mathrm{A}}$ é a constante de Avogadro, $Z$ é o número atômico e $A$ é o peso atômico do Ge. Simplificando a notação pode-se escrever a equação A.10 como:

$$
C_{1}(\epsilon, E ; L, R)=H(\epsilon, E) G(\epsilon, E ; L, R)
$$


Por outro lado

$$
\begin{aligned}
C_{2}(\epsilon, E ; L, R)= & \left(\left(\epsilon_{2 \mathrm{C}}-\epsilon\right) /\left(\epsilon_{2 \mathrm{C}}-\epsilon_{\mathrm{C}}\right)\right)\left(m_{\mathrm{e}} c^{2} \pi r_{\mathrm{e}}^{2} N_{\mathrm{A}} Z / A\right)^{2} \\
& \times\left(\sigma_{\mathrm{inc}}(E) / \sigma_{\mathrm{KN}}(E)\right)\left(\sigma_{\mathrm{inc}}\left(E-\epsilon_{\mathrm{C}}\right) / \sigma_{\mathrm{KN}}\left(E-\epsilon_{\mathrm{C}}\right)\right) \\
& \times 4 T\left\{E\left(E-\epsilon_{\mathrm{C}}\right)\left(\mu(E)+\mu\left(E-\epsilon_{\mathrm{C}}\right)\right) / \rho_{\mathrm{Ge}}\right\}^{-2} \\
& \times\left\{1+2 E^{2} /\left(m_{\mathrm{e}} c^{2}\left(m_{\mathrm{e}} c^{2}+2 E\right)\right)\right\} \\
& \times\left\{1-\left(1+\left(\mu(E)+\mu\left(E-\epsilon_{\mathrm{C}}\right)\right) L\right) \mathrm{e}^{-\left(\mu(E)+\mu\left(E-\epsilon_{\mathrm{C}}\right)\right) L}\right\}
\end{aligned}
$$

onde a constante $T$ é o fator de normalização.

A contribuição de múltiplo espalhamento $C_{2}$ é independente do raio do detector e o efeito médio devido a incidência não central varia muito pouco. Portanto, esta contribuição não foi modificada. Como a função que descreve o espalhamento simples é composta de uma constante multiplicada pela função $G$, que contém toda a informação da geometria do detector, o trabalho proposto aqui se restringiu a modificar a função $G$.

\section{A.2 Função geometria para o espalhamento Compton simples}

A fim de deixar a leitura mais agradável, a partir deste momento se utilizará a notação $\mu(E)=\mu$ e $\mu(E-\epsilon)=\mu^{\prime}$ para o coeficiente de atenuação do Ge.

A função adimensional $G$ foi obtida no modelo de Seltzer da seguinte forma:

$$
G=\mu \int_{0}^{L} \mathrm{e}^{-\mu l} e^{-\mu^{\prime} s} \mathrm{~d} l
$$


onde $s$ é a distância percorrida do ponto de interação $l$ até escapar do cilindro do detector. A primeira exponencial multiplicada por $\mathrm{d} l$ e por $\mu$ é a probabilidade do fóton interagir entre $l$ e $l+\mathrm{d} l$ e a segunda exponencial é a probabilidade do fóton espalhado percorrer um caminho $s$ até a superfície do detector sem sofrer um segundo espalhamento.

Para levar em conta o fato da incidência não central, a equação A.14 foi modificada:

$$
G=\frac{\mu}{\pi R^{2}} \int_{0}^{R} \int_{0}^{L} \int_{0}^{2 \pi} e^{-\mu l} \mathrm{e}^{-\mu^{\prime} s} r \mathrm{~d} \phi \mathrm{d} l \mathrm{~d} r
$$

No caso onde os fótons incidem no centro do cilindro de Ge, a integral dada na equação A.15 recai na integral dada na equação A.14).

De acordo com a equação A.5, para determinar $P_{\text {inc }}$ devemos integrar o resultado da equação A.12 em $\epsilon$, energia perdida pelo elétron espalhado, que se relaciona com $\theta$ pela equação A.8. Porém, devido as condições de contorno, a integral apresentada na equação A.15 foi dividida em partes e foi constatado que é mais fácil descrever os limites de integração primeiro em $\theta$, que é o equivalente a integrar no intervalo de energia do espalhamento Compton único. O diferencial de energia, $\mathrm{d} \epsilon$, se relaciona com o ângulo de espalhamento, $\theta$, pela seguinte equação:

$$
\mathrm{d} \epsilon=\frac{E^{2} m_{\mathrm{e}} c^{2} \sin \theta}{\left[m_{\mathrm{e}} c^{2}+E(1-\cos \theta)\right]^{2}} \mathrm{~d} \theta=F(\theta, E) \mathrm{d} \theta
$$

onde $F(\theta, E)$ é o jacobiano da transformação.

Combinando a equação A.15 com A.12 e utilizando o diferencial A.16 para integrar no intervalo de energia, que equivale a integrar no intervalo de ângulo polar de espalhamento, obtém-se a contribuição Compton para a eficiência de detecção dada por:

$$
G^{\prime}=\frac{\mu}{\pi R^{2}} \int_{0}^{R} \int_{0}^{L} \int_{0}^{2 \pi} \int_{0}^{\pi} \mathrm{e}^{-\mu l} \mathrm{e}^{-\mu^{\prime} s} r H(\theta, E) F(\theta, E) \mathrm{d} \theta \mathrm{d} \phi \mathrm{d} l \mathrm{~d} r
$$

onde $\epsilon$ é trocada por $\theta$ em $H(\epsilon, E)$. 
Na Ref. [5], a integral (A.17) é efetuada considerando no lugar do coeficiente de atenuação dos fótons espalhados, o coeficiente de atenuação de energia, $\mu_{\mathrm{en}}$, para os fótons espalhados. A função que melhor representa o espalhamento Compton, de acordo com simulações Monte Carlo, será portanto dada pela combinação dessas duas integrais, sendo que o peso estatístico de cada contribuição é dado pelo fator $\nu=\left(\frac{\epsilon}{\epsilon_{\mathrm{C}}}\right)^{0.6}=\left[\frac{\epsilon}{E}\left(1+\frac{m_{\mathrm{e}} c^{2}}{2 E}\right)\right]^{0.6} \cdot \mathrm{A}$ soma dos dois efeitos é dado por:

$$
\begin{aligned}
G^{\prime \prime}= & \frac{\mu}{\pi R^{2}} \int_{0}^{R} \int_{0}^{L} \int_{0}^{2 \pi} \int_{0}^{\pi} \mathrm{e}^{-\mu l} H(\theta, E) F(\theta, E) \\
& \times\left[(1-\nu) \mathrm{e}^{-\mu^{\prime} s}+\nu \mathrm{e}^{-\mu_{\mathrm{en}}^{\prime} s}\right] r \mathrm{~d} \theta \mathrm{d} \phi \mathrm{d} l \mathrm{~d} r
\end{aligned}
$$

Somando a equação A.18 com a contribuição de múltiplo espalhamento dada pela integral em energia da equação A.13, tem-se a contribuição Compton total:

$$
\int_{\epsilon_{\mathrm{C}}}^{\epsilon_{\mathrm{C} 2}} C_{2}(\epsilon, E ; R, L) \mathrm{d} \epsilon
$$

As integrais apresentadas nas equações A.18 e A.19 foram efetuadas por cálculo numérico utilizando o método de quadraturas Gauss-Legendre de grau 5. O código foi desenvolvido no software Wolfram Mathematica 10.2. A descrição de como foi resolvida a integral A.18 encontra-se no apêndice B. Os resultados estão em acordo com simulações utilizando o código PENELOPE [20].

\section{A.3 Eficiência}

A eficiência em energias mais baixas é obtida pela eficiência intrínseca de deteç̧ão, equação A.4 , acrescentando os fatores de atenuação das janelas e da camada morta do Ge, equação A.20, multiplicados pela fração de ângulo 
sólido:

$$
\varepsilon_{\mathrm{FE},<}(E)=\frac{\Omega}{4 \pi} \mathrm{e}^{-\vec{\mu} \cdot \vec{d}} P_{\mathrm{f},<}(E)
$$

A eficiência para energias mais altas $(\approx 200 \mathrm{keV})$ é dada pela equação:

$$
\varepsilon_{\mathrm{FE},>}(E)=\frac{\Omega}{4 \pi} \mathrm{e}^{-\vec{\mu} \cdot \vec{d}} P_{\mathrm{f},>}(E)
$$

onde o logaritmo de $P_{\mathrm{f},>}(E)$ é uma série de potências logarítmicas na energia, o coeficiente de atenuação $\vec{\mu}=\left(\mu_{1}, \mu_{2} \ldots\right)$ e $\vec{d}=\left(d_{1}, d_{2}, \ldots\right)$, com $\mu_{i}$ e $d_{i}$ sendo o coeficiente de atenuação e a espessura da camada $i$ da janela, respectivamente. O fator que representa a atenuação na camada morta do Ge também está embutido em $\vec{d}$ e $\vec{\mu}$.

Por simplicidade numérica, a função adotada para descrever os dados é um polinômio no logaritmo da eficiência, logo o logaritmo das equações A.20 e A.21 é a função proposta para o intervalo de energia entre $50-2000 \mathrm{keV}$ :

$$
\ln \varepsilon_{\mathrm{FE}}(E)= \begin{cases}b-\vec{\mu} \cdot \vec{d}+\ln \left(P_{\mathrm{f},<}(E ; R, L)\right), & \text { se } 50 \mathrm{keV} \leq E \leq E_{\mathrm{c}} \\ a_{0}-\vec{\mu} \cdot \vec{d}+a_{1} \ln \left(\frac{E}{E_{\mathrm{c}}}\right)+a_{2}\left(\ln \left(\frac{E}{E_{\mathrm{c}}}\right)\right)^{2}, & \text { se } E_{\mathrm{c}} \leq E \leq 2000 \mathrm{keV}\end{cases}
$$

A fim de que a função seja contínua no ponto de junção $E_{\mathrm{c}}$, o parâmetro $b$ deve ser uma função de $a_{0}$. Esses dois parâmetros $a_{0}$ e $b$ estão relacionados com a fração de ângulo sólido $\Omega / 4 \pi$. Os parâmetros não lineares são $E_{\mathrm{c}}, R$ e $L$. Se o volume ativo é bem conhecido, $R$ e $L$ são mantidos fixos, mas normalmente os detectores possuem camadas mortas que devem ser levadas em consideração. Sabendo o valor aproximado de um dos parâmetros, o outro pode ser utilizado como parâmetro de ajuste, reduzindo assim para dois os parâmetros de ajuste não lineares. Foi fixada a espessura $L$ do detector para determinação da eficiência. Os parâmetros lineares a serem ajustados são $b, d_{1}, d_{2}, \ldots, a_{1}, a_{2}$. A estratégia para ajustar a função é fazer o ajuste linear dos parâmetros $b, d_{1}, d_{2}, \ldots, a_{1}, a_{2}$ para um dado $E_{\text {c }}$ e $R$ ou $L$ fixos e depois variar os parâmetros não lineares e desenhando as curvas de nível de $\chi^{2}$. Claro que se alguns parâmetros de atenuação das janelas são conhecidos, e normalmente são, eles devem ser fixados, reduzindo assim o número de 
parâmetros lineares. 


\section{Função Geometria}

O intervalo de integração $0 \leq \phi \leq 2 \pi$ da equação A.18 pode ser substituído pelo intervalo $0 \leq \phi \leq \pi$, se multiplicarmos a equação A.18 por 2 devido a simetria. Desta forma:

$$
\begin{aligned}
G^{\prime \prime}= & \frac{2 \mu}{\pi R^{2}} \int_{0}^{R} \int_{0}^{L} \int_{0}^{\pi} \int_{0}^{\pi} \mathrm{e}^{-\mu l} H(\theta, E) F(\theta, E) \\
& \times\left[(1-\nu) \mathrm{e}^{-\mu^{\prime} s}+\nu \mathrm{e}^{-\mu_{\mathrm{en}}^{\prime} s}\right] r \mathrm{~d} \theta \mathrm{d} \phi \mathrm{d} l \mathrm{~d} r
\end{aligned}
$$

Fixando o ponto de interação $(l, r)$ onde ocorreu o espalhamento simples, é possível descrever o caminho do fóton espalhado dentro do cristal de Ge. Para descrever o domínio de integração, a integral apresentada na equação (B.1) foi separada em algumas regiões. As integrais em $l$ e $r$ foram calculadas por último, então estas integrais, assim como algumas constantes da equação (B.1), foram omitidas:

$$
\begin{aligned}
J= & \frac{1}{\pi} \int_{0}^{\pi} \int_{0}^{\pi} \mathrm{e}^{-\mu l} H(\theta, E) F(\theta, E) \\
& \times\left[(1-\nu) \mathrm{e}^{-\mu^{\prime} s}+\nu \mathrm{e}^{-\mu_{\text {en }}^{\prime} s}\right] \mathrm{d} \theta \mathrm{d} \phi
\end{aligned}
$$

Por consequência, a integral dada na equação (B.1) pode ser escrita como:

$$
G^{\prime \prime}=\frac{2 \mu}{R^{2}} \int_{0}^{R} \int_{0}^{L} J r \mathrm{~d} l \mathrm{~d} r
$$

i) Considerando fótons que escapam somente pela superfície frontal do 
detector, temos que o limite de integração para $\theta$ será dado por $\pi \geq \theta \geq$ $\pi-\arctan \left(\frac{R-r}{l}\right)=\theta_{2}$. Para essa condição o caminho do fóton, $s$, é dado por $s=\frac{-l}{\cos \theta}$, ou seja, não depende do ângulo $\phi$. Integrando primeiro em $\phi \mathrm{e}$ substituindo os limites de integração para $\theta$ na equação (B.2):

$$
\begin{aligned}
J_{1}= & \int_{\theta_{2}}^{\pi} \mathrm{e}^{-\mu l} H(\theta, E) F(\theta, E) \\
& \times\left[(1-\nu) \mathrm{e}^{\mu^{\prime} l / \cos \theta}+\nu \mathrm{e}^{\mu_{\text {en }}^{\prime} l / \cos \theta}\right] \mathrm{d} \theta
\end{aligned}
$$

ii) Da mesma forma a integral apresentada na equação $(\mathrm{B} .2)$ não possui dependência com $\phi$ para os fótons que saem pela superfície traseira do detector. Logo, integrando em $\phi$ e determinando os limites de integração para $\theta$ na região $0 \leq \theta \leq \arctan \left(\frac{R-r}{L-l}\right)=\theta_{1}$ :

$$
\begin{aligned}
J_{2}= & \int_{0}^{\theta_{1}} \mathrm{e}^{-\mu l} H(\theta, E) F(\theta, E) \\
& \times\left[(1-\nu) \mathrm{e}^{\mu^{\prime}(l-L) / \cos \theta}+\nu \mathrm{e}^{\mu_{\mathrm{en}}^{\prime}(l-L) / \cos \theta}\right] \mathrm{d} \theta
\end{aligned}
$$

Dependendo do ângulo de espalhamento $\theta$, os fótons espalhados podem sair pela superfície frontal ou pela lateral para um dado ângulo $\phi$. Nesse caso, considerando o ponto de interação $(l, r)$, é dado que o limite de integração para $\theta$ é $\theta_{4}=\pi-\arctan \left(\frac{R+r}{l}\right) \leq \theta \leq \theta_{2}$. Nessa condição, os fótons emergem pela superfície frontal do detector quando o ângulo $\phi$ estiver no intervalo $\phi_{2}=\arccos \left(\frac{r^{2}+l^{2} \tan ^{2} \theta-R^{2}}{2 l r \tan \theta}\right) \leq \phi \leq \pi$ e saem pela lateral quando $0 \leq \phi \leq \phi_{2}$. Nessa condição a integral da equação (B.2) fica:

$$
\begin{aligned}
J_{3}= & \frac{1}{\pi} \int_{\theta_{4}}^{\theta_{2}} \mathrm{e}^{-\mu l} H(\theta, E) F(\theta, E) \\
& \times\left\{\int_{0}^{\phi_{2}}\left[(1-\nu) \mathrm{e}^{-\mu^{\prime} s_{1}}+\nu \mathrm{e}^{-\mu_{\mathrm{en}}^{\prime} s_{1}}\right] \mathrm{d} \phi\right. \\
& \left.+\int_{\phi_{2}}^{\pi}\left[(1-\nu) \mathrm{e}^{\mu^{\prime} l / \cos \theta}+\nu \mathrm{e}^{\mu_{\mathrm{en}}^{\prime} l / \cos \theta}\right] \mathrm{d} \phi\right\} \mathrm{d} \theta
\end{aligned}
$$


onde é possível demonstrar que o caminho percorrido pelos fótons que escapam pela superfície lateral é dado por: $s_{1}=\frac{\sqrt{R^{2}-r^{2} \sin ^{2} \phi}-r \cos \phi}{\sin \theta}$. O caminho percorrido pelos fótons que emergem pela superfície frontal não dependem de $\phi$, por esse motivo a integral apresentada na equação (B.6) fica:

$$
\begin{aligned}
J_{3}= & \frac{1}{\pi} \int_{\theta_{4}}^{\theta_{2}} \mathrm{e}^{-\mu l} H(\theta, E) F(\theta, E) \\
& \times\left\{\int_{0}^{\phi_{2}}\left\{(1-\nu) \mathrm{e}^{-\mu^{\prime} s_{1}}+\nu \mathrm{e}^{-\mu_{\text {en }}^{\prime} s_{1}}\right\} \mathrm{d} \phi\right. \\
& \left.+\left(\pi-\phi_{2}\right)\left[(1-\nu) \mathrm{e}^{\mu^{\prime} l / \cos \theta}+\nu \mathrm{e}^{\mu_{\text {en }}^{\prime} l / \cos \theta}\right]\right\} \mathrm{d} \theta
\end{aligned}
$$

Para o ângulo $\theta$ no intervalo de integração dado por $\theta_{1}=\arctan \left(\frac{R-r}{L-l}\right) \leq$ $\theta \leq \arctan \frac{R+r}{L-l}=\theta_{3}$, os fótons saem pela superfície traseira ou pela superfície lateral, dependendo do ângulo $\phi$. Utilizando o mesmo raciocínio da integral dada pela equação (B.7) é dado que:

$$
\begin{aligned}
J_{4}= & \frac{1}{\pi} \int_{\theta_{1}}^{\theta_{3}} \mathrm{e}^{-\mu l} H(\theta, E) F(\theta, E) \\
& \times\left\{\int_{0}^{\phi_{2}}\left[(1-\nu) \mathrm{e}^{-\mu^{\prime} s_{1}}+\nu \mathrm{e}^{-\mu_{\mathrm{en}}^{\prime} s_{1}}\right] \mathrm{d} \phi\right. \\
& \left.+\left(\pi-\phi_{1}\right)\left[(1-\nu) \mathrm{e}^{\mu^{\prime}(l-L) / \cos \theta}+\nu \mathrm{e}^{\mu_{\mathrm{en}}^{\prime}(l-L) / \cos \theta}\right]\right\} \mathrm{d} \theta
\end{aligned}
$$

onde $0 \leq \phi \leq \phi_{1}=\arccos \left(\frac{R^{2}-r^{2}-(L-l)^{2} \tan ^{2} \theta}{2(L-l) r \tan \theta}\right)$ é a região onde os fótons saem pela superfície lateral e $\phi_{1} \leq \phi \leq \pi$ é a região onde os fótons saem pela superfície traseira.

A região onde o fóton é espalhado, de forma a escapar pela superfície lateral, ocorre quando o ângulo de espalhamento está entre $\theta_{3} \leq \theta \leq \theta_{4}$. 
Nesse caso, a contribuição para a integral dada pela equação (B.2) fica:

$$
\begin{aligned}
J_{5}= & \frac{1}{\pi} \int_{0}^{\pi} \int_{\theta_{3}}^{4} \mathrm{e}^{-\mu l} H(\theta, E) F(\theta, E) \\
& \times\left[(1-\nu) \mathrm{e}^{-\mu^{\prime} s_{1}}+\nu \mathrm{e}^{-\mu_{\mathrm{en}}^{\prime} s_{1}}\right] \mathrm{d} \theta \mathrm{d} \phi
\end{aligned}
$$

Com o ponto de interação $(l, r)$ fixo, as integrais $J_{1}, J_{2}, J_{3}, J_{4}$ e $J_{5}$ são facilmente resolvidas por quadratura de Gauss-Legendre de grau 5, pois as funções são muito suaves. A fim de obter a contribuição Compton do espalhamento simples, a integral dada pela equação (B.10) é efetuada primeiro em $l$ e depois em $r$, pelo mesmo método de quadratura. O resultado final é dado pela seguinte equação:

$$
C_{1}=\frac{2 \mu}{R^{2}} \int_{0}^{R} \int_{0}^{L}\left(J_{1}+J_{2}+J_{3}+J_{4}+J_{5}\right) r \mathrm{~d} l \mathrm{~d} r
$$




\section{REFERÊNCIAS BIBLIOGRÁFICAS}

[1] V. R. Vanin, M. V. Manso Guevara, N.L. Maidana, M.N. Martins e J.M. Fernández-Varea. Radiation Physics and Chemistry 119, 14-23 (2016).

[2] J. M. Fernández-Varea, V. Jahnke, N. L. Maidana, A. A. Malafronte e V. R. Vanin. Journal of Physics B: Atomic, Molecular and Optical Physics 47(15), 155201 (2014).

[3] S. F. Barros, V. R. Vanin, N. L. Maidana e J. M. Fernández-Varea. Journal of Physics B: Atomic, Molecular and Optical Physics 48(17), 175201 (2015).

[4] X. Llovet, C. J. Powell., F Salvat e A. Jablonski. Journal of Physical and Chemical Reference Data 43(1), 013102 (2014).

[5] S. M. Seltzer. Nuclear Instruments and Methods 188(1), 133-151 (1981).

[6] M. E. Rose. Relativistic Electron Theory. John Wiley \& Sons, New York, (1961).

[7] I. P. Grant. Relativistic calculation of atomic structure. Advances in Physics, (1970).

[8] D. Bote. Colisiones de partículas cargadas. Modelos de interacción y algoritmos numéricos. Tese de doutoramento, Universitat de Barcelona, (2010).

[9] D. Bote e F. Salvat. Physical Review A 77, 042701 (2008).

[10] http://portal.if.usp.br/microtron/. Setembro (2015). 
[11] N. L. Maidana, V. R. Vanin, V. Jahnke, J. M. Fernández-Varea, M. N. Martins e L. Brualla. Nucl. Instr. Meth. A729, 371-380 (2013).

[12] http://www2.if.usp.br/ lamfi/tutoriais.htm. Outubro (2015).

[13] T. F. Silva, C. L. Rodrigues, M. Mayer, M. V. Moro, G. F. Trindade, F. R. Aguirre, N. Added, M. A. Rizzutto e M. H. Tabacniks. Nucl. Instr. Meth. B 371, 86-89 (2016). The 22nd International Conference on Ion Beam Analysis (IBA 2015).

[14] M. Mayer. American Institute of Physics Conference Proceedings 475, 541 (1999). Proceedings of the 15th International Conference on the Application of Accelerators in Research and Industry.

[15] J. H. Scofield. Atomic Data and Nuclear Data Tables 14(2), 121-137 (1974).

[16] R. D. Deslattes, E. G. Kessler, P. Indelicato, L. de Billy, E. Lindroth e J. Anton. Reviews of Modern Physics 75, 35-99 Jan (2003).

[17] M. O. Krause. Journal of Physical and Chemical Reference Data 8(2), 307-327 (1979).

[18] L. Kissel, C. A. Quarles e R. H. Pratt. Atomic Data and Nuclear Data Tables 28(3), 381-460 (1983).

[19] S. M. Seltzer e M. J. Berger. Atomic Data and Nuclear Data Tables 35(3), 345-418 (1986).

[20] F. Salvat, J. M. Fernández-Varea e J. Sempau. A Code System for Monte Carlo Simulation of Electron and Photon Transport. Issy-lesMoulineaux: OECD Nuclear Energy Agency., (2011).

[21] G. F. Knoll. Radiation Detection and Measurement. John Wiley \& Sons, (2000). 
[22] O. A. M. Helene e V. R. Vanin. Tratamento estatistico de dados em Fisica experimental. Blucher,2ed, (1991).

[23] G. W. Phillips e K. W. Marlow. Nuclear Instruments and Methods 137(3), 525-536 (1976).

[24] A. M. Wegrzynek e D. A. M. Cuevas. X-Ray Spectrometry 30(6), 403$412(2001)$.

[25] L. Kissel, C. A. Quarles e R. H. Pratt. Atomic Data and Nuclear Data Tables 28(3), 381-460 (1983).

[26] S. M. Seltzer e M. J. Berger. Atomic Data and Nuclear Data Tables 35(3), 345-418 (1986).

[27] http://www.nucleide.org. July (2014).

[28] M. S. Pindzola. Journal of Physics B: Atomic, Molecular and Optical Physics 48(1), 015201 (2015).

[29] V.R.Vanin, M.N. Martins, N.L. Maidana, A. Mangiarotti1, O.C.B. Santos, J.A. García-Alvarez, S.F. Barros, M.H. Tabacniks, C.L. Rodrigues, T.F. Silva, M.F. Koskinas, J.M. Fernández-Varea e M.S. Pindzola. EXRS2016 (no. 154) (2016).

[30] O. Klein e Y. Nishina. Z Physik 52(853) (1929).

[31] L. Venturini e V.R. Vanin. Applied Radiation and Isotopes 44(7), 9991002 (1993). 



\section{LisTA DE FiguRAS}

3.1 Sistema de cavidades ressonantes do acelerador Microtron do IFUSP. . . . . . . . . . . . . . . . . . . . 14

$3.2 \quad$ Sistema Racetrack Microtron utilizado para obter energias até $5 \mathrm{MeV} . \ldots \ldots \ldots \ldots \ldots$

3.3 Esquema do acelerador Microtron do IFUSP[10]. . . . . . . . 16

3.4 Linha de $100 \mathrm{keV}$ do acelerador Microtron do IFUSP. . . . . . 17

$3.5 \quad$ Esquema da câmara de $100 \mathrm{keV}$ do acelerador Microtron do IFUSP. . . . . . . . . . . . . . . . . . . . . 18

3.6 (a) Alvo de Ta e (b) fonte radioativa de ${ }^{133} \mathrm{Ba}$ com molduras idênticas. . . . . . . . . . . . . . . . . 19

3.7 Esquema da eletrônica utilizada. . . . . . . . . . . . . . . . 20

3.8 Esboço do experimento utilizado para determinação da espessura dos alvos pela técnica de RBS. A seta apontando para a esquerda representa o feixe. Figura retirada da Ref. [12]. . . . 22

3.9 Curvas de nível $Q=\chi^{2}+n^{2}, \operatorname{com} n=1,2, \ldots, 7$ para o ajuste do tip de bremsstrahlung para o alvo de Ta, $E \approx 95 \mathrm{keV}$ e $\theta=35^{\circ}$. . . . . . . . . . . . . . . . . 27

3.10 Ajuste do tip de bremsstrahlung para o alvo de Ta, com feixe de energia $E \approx 95 \mathrm{keV}$ e $\theta=35^{\circ}$. Os dados experimentais são apresentados pelos pontos com barras, o fundo pela curva azul, o espectro de bremsstrahlung (alvo) pela curva verde e a soma dos espectros pela curva preta. . . . . . . . . . . 28 
3.11 Ajuste do contínuo abaixo dos picos de raios-X $\mathrm{K} \alpha_{2,1}$ do Ta com feixe de $E \approx 95 \mathrm{keV}$, utilizado no método relativo ao bremsstrahlung. . . . . . . . . . . . . . . . . . . . . 29

4.1 Ajuste da soma dos espectros obtidos com alvo de Te e detector 8cc em todas as medições. Dispersão de energia de $\approx 18 \mathrm{eV}$ por canal. . . . . . . . . . . . . . . . . 37

4.2 Exemplo de ajustes dos raios-XK ${ }_{\alpha}$ para o detector 5cc com feixe de energia $E=85 \mathrm{keV}$. Dispersão de energia de $\approx 18 \mathrm{eV}$ por canal. . . . . . . . . . . . . . . . . . . . . . . . . 39

4.3 Exemplos de ajustes dos picos de raios-XK ${ }_{\alpha}$ para o detector 8cc com feixe de energia igual a $E=95 \mathrm{keV}$. Dispersão de energia de $\approx 18 \mathrm{eV}$ por canal. . . . . . . . . . . . . . . . . . 40

4.4 Exemplos de ajustes dos raios-XK ${ }_{\alpha}$ para o detector $\gamma$. Espectro obtido com o alvo de Ta $K \alpha_{2,1}$ e $E=75 \mathrm{keV}$. Dispersão de energia de $\approx 25 \mathrm{eV}$ por canal. . . . . . . . . . . . . . 41

4.5 Exemplo de ajuste para o detector $\gamma$. Espectro obtido com alvo de Te e feixe com $E=75 \mathrm{keV}$. Dispersão de energia de $\approx 25 \mathrm{eV}$ por canal. . . . . . . . . . . . . . . . . . . . . 42

5.1 Ajuste da largura à meia altura. As barras de incerteza dos pontos experimentais correspondem a um desvio padrão. As linhas contínuas são dadas pela equação (4.5), com os parâmetros $\eta$ e $\delta$ ajustados. . . . . . . . . . . . . . . . . . . . . 45

5.2 Curva de $\chi^{2}$ para determinação da camada morta do detector 5cc. . . . . . . . . . . . . . . . . . . 48

5.3 Eficiência do detector 5cc. A curva azul tracejada representa a eficiência utilizada na medição dos alvos durante a irradiação e a vermelha, a eficiência obtida com as fontes de calibração. Os pontos com barras de incerteza representam os dados experimentais. . . . . . . . . . . . . . . . . . 49 
$5.4 \quad$ Curvas de nível para o detector 8cc definidas com $\chi^{2}+i^{2}$ onde

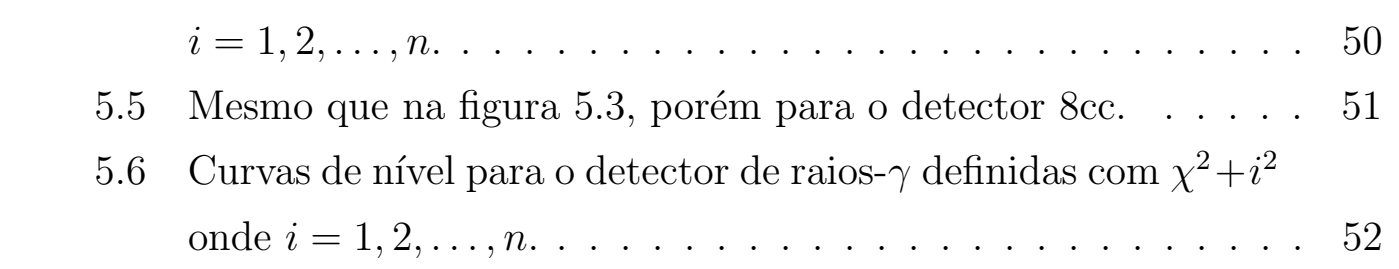

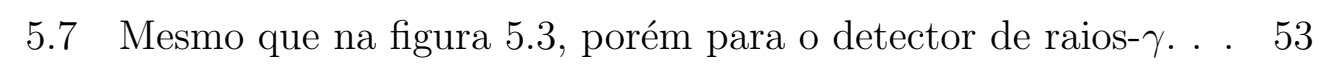

6.1 Espectros obtido com a técnica RBS para o alvo de Te. Os \begin{tabular}{|l|}
\hline pontos são os dados experimentais e a função obtida por simu- \\
\hline lação pelo programa SIMNRA e Mult-SIMNRA com os parâ- \\
\hline
\end{tabular} metros ajustados. . . . . . . . . . . . . . 56

6.2 Mesmo que na figura 6.1 , mas para o Ta. . . . . . . . . . . . . 57

6.3 Seção de choque de ionização por impacto de elétrons obtida pelo método absoluto para o alvo de Te. . . . . . . . . . 61

6.4 Mesmo que na figura 6.3 , mas para o Ta. . . . . . . . . . . . . 61

6.5 Seção de choque de ionização da camada K do Te por impacto

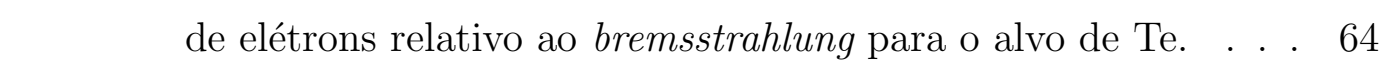

6.6 Mesmo que na figura 6.5 , mas para o Ta. . . . . . . . . . . . . 64

6.7 Comparação entre os valores médios da seção de choque obti-

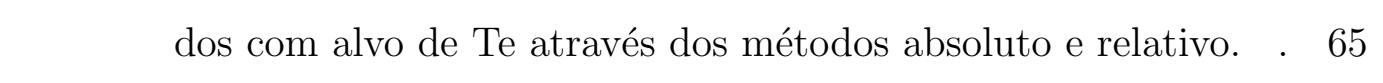

6.8 Mesmo que na figura 6.7 , mas para o Ta. . . . . . . . . . . . . 65

6.9 Comparação da seção de choque de ionização da camada K \begin{tabular}{|c|}
\hline do Te com o modelo SCADW. Os dados experimentais são \\
\hline representados pelos pontos com barras de incerteza (um desvio \\
\hline
\end{tabular}

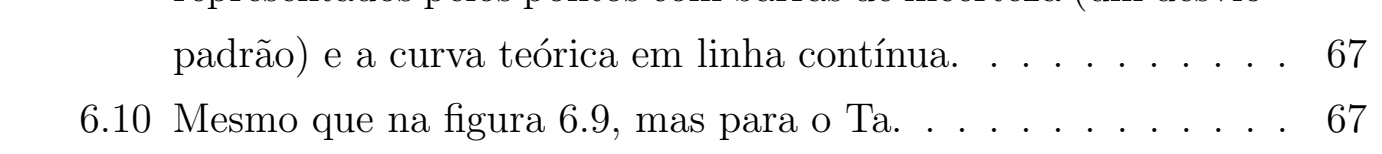

A.1 Esboço de um cilindro de Ge com o fóton incidente percor-

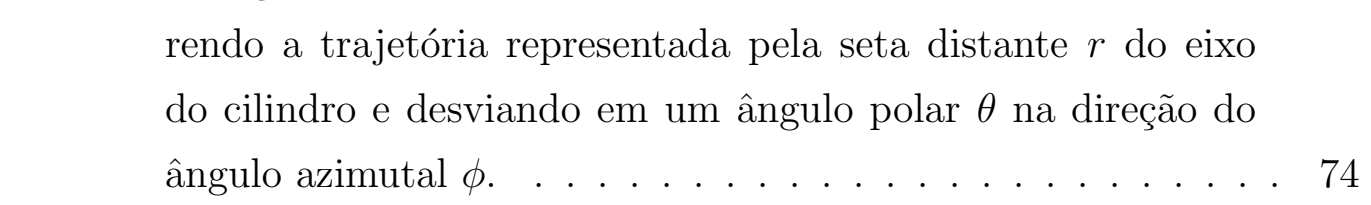





\section{LisTA DE TABELAS}

3.1 Valores de rendimento de fluorescência e razão das taxas de emissão de raios-X K $\alpha$ para os alvos de Te e Ta. . . . . . . . . 24

$4.1 \quad$ Testes de compatibilidade dos valores de $h$ com zero. Note que $\mathrm{z}=\frac{d-d_{\mathrm{c}}}{\sigma_{\mathrm{d}}}$, onde $d_{\mathrm{c}}=0 . \ldots \ldots \ldots \ldots \ldots \ldots$

5.1 Parâmetros da calibração de energia ajustados. . . . . . . . . 44

5.2 Parâmetros necessários na obtenção da eficiência do detector 5cc. . . . . . . . . . . . . . . . . . 49

5.3 Parâmetros para obter a eficiência do detector $8 \mathrm{cc}$. . . . . . . 51

5.4 Parâmetros necessários na obtenção da eficiência do detector

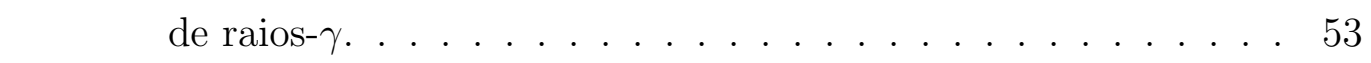

6.1 Valores de densidade superficial obtidos pelo método RBS. . . 55

6.2 Valores de eficiência obtidos para os alvos de Te e Ta nos detectores $5 \mathrm{cc}, 8 \mathrm{cc}$ e $\gamma$ e energia média dos fótons $E_{K \alpha_{2,1}}$. . . . 58

6.3 Valores das seções de choque de ionização da camada $\mathrm{K}$ do Te por impacto de elétrons obtidas pelo método absoluto usando os detectores $5 \mathrm{cc}, 8 \mathrm{cc} \mathrm{e} \gamma$, com o respectivo valor médio. . . . 59

6.4 Mesmo que na tabela 6.3 , mas para o Ta. . . . . . . . . . . 60

6.5 Valores das seções de choque de ionização da camada K do Te por impacto de elétrons obtidos pelo método relativo utilizando os detectores $5 \mathrm{cc}, 8 \mathrm{cc}$ e $\gamma$, com o respectivo valor médio. 62

6.6 Mesmo que na tabela [6.5, mas para o Ta. . . . . . . . . 63 
